University of Louisville

ThinkIR: The University of Louisville's Institutional Repository

Electronic Theses and Dissertations

$5-2017$

\title{
Instructional teacher job resources and student achievement in mathematics.
}

Amy Stokes-Levine

University of Louisville

Follow this and additional works at: https://ir.library.louisville.edu/etd

Part of the Curriculum and Instruction Commons, Elementary and Middle and Secondary Education Administration Commons, Elementary Education and Teaching Commons, Higher Education and

Teaching Commons, Junior High, Intermediate, Middle School Education and Teaching Commons, Leadership Studies Commons, Organization Development Commons, Other Educational Administration and Supervision Commons, Other Teacher Education and Professional Development Commons, PreElementary, Early Childhood, Kindergarten Teacher Education Commons, Science and Mathematics Education Commons, Secondary Education Commons, Secondary Education and Teaching Commons, and the Special Education Administration Commons

\section{Recommended Citation}

Stokes-Levine, Amy, "Instructional teacher job resources and student achievement in mathematics." (2017). Electronic Theses and Dissertations. Paper 2662.

https://doi.org/10.18297/etd/2662

This Doctoral Dissertation is brought to you for free and open access by ThinkIR: The University of Louisville's Institutional Repository. It has been accepted for inclusion in Electronic Theses and Dissertations by an authorized administrator of ThinkIR: The University of Louisville's Institutional Repository. This title appears here courtesy of the author, who has retained all other copyrights. For more information, please contact thinkir@louisville.edu. 
INSTRUCTIONAL TEACHER JOB RESOURCES AND STUDENT ACHIEVEMENT IN MATHEMATICS

\author{
By
}

Amy Stokes-Levine

B.S., Southern Methodist University, 2002

M.A., Bellarmine University, 2006

\begin{abstract}
A Dissertation
Submitted to the Faculty of the in Partial Fulfillment of the Requirements for the Degree of

Doctor of Philosophy

in Curriculum and Instruction

Department of Teaching and Learning

University of Louisville

Louisville, Kentucky
\end{abstract}

College of Education and Human Development of the University of Louisville

May 2017 
Copyright 2017 by Amy Stokes-Levine

All rights reserved 

INSTRUCTIONAL TEACHER JOB RESOURCES AND STUDENT ACHIEVEMENT IN MATHEMATICS

\author{
By \\ Amy Stokes-Levine \\ B.S., Southern Methodist University, 2002 \\ M.A., Bellarmine University, 2006 \\ A Dissertation Approved on
}

April 11, 2017

by the following Dissertation Committee:

Maggie B. McGatha, Co-Chair

Jill L. Adelson, Co-Chair

Michael (Brad) Shuck

Jennifer M. Bay-Williams

Susan A. Peters 


\section{DEDICATION}

This dissertation is dedicated to mathematics educators working in K-12 schools; their effort and perseverance in teaching students amidst strenuous working conditions is inspiring. My motive for pursuing this study, and this degree, was the hope of bringing attention to the need for and ways in which administrators may offer support to K-12 mathematics teachers.

This dissertation is also dedicated to my 6-month-old daughter, Tenley; may you always feel your goals and dreams are achievable, have the grit to initiate them, and persevere in your pursuit of those ideas until you find what you are called to do. 


\section{ACKNOWLEDGMENTS}

I would like to thank my family for their endless support and encouragement throughout my journey becoming a teacher, growing as a researcher, and completing this study. Most importantly, I would like to thank my husband, Blake, for his confidence in me and his patience with my passion for the pursuit of this goal. Thank you for your support, your flexibility, and for making me take cookie or dance breaks when I worked too long.

My experience throughout this process would not be the same without the effortless advocacy and guidance of Dr. Maggie McGatha and the thorough statistical direction of Dr. Jill Adelson. I am also grateful for Dr. Susan Peter's encouraging and high standards, Dr. Jenny Bay-Williams' inspirational opportunities, and Dr. Brad Shuck’s positive reinforcement. I am grateful for the network of support I have found at the University of Louisville and I hope to continue collaborating so that we may support teachers.

Lastly, I would like to thank my friends for understanding when it must have felt like I fell off the face of the earth, completely absorbed in my work. Thank you for being there when I finally came back around, listening even when it was boring, and believing in me. Thank you for friendships that build each other up, encourage self-reflection, and stand the test of time. 


\section{ABSTRACT \\ INSTRUCTIONAL TEACHER JOB RESOURCES AND STUDENT ACHIEVEMENT \\ IN MATHEMATICS}

Amy Stokes-Levine

April 11, 2017

Research shows that teachers who are supported with job resources are more engaged regardless of the level of demands (Klusmann et al., 2008). Additionally, teachers who are engaged with their work are less likely to report their intention to leave the teaching profession (Klassen et al., 2012), which is particularly important for mathematics teachers who are in high demand (Sutcher, Darling-Hammond, \& Carver-Thomas, 2016). Supporting employees with job resources is a commonly accepted practice in many professional fields (e.g., Christian, Garza, \& Slaughter, 2011), yet is not a common practice in education (e.g., Bidwell, 2013; Gewertz, 2014; Layton, 2015; Rentner \& Kober, 2014a). Current research on teacher work engagement and job resources has focused on big ideas like access to information and supervisory support (e.g., Hakanen, Bakker, \& Schaufeli, 2006). However, a more specific set of instructional job resources that support educators' engagement on a day-to-day basis needs to be examined, as well as their relationship to student achievement. This quantitative study examined indicators of instructional teacher job resources (ITJR) and the relationship between those resources and student mathematics achievement in grades 4-9. Data from The Gates Foundation's MET Project were used to conduct Exploratory Factor Analysis, Confirmatory Factor 
Analysis, and Hierarchical Linear Modeling analyses. With the survey questions that were available in the dataset, the factors for mathematics ITJR that were identified were curriculum, professional development, instructional autonomy, and time to collaborate with colleagues. The relationship between teacher instructional autonomy and studentachievement in mathematics for grades 4-8 was statistically significant, but not for grade 9. Relationship between student achievement and the other ITJR for all grades were not statistically significant. This study provides validity evidence for a 4-factor model of ITJR, which may provide administrators an operationalized understanding of how to support teachers. Specifically, administrators should look for ways to offer, communicate, and encourage instructional autonomy for their teachers given its relationship with achievement. Finally, if a model for teacher merit pay is being considered, teacher job resources such as ITJR, or at least instructional autonomy, need to be considered. Suggestions for future studies are included. 


\section{TABLE OF CONTENTS}

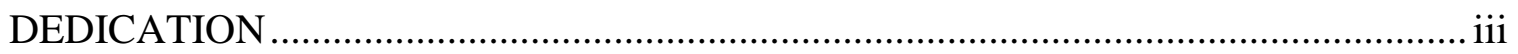

ACKNOWLEDGMENTS …………………………......................................... iv

ABSTRACT

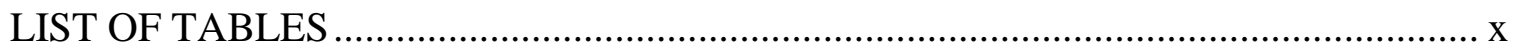

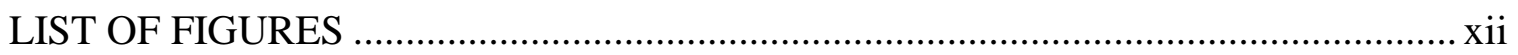

\section{CHAPTER 1}

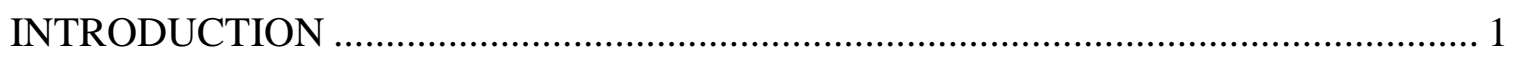

Problem Statement ………………….......................................................... 1

Research on Resources to Support Teachers.......................................................... 2

Research on Resources to Support Other Professionals.................................................. 3

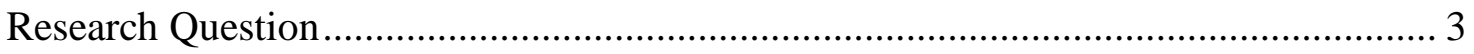

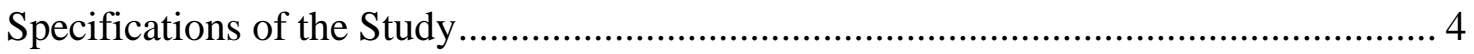

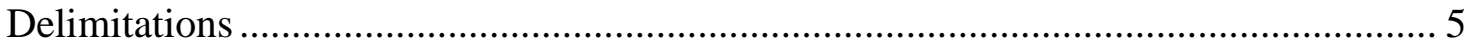

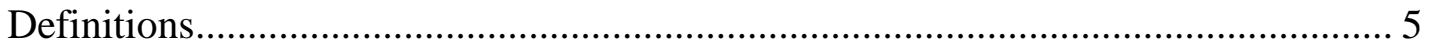

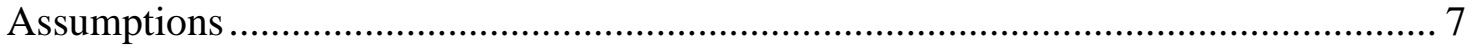

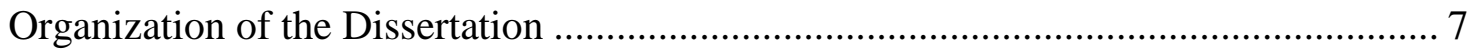

\section{CHAPTER 2}

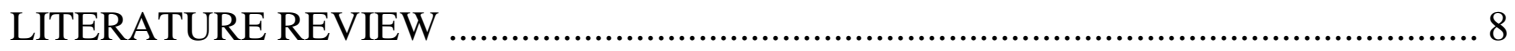

Engagement in the Work Place ............................................................................. 9

A Model for Work Engagement ............................................................................. 11

Work Engagement in Education .......................................................................... 13

Theoretical Framework ………………........................................................... 15

Teacher Job Resources according to Hakanen and Colleagues. ................................. 16

Additional Teacher Job Resources according to Runhaar and colleagues'.............. 19

Teacher job resources for day-to-day work. ........................................................... 20

Teacher Job Resources that Support Effective Pedagogy: A New Framework ............ 23

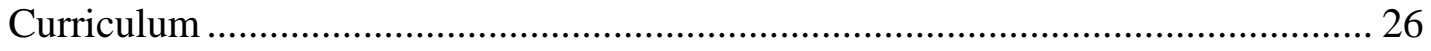

Professional Development .................................................................................. 30 


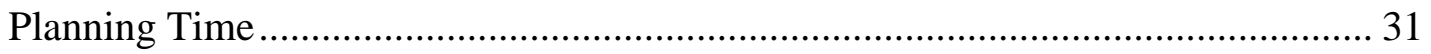

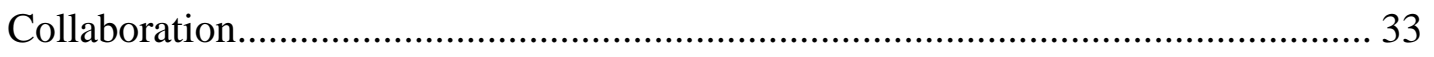

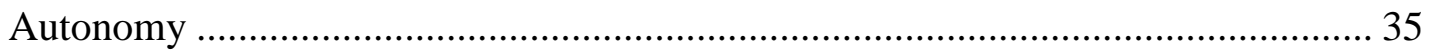

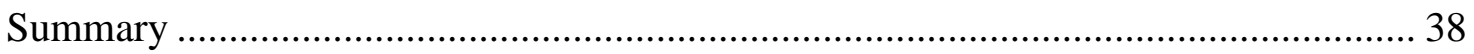

\section{CHAPTER 3}

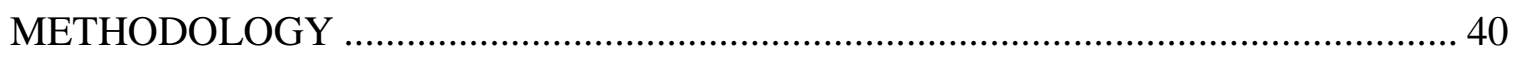

Sample

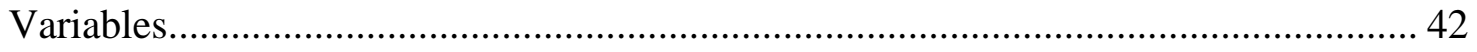

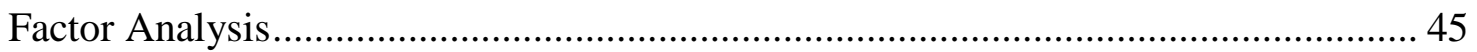

Relationship between Teacher Job Resources and Student Achievement ..................... 48

HLM Model-Building Process ........................................................................... 49

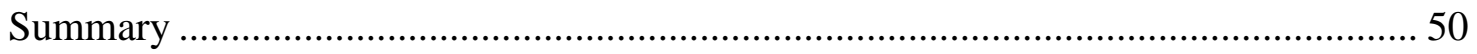

\section{CHAPTER 4}

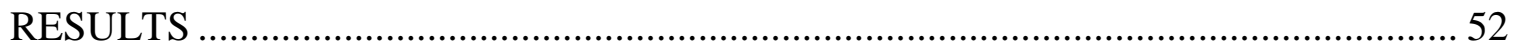

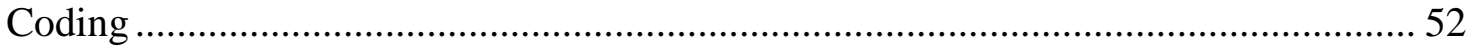

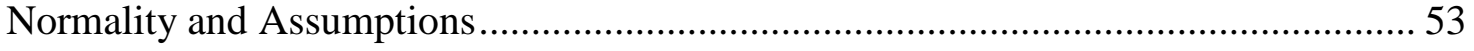

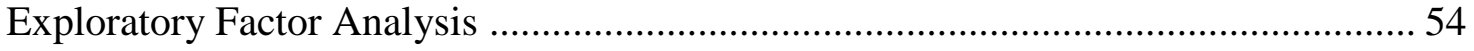

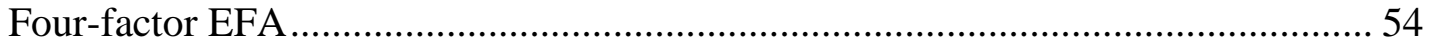

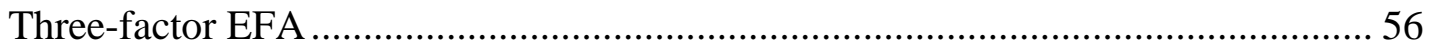

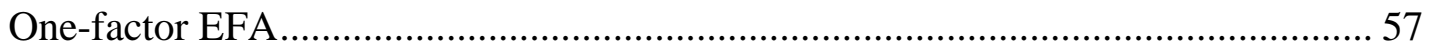

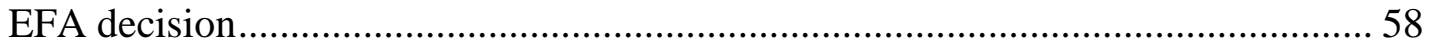

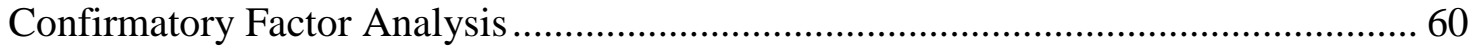

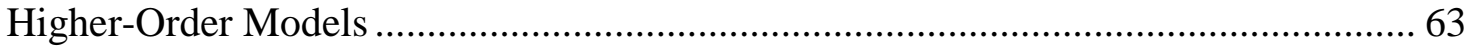

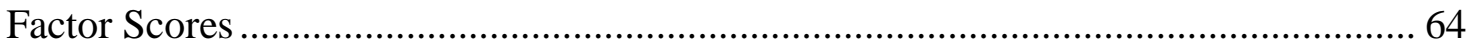

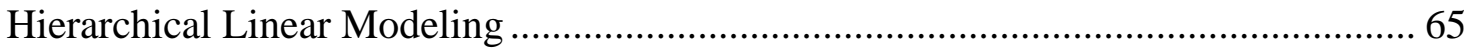

Results for student achievement on BAM, grades 4-8 ............................................. 66

Results for student achievement on ACT, grade 9 ................................................. 81

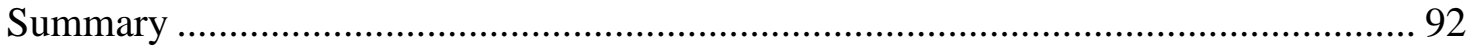

\section{CHAPTER 5}

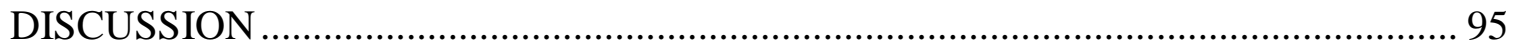

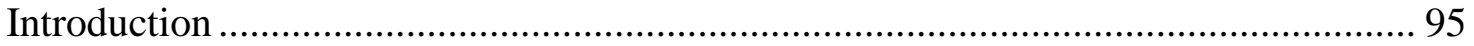

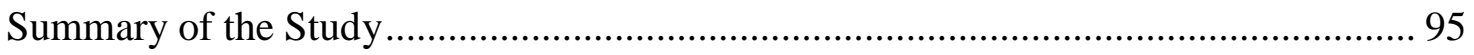

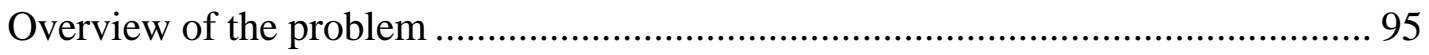

Purpose statement and research question................................................................. 95 


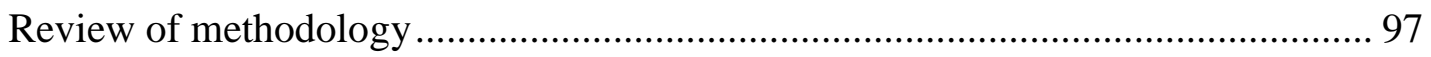

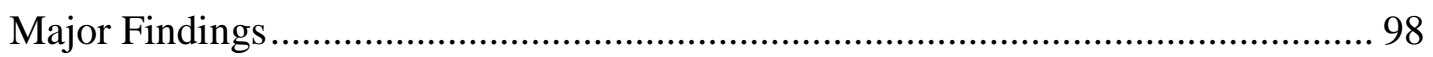

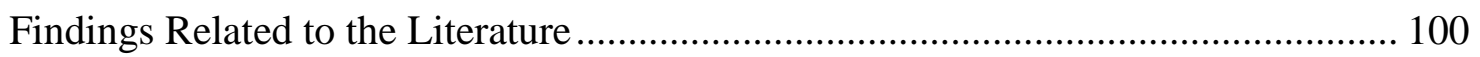

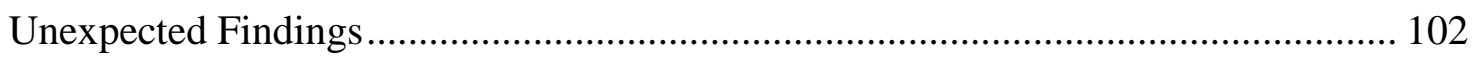

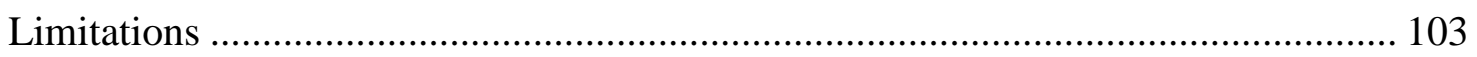

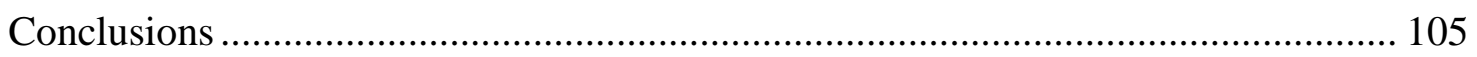

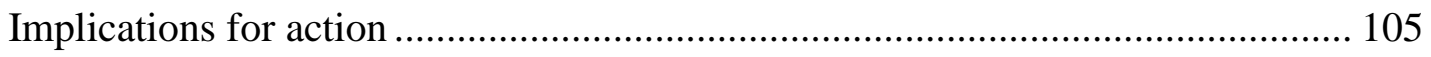

Recommendations for further research .......................................................... 106

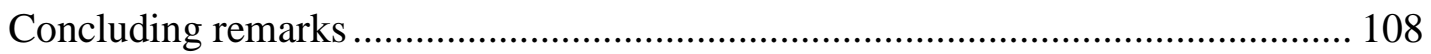

CHAPTER 6

INSTRUCTIONAL TEACHER JOB RESOURCES: A CURRENT EXAMPLE ........ 110

Resources for CCSS-M Implementation............................................................ 110

Student assessments aligned to the CCSS-M..................................................... 112

Mathematics teacher recruitment and retention ................................................... 113

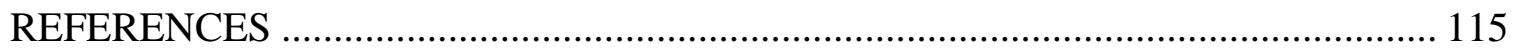

APPENDIX A: COPYRIGHT PERMISSIONS ................................................ 127

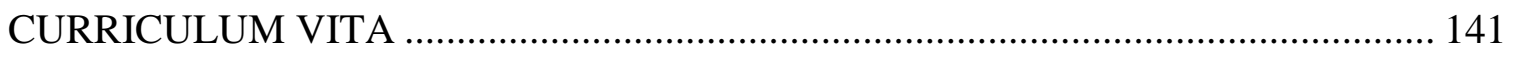




\section{LIST OF TABLES}

TABLE PAGE

1. Control Variables for Student and Teacher Participants................................... 42

2. MET Survey Questions on Curriculum, PD, Collaboration, and Instructional 44 Autonomy.

3. MET Survey Questions on Planning Time...................................................... 45

4. Hypothesized Five-Factor Model Independent Variables of Interest.................... 48

5. Hypothesized Higher-Order Model Independent Variables of Interest.................. 48

6. Recoded Control Variables for Student and Teacher Participants......................... 53

7. Pattern Matrix for the Four-Factor EFA....................................................... 55

8. Pattern Matrix for the Three-Factor EFA..................................................... 57

9. Pattern Matrix for the One-Factor EFA............................................................ 58

10. MET Survey Items as Selected for each EFA Model...................................... 59

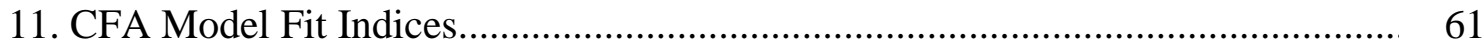

12. Four-Factor Model Standardized Regression Weights.................................. 62

13. Higher-Order CFA Model Fit Indices............................................................ 63

14. Higher-Order Model Standardized Regression Weights................................... 64

15. Tests of Normality for ITJR Factor Scores.................................................. 65

16. Final Estimation of the Fixed and Random Effects for the Final Level-1 Control Model for BAM........................................................................... 69

17. Final Estimation of the Fixed and Random Effects for the Final Level-2 Control Model for BAM......................................................................... 73

18. Final Estimation of the Fixed Effects for the Final Individual-Factor, Level-2

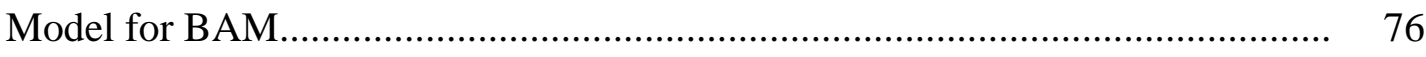

19. Final Estimation of the Fixed Effects for the Final Higher-Order Level-2

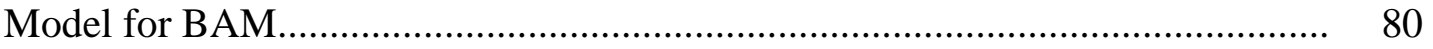

20. Final Estimation of the Fixed and Random Effects for the Final Level-1 Control Model for ACT ........................................................................ 84

21. Final Estimation of the Fixed and Random Effects for the Final Level-2 Control Model for ACT 
22. Final Estimation of the Fixed Effects for the Final Higher-Order Level-2 Model for ACT..

23. Summary of Explained Variance from the Final Individual-Factor, Level-2 Models for BAM and ACT. 


\section{LIST OF FIGURES}

FIGURE PAGE

1. Job Demands-Resources Model......................................................................... 12

2. Job Demands-Resources Model for Education.................................................. 13

3. Conjectured relationship of teacher job resources and student achievement......... 15

4. Interpreted relationship between Hakanen and colleagues' (2006) job resources... 17

5 . Theorized job resources related to the interpreted relationship between Hakanen and colleagues' (2006) job resources.................................................. 21

6. Theorized job resources associated with the interpreted relationship between Hakanen and colleagues' (2006) job resources as they relate to student achievement..

7. Conjectured relationship of teacher job resources that may impact lesson planning and instruction and student achievement

8. Higher-order model of the conjectured relationship of teacher job resources that may impact lesson planning and instruction and student achievement..

9. Five-factor model (left) and higher-order model (right) of the conjectured relationship of teacher job resources that may impact lesson planning and instruction and student achievement.

10. CFA diagrams for the one-factor, three-factor, and four-factor Models...

11. Job Demands-Resources Model for Education with resources for day-to-day instructional support. 


\section{CHAPTER 1 \\ INTRODUCTION}

Overview

\section{Problem Statement}

Supporting employees with job resources may be a commonly accepted practice in many professional fields (e.g., Christian, Garza, \& Slaughter, 2011; Endres \& Mancheno-Smoak, 2008; Rich, Lepine, \& Crawford, 2010), yet is not a common practice in education (e.g., Bidwell, 2013; Gewertz, 2014; Layton, 2015; Rentner \& Kober, 2014a). In teacher surveys for the Measures of Effective Teaching Project (MET), teachers were asked, "Which aspect of your teaching conditions is most important to you in promoting student learning? (Select one.)" (MET, 2010, Teacher Work Conditions Survey, p. 58). Teachers' most frequent response, $32 \%$ of responses, was Instructional Practice and Support. According to the survey, Instructional Practice and Support for teachers might include job resources such as: providing instructional coaching, working in professional learning communities to develop and align instructional practices, feeling encouraged to try new things to improve instruction, and having autonomy to make decisions about instructional delivery (i.e. pacing, materials, and pedagogy) (MET, 2010, Teacher Work Conditions Survey). However, research suggests these resources may not be provided to teachers (e.g., Bidwell, 2013; Layton, 2015; Rentner \& Kober, 2014a), especially mathematics teachers (Gewertz, 2014) this lack of resources may cause teachers to be less engaged with their work (Klusmann et al., 2008), and possibly less 
effective as educators (Bakker \& Bal, 2010; Christian, Garza, \& Slaughter, 2011; Kahn, 1990). Additionally, mathematics teachers are currently in immense demand due to issues with attrition (Sutcher, Darling-Hammond, \& Carver-Thomas, 2016), making analysis of their working conditions important.

Against that background, this study examined the relationship between teacher job resources that support mathematics teachers' instruction and student achievement.

\section{Research on Resources to Support Teachers}

Current research on teacher work engagement has focused on big ideas such as job control, access to information, supervisory support, innovative school climate, and social climate (e.g., Bakker \& Bal, 2010; Hakanen, Bakker, \& Schaufeli, 2006;

Klusmann et al., 2008; Runhaar, Sanders, \& Konermann, 2013). Work engagement can be undesirably impacted by job demands. Teachers have stressful job demands which have been negatively linked to exhaustion or burnout (Klusmann et al., 2008). Job demands for teachers could include disruptive pupil behaviors, work overload, poor physical work environment, and a lack of job resources (Hakanen et al., 2006). However, research shows that teachers who are supported with job resources are more engaged regardless of the level of demands (Klusmann et al., 2008) and teachers who were engaged with their work were less likely to report their intention to leave the teaching profession (Klassen et al., 2012). Clearly, job resources are important. Unfortunately, these studies did not provide detailed and specific job resource descriptions. A more specific set of job resources that support educators' engagement on a day-to-day basis needs to be identified and examined. 


\section{Research on Resources to Support Other Professionals}

Research on job resources in other professional fields (e.g., health care professionals, firefighters, dentists, and flight attendants) is more extensive and has shown that employees who are supported with job-related resources are more engaged in and productive with their work (e.g., Christian, Garza, \& Slaughter, 2011; Kahn, 1992; Leiter \& Maslach, 2004; Schaufeli, Salanova, González-Romá, \& Bakker, 2002). Work engagement or the level of positivity felt towards one's work (Schaufeli et al., 2002), requires job resources specific to the duties in question (Simpson, 2009).

Research conducted in other professional fields indicates that work effectiveness is significantly influenced by an employees' level of engagement in the workplace, which is increased by job resources (Christian, Garza, \& Slaughter, 2011; Kahn, 1992; Leiter \& Maslach, 2004; Schaufeli et al., 2002). While research and attention are growing on work engagement in other professional fields (Lockwood, 2007), research and attention on work engagement in education as a professional field is limited even though there may be a national attrition crisis for mathematics teachers in the U.S. (Sutcher, DarlingHammond, \& Carver-Thomas, 2016).

\section{Research Question}

The purpose of this study was to build on the existing research for both work engagement and effective teaching to examine what relationship exists between mathematics' teacher job resources and their students' mathematics achievement. The research question posed in this study was:

What is the relationship between instructional teacher job resources (ITJR) and student achievement in mathematics? 


\section{Specifications of the Study}

The resources listed below for supporting mathematics instruction for grades 4-9 are fully theorized, researched, and discussed in the Chapter 2. Using survey data from the MET Project and Hakanen et al.'s (2006) five constructs of job resources, this study posed the following questions related to the extent that these job resources support lesson development or lesson planning:

1. Curriculum materials. Did teachers believe the curriculum materials provided to them contained useful information regarding the mathematics content standards as well as information on pedagogy strategies, and anticipated student misunderstandings?

2. Professional development (PD). Were PD sessions focused on mathematics teachers' instructional needs?

3. Collaboration with peers. Were teachers able to collaborate with their peers to refine their teaching practices?

4. Time for individual and group planning. Were teachers allotted time to plan not only with other colleagues but time to plan individually during the work week?

5. Sense of job control. Did teachers feel a sense of job control from their administrators to create their own instructional plans?

In Chapter 2, I describe how these five Instructional Teacher Job Resources (ITJR) were conceptualized in light of Hakanen et al.'s research. Data from the MET Project were used to analyze student (level-1) and teacher (level-2) variables using hierarchical linear modeling (HLM) to explore the relationship between ITJR and student achievement. The 
MET Project, funded by the Gates Foundation, was a multi-year study in various states to attempt to measure effective teaching.

\section{Delimitations}

This study includes data from mathematics teachers and their students who participated in the MET Project. The MET Project was conducted during the 2009-2011 school years and included nearly 3,000 teachers from various content areas in the following states: North Carolina, Texas, Colorado, Florida, Tennessee, and New York. However, teacher data for this study included only mathematics teachers from the 20102011 school year. Teacher data included survey items from the MET Project's Teacher Working Conditions Survey that addressed the five job resources associated with lesson development or lesson planning: curriculum, PD, collaboration, planning time, and autonomy.

Student achievement data for this study came from the mathematics scores for the students in the selected teachers' classes. Student scores on the Balanced Assessment in Mathematics end-of-course test for students in grades 4-8 and the ACT QualityCore ${ }^{\circledR}$ end-of-course test for Algebra 1 students in high school were used. I analyzed separate models for each of the grade-band outcomes.

Definitions. The subsequent terms are used throughout the study and are defined as follows.

Resources: "Things that people value and therefore strive to obtain, retain, and protect" (Hakanen, Perhoniemi, Toppinen-Tanner, 2008). 
Job resources: Physical, psychological, social, or organizational aspects of a job that may reduce effects of job demands and may also encourage work engagement, (Demerouti, Bakker, Nachreiner, \& Schaufeli, 2001).

Instructional teacher job resources (ITJR): Job resources that support teachers to deliver effective instruction (see effective teaching).

Effective Teaching: Providing instructional methods and practices that produce proficient results for student achievement as defined by the MET Project.

Achievement: Students' assessment scores on their end-of-course exam for mathematics. Work engagement: Various definitions can be found in Chapter 2; however, the most relevant definition for this study is the level of positivity felt towards one's work. Quality Curriculum: Instructional materials that address teachers' needs for both their content standards and pedagogical methods.

Quality PD: Refers to professional development (PD) that deepens teachers' content knowledge and addresses teaching methods to improve student learning. Instructional Autonomy: Freedom for instructional decision making including teaching methods, instructional materials, pacing, sequencing, or timing while working either alone or in collaboration with colleagues. It does not include deciding what to teach as those derive from districts' content standards.

Physical job resources: ITJR comprised of quality curriculum materials and quality PD. Social job resources: ITJR comprised of planning time, collaboration, and autonomy for instructional freedom. 


\section{Assumptions}

Due to the fact that the data for this study were collected during a previous MET study, I made assumptions that the trustworthiness of the researchers and participants align with common ethics. For instance, I assumed that end-of-course exams were administered by teaching staff in accordance with standardized testing regulations. In addition, I also assumed that teacher surveys were answered openly and honestly. Finally, I assumed that all data were reported accurately by the researchers for the MET Project.

\section{Organization of the Dissertation}

The following sections of this report are organized into chapters, a bibliography, and appendices, respectively. Chapter 2 includes a review of the literature involving work engagement and a detailed theoretical framework for the study. Chapter 3 outlines the data sources, sample, research design, and methodology for this study. Chapter 4 provides statistical results from the EFA, CFA, and HLM analyses. Lastly, Chapter 5 includes a discussion of the findings, summary, conclusions, and future implications of the study. The report concludes with a bibliography and appendices. 


\section{CHAPTER 2}

\section{LITERATURE REVIEW}

Effective teaching is an issue of emerging significance in the field of education (Chetty, Friedman, \& Rockoff, 2014; Darling-Hammond, 2015; Goldhaber, 2015; Stecher et al., 2016). One of the largest studies analyzing effective teaching was the Measures of Effective Teaching (MET) Project (2013), funded by The Bill and Melinda Gates Foundation. The MET Project, asserted that effective teaching can be measured and subsequently, states are now developing and implementing new rubrics to measure teacher effectiveness (Stecher et al., 2016). Other professional fields have researched effectiveness in the workplace and, in some cases, found that effectiveness is significantly influenced by an employees' level of engagement in the workplace, which is increased by job resources (Christian, Garza, \& Slaughter, 2011; Kahn, 1992; Leiter \& Maslach, 2004; Schaufeli et al., 2002). However, in education little research has been conducted regarding whether teachers are engaged in their workplace or regarding ways in which teacher engagement might be increased and how such engagement relates to teacher effectiveness. We can draw upon work engagement research from other professional fields (e.g., Harter at al. 2002; Kahn, 1990; Schaufeli et al., 2002) as well as a limited collection of research specific to education (e.g., Hakanen et al., 2006; Klusmann et al., 2008), in order to develop a theoretical framework for teacher work engagement to better understand how to support teachers with their work. 


\section{Engagement in the Work Place}

Engagement in the workplace was first defined by Kahn (1990) as the amount to which employees connect to their work on a personal level. He called this personal engagement. Kahn believed that the more engaged employees are with their workplace, the more notable their performance would be. According to Kahn (1990), an employee's decision to engage at work stemmed from three psychological needs being met:

meaningfulness, safety, and availability. Engagement as a predictor of performance has since been substantiated through a variety of theoretical and empirical research (e.g., Christian, Garza, \& Slaughter, 2011; Harter at al. 2002; Kahn, 1992; Leiter \& Maslach, 2004; Schaufeli et al., 2002). As a result of this research, engagement definitions have diverged from Kahn's original focus to now support three additional constructs: (a) burnout (Maslach \& Leiter, 1997), (b) work engagement (Schaufeli et al., 2002), and (c) employee engagement (Parker \& Griffin, 2011; Shuck, Nimon, \& Zigarmi, 2016).

Burnout, which has been confused with engagement (Cole, Walter, Bedeian, \& O’Boyle, 2012), is often caused by job stress (Maslach \& Leiter, 1997). Burnout exists on a spectrum where burnout and personal engagement reside on opposite ends and affect each other converselyF (Leiter \& Maslach, 2004; Maslach \& Leiter, 1997). On the high end of the spectrum where workers are not burnt out but are personally engaged, employees may exhibit high energy, resilient association to their work, and have a sense of self-efficacy (Leiter \& Maslach, 2004). The low end of the spectrum depicts burnt out employees who may experience symptoms of exhaustion (opposite of high energy), cynicism (opposite of resiliency), and inefficacy (opposite of self-efficacious) (Leiter \& Maslach, 2004). Employees who are burned out are less likely to be engaged at work, 
productive, or effective in both their personal and social work efforts (Leiter \& Maslach, 2004). Employees who experience burnout may in fact leave their job altogether or remain but produce at ineffective, lower levels.

Work engagement is defined as a pervasive feeling of positivity toward one's work as characterized by degrees of vigor, dedication, and absorption (Schaufeli et al., 2002). Vigor signifies employees having high energy, resilience, persistence, and willingness to invest effort into his/her work (Bakker, Emmerik, \& Euwema, 2006). Dedication indicates employees have a sense of significance, pride, and challenge about their work (Bakker et al., 2006). Absorption denotes an employee is happily immersed in their work and may have difficulty separating oneself from their work (Bakker et al., 2006). Employees who are engaged with their work, apply themselves within the context of their job (Kahn, 1990) but does not necessarily work extra hours or volunteer for extra responsibilities (Schaufeli \& Bakker, 2010).

Employee engagement has been defined as an active, work-related positive psychological state (Parker \& Griffin, 2011; Shuck et al., 2016). There exists, however, confusion and inconsistencies regarding the definition of employee engagement (Shuck \& Wollard, 2010). Employee engagement often is confused with work engagement and at times the terms are used interchangeably (Schaufeli \& Bakker, 2010). To clarify the distinction, Schaufeli and Bakker (2010) defined employee engagement as an employees' association to their work tasks and their work organization. Although employee engagement is not an organizational-level construct (Shuck \& Wollard, 2010), each individual employee's decisions do involve organizational-level concerns. Those with high levels of employee engagement make individual decisions about their work and 
possess a willingness to adapt their behavior to achieve preferred organizationaloutcomes (Shuck \& Wollard, 2010). After an extensive review of the literature to analyze the inconsistencies in explanations, Shuck and Wollard (2010) determined employee engagement to be "an individual employee's cognitive, emotional, and behavioral state directed toward desired organizational-outcomes" (p. 103).

Of these engagement constructs, work engagement is the most pertinent to this study. Although each of these constructs affects teachers on a daily basis, the focus of this study is teachers' engagement with their work, teaching their students effectively to increase student learning, which may be reflected in student achievement scores, as measured by the MET Project. Because the terms work engagement and employee engagement sometimes are used interchangeably (Schaufeli \& Bakker, 2010), only research regarding employees' relationship with their work (teaching students) and not with their organization (relationship with their school or administration) or organizational structures (relationship with their district rules and expectations) was included in this review. While work engagement can affect many areas of teachers' work (e.g. work with administrators, parents, teachers, or students), this study specifically focused on teachers' efforts to design and deliver instruction to their students.

A Model for Work Engagement. One-way an employees' relationship to their work has been theorized is the Job Demands-Resources (JD-R) Model (Bakker, Demerouti, \& Verbeke, 2004). The JD-R Model outlines two branches of work engagement: energetical (the top branch shown below) and motivational (the bottom 
branch shown below).

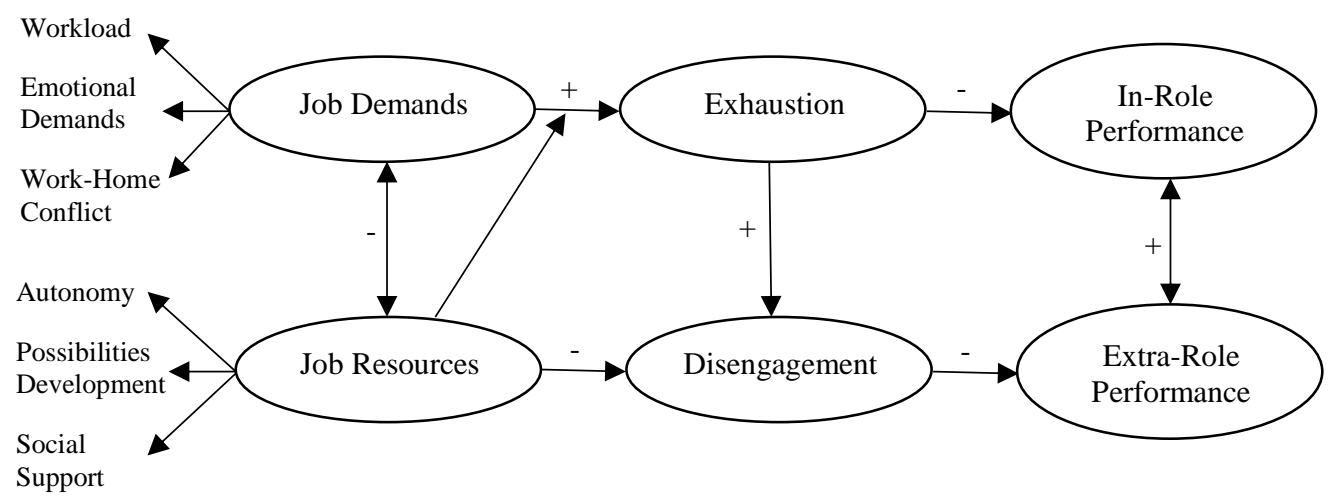

Figure 1. Job Demands-Resources Model. Bakker, A. B., Demerouti, E., \& Verbeke, W. (2004). Using the job demands-resources model to predict burnout and performance. Human resource management, 43(1), p. 87. Copyright 2004 by Wiley Periodicals, Inc. Reprinted with permission.

This model delineates two separate but related progressions of burnout and engagement (Klusmann et al., 2008). The top branch (energetical), illustrates how high job demands may lead to emotional exhaustion or burnout with negative energy toward their in-role performance. The bottom branch (motivational), shows how a lack of job resources may lead to disengaged employees who do not elect any extra-role duties. These separate branches can be related. For instance, a lack of job resources (bottom motivational branch) may contribute to job demands (top energetical branch). Depending on the contextual circumstances, the two branches of the model interact to reveal employee experiences. For example, workers can exhibit no symptoms of exhaustion (they are not burnt out) and yet not be engaged with their work. Conversely, workers who are engaged can simultaneously experience emotional exhaustion or burnout. There are situations where employees may experience both branches at the same time such as having high job 
demands with little to no job resources where they may experience both exhaustion and disengagement.

Work Engagement in Education. As noted earlier, little research has been conducted in work engagement in education. Research validated portions of the JD-R model with teachers in Germany, namely that job demands are linked to exhaustion or burnout and job resources are linked to engagement (Klusmann et al., 2008). They found that exhaustion was related more significantly by individual-level teacher factors while engagement was linked to school-level factors. For instance, teachers' emotional exhaustion was correlated to student discipline. On the other hand, principals' level of support toward pedagogical issues predicted average teacher engagement. This aligns with the assertion of this study that teacher job resources are linked to teacher work engagement and, more specifically, that supporting teachers in their pedagogy may lead to higher levels of teacher engagement.

Hakanen, Bakker, and Schaufeli (2006) adapted the JD-R model proposed by Bakker, Demerouti, and Verbeke (2004) to apply to educational settings (see Figure 2).

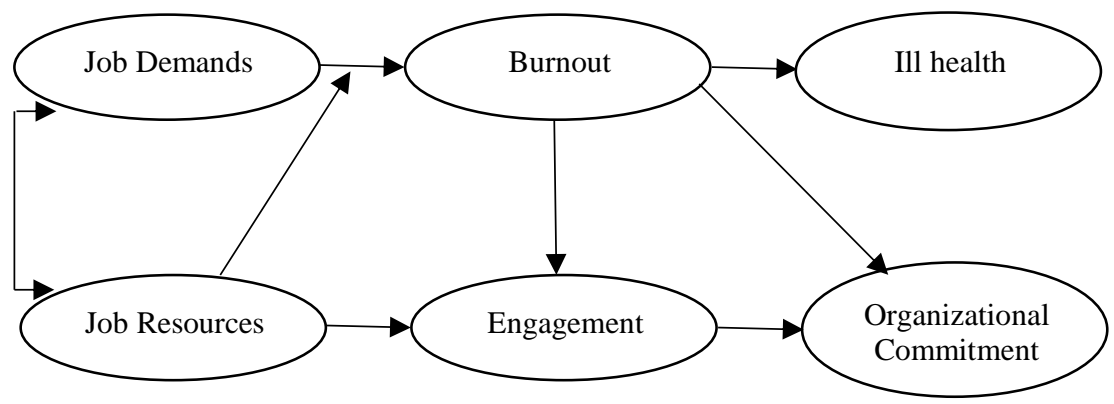

Figure 2. Job Demands-Resources Model for Education. Hakanen, J. J., Bakker, A. B., \& Schaufeli, W. B. (2006). Burnout and work engagement among teachers. Journal of School Psychology, 43, p. 497. Copyright 2005 by the Society for the Study of School Psychology. Reprinted with permission. 
In this model, teachers' work conditions are delineated into two categories similar to the JD-R model: job demands and job resources (Hakanen et al., 2006). To better align with educational settings, the last construct in each row was revised as follows: In-Role performance was replaced by Ill Health and Extra-Role performance was replace by Organizational Commitment. In addition to their visual model, the researchers further explained what job demands and resources might look like for teachers. Job demands for teachers consisted of three sub-categories: disruptive pupil behaviors, work overload, and poor physical work environment. Teacher job resources comprised five sub-categories: job control, access to information, supervisory support, innovative school climate, and social climate. Along with statistically verifying the new energetical and motivational model through structural equation modeling, Hakanen et al. (2006) also found job resources to be directly associated with burnout. It was suggested that because job demands and job resources are not likely to exist independently, further crossover between the energetical and motivational processes may exist.

In addition to the JD-R model, another framework for measuring work engagement, called the Utrecht Work Engagement Scale (UWES) (Schaufeli, Bakker, \& Salanova, 2006), was used to analyze teachers in Australia, Canada, China, Indonesia, and Oman (Klassen et al., 2012). The study revealed that teachers who were engaged with their work were less likely to report their intention to leave the teaching profession (Klassen et al., 2012), which is a great concern, especially for teachers of mathematics (Barnes, Crowe, \& Schaefer, 2007).

Another international study on teacher work engagement differed from those previously mentioned due to its qualitative methodology. A phenomenological study in 
Finland analyzed teacher work engagement by examining teachers' reflections on their work experiences (Mäkinen, 2013). The study, however, yielded unclear conclusions about teachers' experiences and their level of work engagement.

As mentioned previously, mathematics teachers are leaving the profession of teaching due in large part to work conditions (Sutcher, Darling-Hammond, \& CarverThomas, 2016), yet there remains very little research on work engagement in education, especially in the United States. The MET Project (2013), conducted in the United States, while it does not specifically mention job demands and job resources, it includes constructs such as effective, or engaged, teachers.

\section{Theoretical Framework}

Engaged teachers are more effective teachers (Nye, Konstantopoulos, \& Hedges, 2004; Rockoff, 2004) and teacher job resources have been linked to teacher work engagement (Klusmann et al., 2008). Therefore, teachers supported with job resources are more likely to be engaged teachers and may be more likely to be effective, resulting in students with higher achievement (see Figure 3).

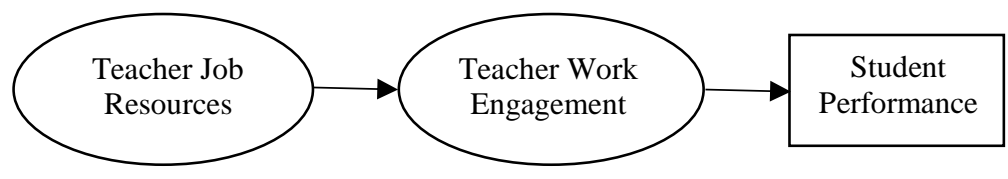

Figure 3. Conjectured relationship of teacher job resources and student achievement.

This conjecture is most like the lower motivational branch of the JD-R model (Figure 1) and addresses the research question, how are teacher job resources related to student achievement, in this study. This is not to say that the top energetical branch is not important, job demands are a concern for teachers; however, that is not the focus of this 
study. To better understand teacher job resources, a closer look at Hakanen et al.'s (2006) categories with teacher lesson planning and pedagogy in mind is needed.

Teacher Job Resources according to Hakanen and Colleagues. Hakanen and colleagues (2006) sub-categories of job resources included: (a) access to information, (b) supervisory support, (c) innovative school climate, (d) job control, and (e) social climate. Access to information refers to an employee's access to the disbursement of information needed for job-relevant tasks in the work place. For example, a teacher with access to information may be included in decisions regarding the adoption of new textbooks or other curriculum materials and may be informed of professional development sessions that may support their teaching materials or teaching style.

Supervisory support addresses the general communication structures that exist between peers, from administration to subordinates, and across or between units. Whether teachers feel comfortable voicing their concerns to administrators might be an example of supervisory support. For example, a teacher in a school with high supervisory support toward pedagogy may feel comfortable voicing concerns to his/her administrators about their teaching practices or materials. These teachers may feel comfortable asking for supports such as additional teaching materials, an observation, or feedback to help improve their teaching without fear of retribution.

Innovative school climate as a resource refers to how much an organization values improving work by including discussions and feedback and then follows through in implementing department or school plans. For example, in a school with an innovative school climate, teachers' opinions on curriculum and pedagogical concerns might be sought by administrators instead of teachers needing to ask their supervisor(s). 
Additionally, teachers may see follow-through from their administrators after observations on pedagogical comments or concerns.

Job control as a resource refers to the perception of control an employee has over the pace of work, order of tasks, and general influence over job tasks. For example, a teacher with pedagogical job control may choose their own pacing guide or may make changes to a district pacing guide, may choose their teaching style, and may have choice in the materials, technology, and textbooks they use with their students.

Finally, social climate refers to the extent to which the interaction with other people at their work place is relaxed and comfortable. For example, teachers in a school with a high functioning social climate may collaborate with their peers on curriculum planning and instruction. Figure 4 illustrates this author's interpretation of how Hakanen and colleagues' (2006) job resources might interact.

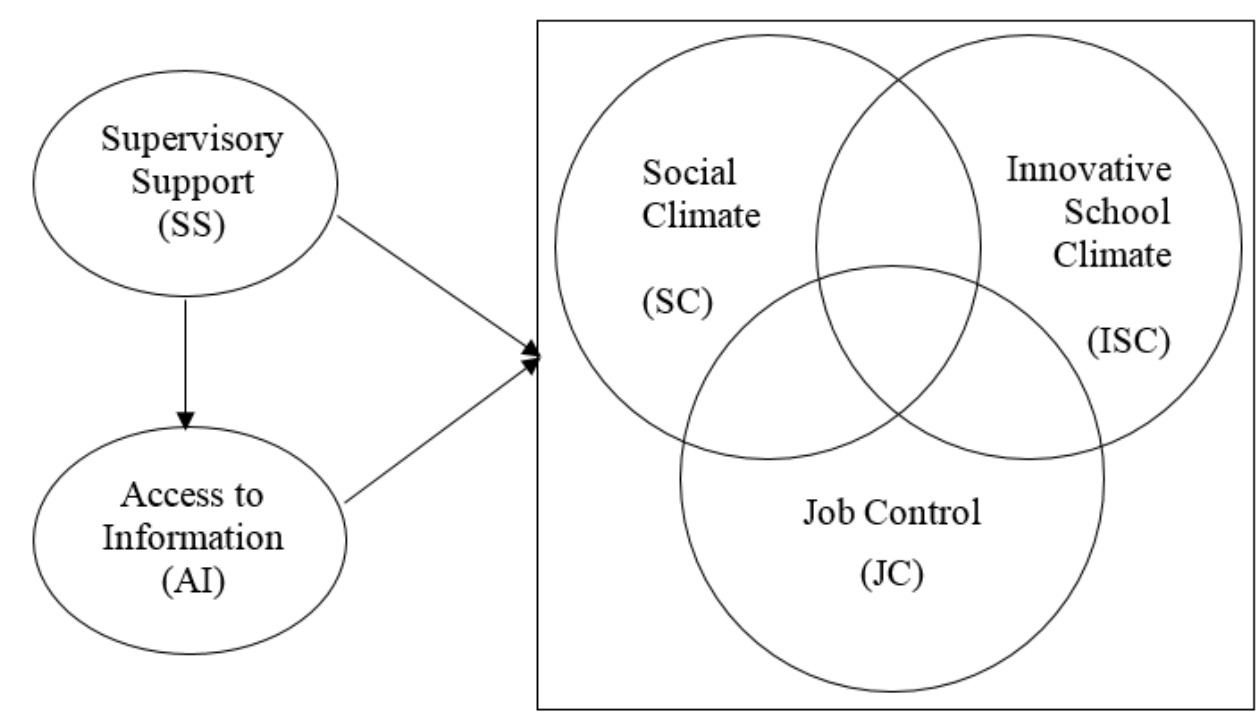

Figure 4. Interpreted relationship between Hakanen and colleagues' (2006) job resources. 
Descriptions of how these resources interact with each other were not provided by Hakanen et al. (2006); the following are the theories of this author. Supervisory Support (SS) may provide teachers with Access to Information (AI). SS and AI collectively may impact each teacher's sense of Job Control (JC), Social Climate (SC), and/or Innovative School Climate (ISC). As noted in Figure 3, all five of these job resources may potentially influence teacher's work engagement and student achievement. The three job resources of Social Climate (SC), Innovative School Climate (ISC), and sense of Job Control (JC) for teachers and are non-directional because they may be related. Each combination of these three job resources will be discussed.

Whether teachers feel relaxed and comfortable (SC) is connected to how much their school honors teacher voice and values organizational growth (ISC). While there is overlap, they are separate constructs. For instance, SC might be relaxed because of high ISC where teacher voice is sought by administrators. On the other hand, ISC may be formed because teachers respond to a relaxed SC where they feel comfortable sharing feedback.

Whether teachers feel relaxed and comfortable (SC) is also connected to teachers' level of perceived control over their work (JC); however, directional relationships are still not assigned. Teachers may feel comfortable in their workplace because they have a sense of job control. For instance, having freedom to make decisions for their instruction (JC) and the freedom to openly discuss ideas without fear of retribution may contribute to a relaxed social climate $(\mathrm{SC})$. Conversely, it may be possible that relationships between teachers and administrators formed from a relaxed social climate lead to job control. For instance, if teachers feel comfortable with their principle enough to discuss new ideas 
(SC), the administrator may be more open to suggestions which may increase teachers' sense of job control (JC).

Lastly, the relationship between how much a school values organizational growth (ISC) and teachers' level of perceived control over their work (JC) is also nondirectional. Schools and administrators who value improving their school (ISC) may be more likely to seek and honor teachers' opinions, giving teachers a sense of influence over their work place or job (JC). Alternatively, teachers with a heightened sense of job control may share ideas with each other and administrators, which may create an environment of positive instructional norms contributing to innovative school norms (ISC).

Additional Teacher Job Resources according to Runhaar and colleagues'. In addition to Hakanen et al.'s (2006) five categories of job resources in education, JC, AI, SS, ISC, and SC, a new job resource was proposed by Runhaar, Sanders, and Konermann (2013). This new construct, interaction with pupils, was found to have a positive relationship with teacher work engagement (Runhaar et al., 2013).

When considering the connection between interaction with pupils and Hakanen et al's (2006) categories, the argument could be made that JC, AI, SS, ISC, and SC are actually sub-categories or supporting resources for interacting with pupils. For instance, if teachers have access to the information they need to understand their standards and work in an innovative school climate where their voices are heard and ideas are honored, they may be more prepared and encouraged to interact with pupils. Runhaar et al. (2013) defined interaction with pupils as working with students to develop their intellect; however, they did not address the external resources needed for teachers to interact with 
pupils successfully. This goal of this study is to identify specific job resources that an administrator might supply that are related to increased student achievement. Because interaction with pupils was theorized by this author to be a possible internal result for teachers from Hakanen et al's (2006) job resource categories, Interaction with pupils is therefore not included as a separate factor in this study.

Teacher job resources for day-to-day work. The five job resources identified by Hakanen et al. (2006) reside on a macro-level view of school operations; however, the daily grind of a teacher's workday necessitates a smaller lens, or a micro-level view, of what these resources might look like for teachers on a day-to-day basis. Although many resources may affect teachers on a day-to-day basis, this study is only concerned with teacher job resources that might promote effective teaching and ultimately relate to higher student achievement. As previously discussed, the MET Project (2013) does not specifically mention job demands and job resources as factors for effective teaching. However, several survey items from the MET study deal with issues related to job resources that may affect teacher effectiveness and ultimately student achievement. From the MET Project dataset, I identified five school-level day-to-day job resources, in addition to the five big-picture job resources, that may support effective teaching to answer the research question for this study. The identified job resources that may affect teachers' instruction on a daily basis include: Quality Curriculum, Quality PD, Collaboration, Autonomy, and Time. The following model illustrates how these five teacher resources may connect to Hakanen and colleagues' (2006) research (see Figure 5). 


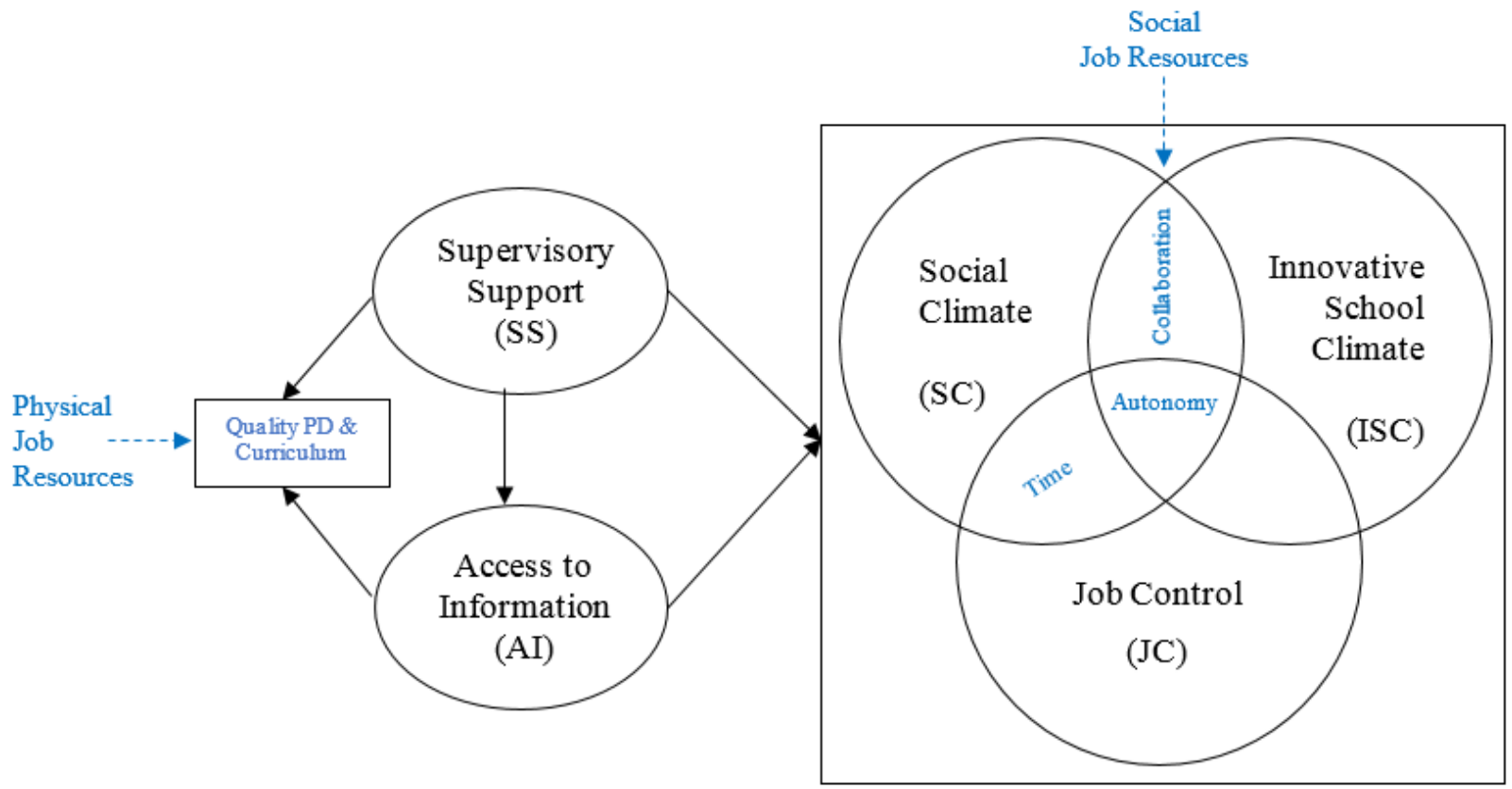

Figure 5. Theorized job resources related to the interpreted relationship between Hakanen and colleagues' (2006) job resources.

This model illustrates that teachers in schools with SS and AI may have job resources such as quality curriculum materials that align to their content teaching standards. In addition to content alignment, teachers with both SS and AI may theoretically be more aware of curriculum materials that provide activities and ideas for student-centered instruction and provide helpful information such as potential student misconceptions and ways to scaffold instruction. Quality curriculum refers to materials that address teachers' needs for both their content and pedagogical methods (e.g., Garland, 2014; Herbel-Eisenmann, 2007; McCrory et al., 2012; Remillard, 2005).

Additionally, in my conceptual model, I theorize that teachers with both SS and AI may be more likely than teachers in schools without SS and AI to attend PD that supports their adopted curriculum materials or pedagogical methods. Quality PD refers to PD that deepens teachers' content knowledge and addresses teaching methods to 
improve student learning (e.g., Brodie \& Shalem, 2011; McCrory, 2012). In this study, I considered both curriculum and PD to be physical job resources.

Within Hakanen's (2006) resources for SC, ISC, and JC, I theorized that three are social job resources for teachers: time, collaboration, and autonomy. The first of these is time to plan instruction. Teachers' planning time can be used for different purposes, such as department meetings or other duties. Teachers who are in schools with an ISC and have a sense of JC theoretically may be more likely than teachers without those resources to have time during the work day that is reserved for planning. This time could be either for individual planning or for planning with their colleagues.

In my theoretical model, I contend that teachers in schools where the SC and ISC are both healthy may have more opportunities to collaborate with their colleagues than teachers in schools without these job resources. Collaboration may occur within Professional Learning Communities (PLCs) or during PD or may be the result of teachers connecting and sharing ideas. Teachers may collaborate with others in their content area or teachers with a cross-content lens.

Lastly, I theorize that teachers who are in schools with both an ISC and a relaxed SC and who have a sense of JC may be more likely to have autonomy for decisions they make in their teaching. Autonomy is most closely related to JC, but the existence of any of these three elements may signify the existence of teachers having autonomy. For example, SCs may be more relaxed because teachers are allowed to self-regulate their work (autonomy).

With SS and AI, I theorize that it is possible that teachers may experience positive change in their SC, ISC, or sense of JC so that they feel informed, heard, and have some 
control over their work. For instance, with AI, teachers may find resources available to them, such as quality PD and curriculum. If SS and AI are lacking, teachers may feel diminished levels of SC, ISC, and JC if information and communication are not shared, and teachers may not have either the physical job resources, such as training, materials (quality PD and curriculum), or social job resources they need, to be as effective as they could be.

\section{Teacher Job Resources that Support Effective Pedagogy: A New Framework}

As previously outlined, mathematics educators are likely to benefit from supportive job resources to reduce job demands and engage in the workplace and require job resources that are specific to their needs. Teachers who are supported with curriculum materials, PD, have instructional autonomy as well as time to plan and collaborate, may be more likely to present effective instruction to students (Christian, Garza, \& Slaughter, 2011). This effective instruction may lead to greater student achievement (Goldhaber, 2015). Mathematics teachers are working with misaligned curriculum, without PD that focuses on their needs, and are pressured to produce highachieving students.

By focusing on the framework derived from Hakanen et al. (2006), I seek to analyze job resources specific to education that may increase teacher engagement at work and ultimately increase student achievement. Resources believed to be needed include but are not limited to: (a) availability to quality curriculum, (b) PD sessions that develop teacher knowledge, (c) appropriate planning time provided during the work week, (d) opportunities to collaborate with other math teachers, and (e) a feeling of autonomy from 
their administrators to create or modify their instructional plans to meet their students' needs.

With Hakanen and colleagues' (2006) job resources as a context, the relationship shared by the five additional theorized resources, now with relation to student achievement, is shown in the framework below (Figure 6).

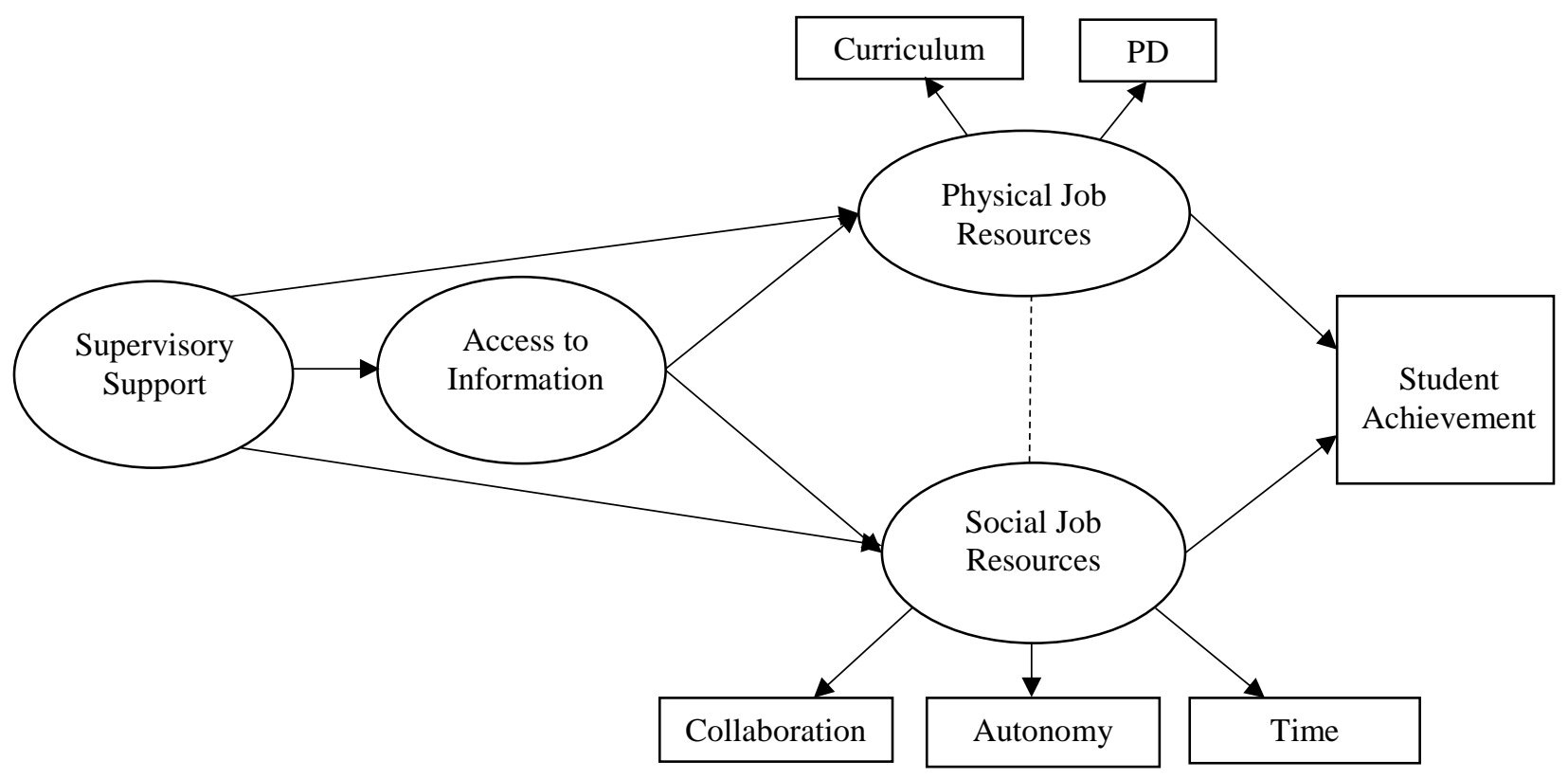

Figure 6. Theorized job resources associated with the interpreted relationship between Hakanen and colleagues' (2006) job resources as they relate to student achievement.

Here, the model still indicates that SS and AI may support both physical and social teacher job resources. The model also indicates that either or both physical and social teacher job resources may support student achievement. New to this model is the possible relationship between physical and social job resources. Perhaps teachers with supportive social job resources are able to find or create physical job resources for themselves. On the other hand, it might be possible that teachers with supportive 
physical job resources feel more comfortable reaching out to their colleagues or administrators to stimulate healthy social job resources for each other.

Recall Figure 3, which presented the conjectured relationship of teacher job resources and student achievement. With the specific teacher job resources identified through the MET Project in mind, the following figure shows a more detailed conjectured relationship of teacher job resources that may affect teachers' work engagement and thus their lesson planning and instruction and ultimately student achievement (Figure 7).

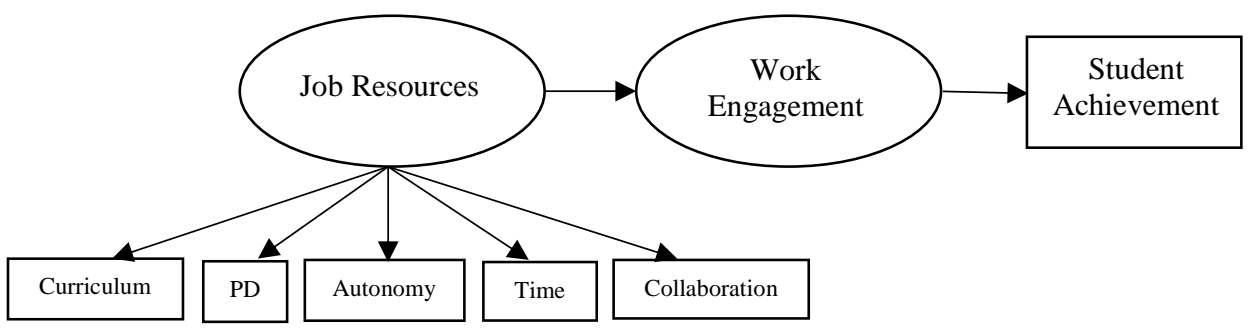

Figure 7. Conjectured relationship of teacher job resources that may impact lesson planning and instruction and student achievement.

This model does not, however, account for the social and physical classification of job resources as seen in Figure 8. In the following model, the same five job resources are additionally categorized as physical and social teacher job resources.

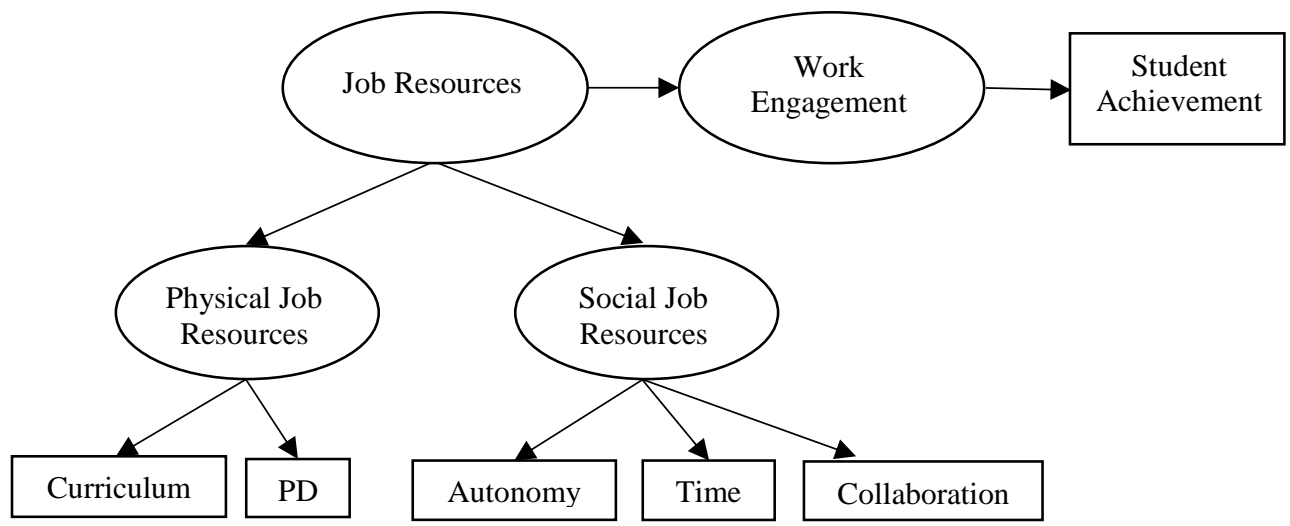


Figure 8. Higher-order model of the conjectured relationship of teacher job resources that may impact lesson planning and instruction and student achievement.

In the following sections, each of these teacher job resources will be discussed: (a) quality curriculum, (b) quality PD, (c) planning time, (d) collaboration, and (e) autonomy.

Curriculum. Once a teacher understands their content standards and has determined what needs to be taught, curriculum materials need to be acquired or developed to help carry out their lessons (Reys, Reys, \& Rubenstein, 2010). Resources and materials that help teachers deliver instruction often are referred to as curriculum; however, there is still some variation in what that entails (Flinders \& Thornton, 2013). Curriculum can mean anything from overarching frameworks that guide teachers while designing their own instructional resources to scripted lessons complete with assessment materials (Remillard, 2005). Teachers may use materials presented to them, discover materials for themselves, develop their own materials, or use a hybrid of any of these sources of resources to implement the content standards required in their district. The main curriculum resource for teaching mathematics over the years has been textbooks, somewhat due to how mathematics assignments are given as well as the teacher's comfort and confidence with the content (Nicol \& Crespo, 2006; Remillard, 2005). Implementation of these curriculum materials can fall into the following categories: formal, intended, enacted, or experienced (Remillard, 2005; Remillard \& Heck, 2014). For instance, intended curriculum implementation can mean either the author's or the teacher's intentions for instruction (Reys et al., 2010; Remillard, 2005). 
On the other hand, enacted curriculum implementation refers to what actually occurred in the classroom (Remillard, 2005). In short, curriculum materials are the tangible tools that support teachers' goals of introducing content and practice standards to students during instructional time (Herbel-Eisenmann, 2007).

Intended curriculum and enacted curriculum can be significantly different than the curriculum described and designed by the curriculum authors (Remillard, 2005; Stein \& Smith, 1998). A study analyzing mathematics curriculum implementation found teacher use of textbooks varied immensely even though those included in the study reported feeling they honored the ideas of the curriculum simply because they used a textbook that was written for their adopted standards (Remillard, 2005). Potential reasons for misused mathematics curriculum includes an underappreciated sense of how teachers might misunderstand, misrepresent, or even ignore content that is unfamiliar to them (Remillard, 2005). This is noted in part by the level of teacher familiarity with curriculum resources, influential factors toward their relationship with the materials, as well as the relationship's effect on teacher enacted curriculum coupled with the widespread adoption of textbooks (Remillard, 2005).

Therefore, even if textbooks were accurately aligned to current content standards, evidence shows many teachers are not prepared to engage with the new standards as intended in textbooks (McCrory et al., 2012). Because research has already identified issues with textbook alignment to current content standards, such as CCSS-M (Rentner \& Kober, 2014a), using textbooks alone currently may not offer teachers a complete set of quality curriculum materials. Before the CCSS-M was adopted by much of the United States, each state had their own set of content standards. With content standards varying 
from state to state, publishers may have had to blend content standards from different states to meet state and district textbook needs, which may have offered a clouded set of quality curriculum materials. Moreover, not all districts adopt textbooks (Broussard, 2014), and some teachers do not have access to curriculum materials; outside of textbooks, teachers may create their own materials or use easily accessible resources found online. However, this may be problematic as daily job demands leave little time for teachers to create quality resources and plans (Schmidt, Houang, \& Cogan, 2002), and studies have yet to address the quality and effect of using non-researched online resources, such as Khan Academy (www.khanacademy.org), BrainPOP (www.brainpop.com), or problem generators such as KUTA (www.kutasoftware.com). Crafting quality curriculum materials and planning resources is a needed job resource. Quality curriculum, materials that are aligned to current content standards that help teachers conceptualize these standards and are available to all teachers, is a job resource that may increase teacher clarity for instruction (Layton, 2015). Teachers in countries other than the U.S. have this form of curriculum support.

International comparative studies such as the Trends in International Mathematics and Science Study (TIMSS) have been widely reported and publicized regarding student performance, yet few mention a comparative analysis of teacher support in these same countries. One report analyzing the differences in teacher support in high-achieving countries, asserts that "American students and teachers are greatly disadvantaged by our country's lack of a common, coherent curriculum and the texts, materials, and training that match it" (Schmidt, Houang, \& Cogan, 2002, p. 1). In Singapore, for instance, a consistently high-achieving country in mathematics, textbooks offer educators tutorials 
on the content for each lesson as well as insights to student misconceptions and possible questions before outlining the pedagogy of an exploratory activity that would engage students in discovery learning (Yoong \& Hoe, 2009). Teachers who are not trained for new standards or new curriculum may not implement curriculum as intended; as noted earlier, intended curriculum and enacted curriculum are not the same (Remillard, 2005).

Of interest to this study, student achievement was statistically significantly higher when teachers used standards-based curriculum (Reys et al., 2003) as well as when teachers were involved in the curriculum decision-making process for their students (Waters, Marzano, \& McNulty, 2003). Teachers need a clear guide of what content is to be taught, which concepts are to be emphasized, and what connections to help students make with resources for activities, practice, and assessment (Garland, 2014; McCrory et al., 2012; Waters, Marzano, \& McNulty, 2003). Districts that do not provide textbooks, lesson materials such as activities or resources for student practice and assessment, or even curriculum maps submit their students' experience with mathematics to the variance of teacher interpretation and submit their teachers to the job demand of creating or finding such resources for themselves. This is potentially an example of job demands (teaching to specific standards) without job resources (ready-to-use curriculum resources for students focused on those standards) that was predicted to decrease work engagement (Hakanen et al., 2006; Mauno, Kinnunen, \& Ruokolainen, 2007; Schaufeli \& Bakker, 2004).

The issues with curriculum implementation go deeper than mathematics teachers misinterpreting intentions of curriculum materials. For instance, a widely-adopted set of content standards is the CCSS-M. One of the CCSS-M authors, Jason Zimba, 
acknowledged that many teachers of mathematics, parents, and even textbook publishers may not be correctly interpreting the CCSS-M content standards (Garland, 2014). Efforts to train teachers and provide support continue to be a chief concern for the success of CCSS-M as Zimba “acknowledged better standards aren’t enough” (Garland, 2014). Teachers with unclear understandings of the expectations of their content standards may lead to misinterpretations while building their lessons and delivering instruction.

Professional Development (PD). Research delineates four elements for effective PD for mathematics teachers: long-term delivery with ongoing support, a clear focus on teacher practices as well as content knowledge, teacher involvement in designing student learning experiences as well as teacher reflection, and a professional network for support (Garet et al., 2001). The foundation of understanding content and curriculum is paramount (Brodie \& Shalem, 2011; McCrory et al., 2012), and mathematics educators need to know "both what knowledge matters and how it is manifest in practice" (McCrory et al., 2012, p. 586). In this study, quality PD is considered PD opportunities for mathematics teachers that is focused on teachers' current mathematics content standards as well as either identifying or addressing any pedagogy areas needed for implementing curriculum that is aligned to those content standards. PD addressing adopted curriculum materials alone is not enough and must cover content knowledge as it is a key component toward the severity of misinterpretations of curriculum and overall effectiveness as a mathematics teacher (McCrory et al., 2012). Most importantly, PD has been found to increase student achievement (Yoon et al., 2007).

PD sessions often are presented for a prescribed amount of time each year to school-wide audiences focusing on generalized education concerns, leaving mathematics 
teachers to deal with their most basic needs on their own time (Gewertz, 2014; Rentner \& Kober, 2014a). With new content standards that demand extended content knowledge as well as conceptual connections, middle and secondary mathematics educators may not have the knowledge required to be effective teachers. A study exploring the content knowledge of middle school mathematics teachers found that the teachers sampled demonstrated only about $50 \%$ of the content knowledge required to teach middle school according to the standards at that time (Saderholm, Ronau, Brown, \& Collins, 2010).

Even for the content standards currently used, the CCSS website states that the standards clearly communicate what is expected of students at each grade level which will allow teachers to be better equipped to know exactly what they need to help students learn and establish individualized benchmarks for them (CCSSO, 2010). The CCSS website also describes a new sense of flexibility to focus on the core concepts within each grade level in order to teach to a deeper understanding (CCSSO, 2010). However, the documents address elementary and some middle school concepts but scarcely provide a sense of the connections to be made within secondary mathematics or the focus points highlighting which content takes precedence for secondary topics (CCSSO, 2010); PD sessions, especially for high school teachers, would be a helpful job resource for teachers to sort through this confusion. As previously outlined, mathematics teachers need job resources that are specific for their job demands such as PD tailored to their content and pedagogical needs.

Planning Time. Little is written specifically about teachers' need for time or the impact of additional planning time on teacher effectiveness or student learning, yet the nature of learning and growing as a professional, even for teachers, is incremental, 
iterative, and takes time (Doerr, Goldsmith, \& Lewis, 2010). Teachers need time to absorb their content standards as well as create or adapt curriculum resources, even if resources are provided (Darling-Hammond, Wei, \& Andree, 2010). A research brief comparing teacher supports for U.S. teachers and teachers in high-achieving countries revealed teachers in the U.S. have 20 percent less time during their workdays to plan, collaborate, and meet with parents and students (Darling-Hammond, Wei, \& Andree, 2010).

If teacher understanding (either in terms of content knowledge, or pedagogy) is low, even more time will be needed to comprehend the task of implementing the standards and understanding a variety of ways in which they can be implemented. Teachers with high teacher understanding still need time to familiarize themselves with new curriculum resources as they may be new in both form and content and both take time to comprehend (Remillard, 2005). Teachers' need for time is an area where research is lacking, possibly due to the fact that it is common knowledge or that it is imbedded within other constructs such as planning or PD, for instance.

On a district or state level, time for curriculum implementation can be allotted by administrators if a lapse exists between introducing new standards to teachers and expecting them to implement the new standards (ASCD, 2012; NCTM, 2013). Allowing teachers time to understand the standards prior to receiving and/or creating curriculum may also increase teacher understanding; for instance, "the rapid adoption of [CCSSM] .. created a number of challenges in implementing the new standards" (ASCD, 2012, p. 12). Without ample time to absorb the expectations of both the content standards and 
the curriculum materials, teachers might feel unclear, overwhelmed, and ineffective towards their objectives.

On a school level, time can be allotted to teachers during their workday to plan for instruction (ASCD, 2012; Darling-Hammond, Wei, \& Andree, 2010). This planning can occur individually or collaboratively with other teachers (Darling-Hammond, Wei, \& Andree, 2010). Planning time however would need to focus on instructional planning rather than attending meetings or other extraneous school duties (VanTassel-Baska \& Stambaugh, 2005). In this study, time is considered as portions of the workday set aside for planning either individually or collaboratively.

Collaboration. Because teaching can be an isolating profession, efforts have been made over the last decade to increase collaboration among colleagues partly due to research in the business sector on professional learning communities (PLCs) (Vescio, Ross, \& Adams, 2008). With the emphasis on PLCs, research on implementation, characteristics of quality, and effects of teacher collaboration have followed. Collaborating with teacher colleagues has increased both teacher learning and teacher performance growth especially when teachers receive actionable feedback for improvement (Kraft \& Papay, 2014). Teachers learned at faster rates working in schools where the quality of collaboration was higher (Ronfeldt, Farmer, McQueen, \& Grissom, 2015), and they were found to be more eager, energized, and innovative toward teaching all students than those in lesser quality PLCs (McLaughlin \& Talbert, 1993). Quality collaboration means dialogue in PLCs is regulated by group selected norms that focus primarily on student learning and provide teachers with feedback where trust and rapport are strong (Bolam, McMahon, Stoll, Thomas, \& Wallace, 2005; Vescio et al. 2008). As 
illustrated in Figure 5, the quality of PLC collaboration can be influenced by school leadership (Coburn \& Turner, 2011). Teachers participating in quality collaboration may be more likely to feel a sense of success, which may additionally reduce teacher attrition, keeping teachers at their schools in which they feel successful (Johnson \& Birkeland, 2003).

Teacher learning can focus on teacher content knowledge, pedagogy, or student learning. Like PD, collaboration among colleagues can provide opportunities for teachers to clarify their understanding of content standards but unlike typical PD sessions, collaboration presents teachers with small group or even one-on-one opportunities to learn. Collaboration can also focus on department-adopted curriculum addressing instructional practices and resources. A third way in which teachers may learn is more data driven, focusing on ways to address students' learning needs (Ronfeldt et al., 2015). More than infrequent PD sessions, collaboration offers teachers an ongoing and accessible source for increasing teacher learning, focusing on various ways to provide better instruction.

Most importantly, teacher collaboration has been positively linked to student achievement (Goddard, Goddard, \& Tschannen-Moran, 2007; Kraft \& Papay, 2014; Louis \& Marks, 1998; Ronfeldt et al., 2015). Although hesitant to claim causality, researchers have suggested that the amount and quality of collaboration within a school corresponds with increased levels of student achievement (Goddard et al., 2007; Ronfeldt et al., 2015). In one study, the strength of a school's professional community, defined as "shared values, focus on student learning, collaboration, deprivatized practice, and 
reflective dialogue" (p. 539), was found to account for as much as $85 \%$ of the variance in student achievement (Louis \& Marks, 1998).

Again, larger organizational structures may impact teachers' engagement levels during collaboration time; providing time for small group collaboration alone is not enough to cause teachers to engage in professional growth but merely presents the opportunity to do so (Vescio et al., 2008). Teachers need support from their schools to foster environments such as ISC and SC where teachers collaborate by providing time and training for cultivating cooperative educator groups.

Autonomy. Teachers with a higher sense of autonomy provide better teaching (Porter, 1989) and are "more willing and supportive of common change" (Friedman, 1999, p. 59). Teachers' levels of autonomy also may be linked to their levels of job tension, frustration, and anxiety (Pearson \& Moomaw, 2006) and to teacher commitment, retention, and professionalism (Certo \& Fox, 2002; Kim \& Loadman, 1994; Pearson \& Moomaw, 2006). Autonomy as both internal and external control has been found to affect teacher satisfaction (Dinham \& Scott, 1996; Kim \& Loadman, 1994).

Teacher autonomy has been studied in multiple ways, resulting in various interpretations of the construct. One definition of autonomy is "a means of encouraging and strengthening the power of teachers in the personal or professional senses, not just as a buffer against pressures exerted on the teacher" (Friedman, 1999, p. 60). Another definition alludes to attaining a locus of control (Pearson \& Hall, 1993). Regardless of the definition, the overarching idea in autonomy studies focuses on teachers having the power to make important decisions for their work. Friedman (1999) suggests that teacher decisions fall into two categories: the "content axis" which includes pedagogical and 
organizational decisions and the "level axis" which includes principle or routine decisions. Both the content and level axis of teacher decisions were found to be statistically related to teacher autonomy (Friedman, 1999).

Understandings of teacher autonomy are complicated because of the various definitions in the literature and also because each teacher perceives autonomy differently (Pearson \& Moomaw, 2006). Although teachers' personal perceptions of autonomy may vary, one reason teachers reportedly leave the teaching profession is even when they do have power to make decisions they do not feel respected for their efforts (Dinham \& Scott, 1996; Pearson \& Moomaw, 2006). Teacher perception of autonomy depends on "their understandings of the organizational control system" (Leiter, 1981, p. 225), which emphasizes the importance of teachers' relationship with their administrators. In this study, autonomy refers to teachers' instructional autonomy to make decisions regarding their lesson delivery for their students. In this study, instructional autonomy assumes teachers refer to current content standards to determine what should be taught and have professional flexibility to decide the best curriculum materials, instructional methods, pacing, and timing of that content for educating their students.

Of particular interest to this study are connections between autonomy and effective teaching. Öztürk (2012) found that when teachers in Turkey were not included in the decision-making process for selecting curriculum materials, teachers adapted the curriculum, seeking internal autonomy. Teachers in the study noted exceptional differences between the mandated curriculum and their ability to adapt the curriculum materials to meet their students' needs, particularly different learning styles. Therefore, these instructional changes often fell short of "bridg[ing] the gap between instructional 
plans and classroom realities" (p. 297). Macpherson, Brooker, Aspland, and Elliott (1999) along with Öztürk (2012) found teachers were able to more effectively use curriculum materials when they were involved in the curriculum decision-making process.

Another research connection is found between teacher autonomy and stress, work satisfaction, empowerment, and professionalism (Pearson \& Moomaw, 2005). In the 2005 study, teacher autonomy was defined as curriculum autonomy and general teaching autonomy as measured by the Teaching Autonomy Scale (TAS), which included elements of instructional planning such as selection of instructional activities and materials, instructional sequencing, classroom standards of conduct, and on-the-job decision making. Curriculum autonomy was found to decrease on-the-job stress and general teaching autonomy was found to increase empowerment and professionalism, and this result was consistent across teaching levels from elementary to high school. A review of literature on autonomy and student achievement returned studies on the effects of students having autonomy over their learning (e.g. Froiland, Davison, \& Worrell, 2016; Reeve et al., 2004; Wong, Wiest, \& Cusick, 2002), not whether teachers had instructional autonomy over their teaching and student achievement. The most relevant study from the search of literature used international data from the PISA 2003 exam and found that "school autonomy" and student achievement both increased when students were tested using external exit exams and that "school autonomy is more beneficial in systems with external exams" (Lüdemann, Schütz, West, \& Woessmann, 2007, p. 34). In that study, school autonomy included various avenues for teachers to 
participate in decision-making, one of which included determining course content (Lüdemann et al., 2007).

\section{Summary}

Teachers need job resources to be engaged in and most effective at their work (Hakanen et al., 2006; Mauno et al, 2007; Schaufeli \& Bakker, 2004); however, mathematics teachers, may not have the physical or social job resources needed to be highly effective (Gewertz, 2014). Teachers endure stressful job demands (Hakanen et al., 2006); however, is the availability of job resources, among other considerations, that determines whether employees will engage at work to increase their effectiveness and productivity (Harter et al., 2002; Kahn, 1992; Leiter \& Maslach, 2004; Schaufeli et al., 2002).

Teachers engaged with their work convey characteristics of vigor, dedication, and absorption (Schaufeli et al., 2002). Considerations for work engagement involve both job demands and job resources, which can contribute to teachers' burnout or disengagement. Job demands include issues such as student behavior and work load. Although job demands are a real concern for teachers, the focus in this study in on job resources as they relate to student achievement in mathematics.

Job resources for teachers that affect their daily lesson planning and instruction have not been clearly identified in the literature. In this study, teacher job resources identified for effective teaching included quality curriculum, quality PD, time, collaboration, and autonomy. These are job resources that many mathematics teachers may not be provided (Gewertz, 2014). Districts that do not provide such resources leave their teachers to deal with job demands without job resources, a combination which may 
decrease teacher work engagement and effectiveness (Hakanen et al., 2006; Mauno et. al, 2007; Schaufeli \& Bakker, 2004). 


\section{CHAPTER 3}

\section{METHODOLOGY}

Researchers have found that work engagement is predicted by availability to job resources (Hakanen et al. 2006; Mauno et. al, 2007; Schaufeli \& Bakker, 2004). Therefore, it seems that if teachers have sufficient resources, they will be more likely to engage or remain engaged at work in the face of high job demands, and higher levels of engagement should align with higher levels of student achievement. In this study, five resources associated with lesson development or lesson planning were explored: curriculum materials containing support for mathematics content and pedagogy, professional development (PD) sessions focused on mathematics teacher needs, peer collaboration to refine teaching practices, work day planning time both individually and with colleagues, and teachers' sense of instructional job control.

Data were purchased from the Measures of Effective Teaching (MET) Project (MET Project, 2013). Files included a teacher work conditions questionnaire, student mathematics achievement scores, as well as both teacher and student demographic information. Data from this study were used to analyze student (level-1) and teacher (level-2) variables using hierarchical linear modeling (HLM) to explore the research question posed: How do teacher instructional job resources relate to student achievement in mathematics? 


\section{Sample}

The MET Project, funded by the Bill and Melinda Gates Foundation, gathered data from about 3,000 teacher volunteers from 2009-2011. Teachers worked in public and independent schools in Charlotte-Mecklenburg, North Carolina; Dallas, Texas; Denver, Colorado; Hillsborough County, Florida; Memphis, Tennessee; and New York City, New York. The purpose of the MET Project and data collection was to evaluate teachers during the 2009-2010 schoolyear for their impact on student achievement, randomly assign a classroom of students to the same participating teachers for the 20102011 school year, and then track students' achievement in order to identify and measure attributes of effective teachers (MET, 2013). Although teachers of several content areas participated in the MET Project over two years, only data for mathematics teachers from the 2010-2011 school year were included in this study. There were 22 schools, 46 teachers, and 2,180 students for the $9^{\text {th }}$ grade ACT QualityCore assessment with an average of almost 3 teachers per school $(\mathrm{SD}=1.13)$ and an average of about 40 students in each classroom on average $(\mathrm{SD}=18.26)$. The ACT QualityCore test is an exam that was developed by the ACT research and development team in collaboration with a group a teachers nationwide, and is independent from an identified set of content standards (www.act.org). There were 67 schools, 241 teachers, and 10,251 students for the $4^{\text {th }}-8^{\text {th }}$ grade Balanced Assessment in Mathematics assessment with an average of almost 5 teachers per school $(\mathrm{SD}=2.73)$ and about 44 students in each classroom $(\mathrm{SD}=18.10)$. The Balanced Assessment in Mathematics test is the result of an ongoing project at Harvard University Graduate School of Education from 1993 to 2003. The project generated innovative assessment tasks for mathematics and provided training for teachers 
to prepare their students. Sample tasks are freely available for teachers (hgse.balancedassessment.org/).

\section{Variables}

This study used data from the MET 3d-DS7 questionnaire titled Teacher Working Conditions from file MET 3d-DS7 ICPSR 34345, as well as teacher and student demographics. Teacher demographics from file da34771-0004_REST.sav included racial minority status, gender, and years of experience (see Table 1). Student demographics from file da34414-0004_REST.sav included gender, free or reduced lunch status, and underrepresented minority status (see Table 1). For each teacher and student demographic, attention was paid to issues of normality and skew. Files were linked through School ID and Teacher ID for HLM purposes.

The outcome measure was student achievement scores from one of two 20102011 school-year tests: the ACT QualityCore for Algebra 1 in high school (file da343090004_REST.sav) and the Balanced Assessment in Mathematics (BAM) for grades 4-8 (file da34309-0003_REST.sav). Models were run separately for each of these two grade bands so that the results could be analyzed for fourth through eight graders and for ninth graders separately. The achievement scores were standardized z-scores (mean close to 0 and SD close to 1) so that the results of the models could be compared. The outcome variable for student achievement in mathematics was BAM_Z_4-8 for $4^{\text {th }}-8^{\text {th }}$ and ACT_Z_9 for the $9^{\text {th }}$ grade model.

Table 1

Control Variables for Student and Teacher Participants

\begin{tabular}{lllll}
\hline Level & Variable Name & Description & Coding & Centering \\
\hline \multirow{2}{*}{ StGen } & Student gender & $\begin{array}{l}0=\text { female }, \\
1=\text { male }\end{array}$ & Uncentered \\
& & &
\end{tabular}




\begin{tabular}{|c|c|c|c|c|}
\hline & FRL & $\begin{array}{l}\text { Student free or } \\
\text { reduced lunch status }\end{array}$ & $\begin{array}{l}0=\text { regular lunch } \\
1=\text { free/reduced } \\
\text { lunch }\end{array}$ & Uncentered \\
\hline & UndMin & $\begin{array}{l}\text { Underrepresented } \\
\text { minority status of } \\
\text { student }\end{array}$ & $\begin{array}{l}0=\text { white or Asian } \\
1=\text { underrepresented } \\
\text { minority }\end{array}$ & Uncentered \\
\hline 2 & T_MinSt & Teacher race & $\begin{array}{l}0=\text { white or Asian }, \\
1=\text { underrepresented } \\
\text { minority }\end{array}$ & Uncentered \\
\hline & T_Gend & Teacher gender & $0=$ female, $1=$ male & Uncentered \\
\hline & T_Exper & Years of experience & Continuous & Uncentered \\
\hline
\end{tabular}

Survey items from the Teacher Working Conditions Survey addressed the five resources associated with lesson development or lesson planning previously outlined: Curriculum, PD, Collaboration, Planning Time, and Autonomy. I examined the MET survey questions and identified items that seemed to measure (a) teachers' thoughts on the quality of the curriculum materials provided to them, (b) whether teachers have quality PD sessions that are focused on mathematics, (c) whether teachers are able to collaborate with their peers to refine their teaching practices, (d) teachers' feeling a sense of job control from their administrators to create their own instructional plans, and (e) how much time teachers use during the day for lesson planning, the following survey questions were used. Teacher responses to survey items, which address the first four job resources, found in Table 2, along with their location in the MET codebook, were coded as follows: $1=$ strongly disagree, $2=$ disagree, $3=$ agree, $4=$ strongly agree, and $8=$ don't know, which was considered as missing data. Teacher responses to survey items on planning time found in Table 3, along with their location in the MET codebook, were coded as follows: $0=$ none, $1=$ less than or equal to $1 \mathrm{hr}, 2=$ more than an hour but less than or equal to 3 hours, $3=$ more than 3 hours but less than or equal to 5 hours, $4=$ more 
than 5 hours but less than or equal to 10 hours, and $5=$ more than 10 hours of planning

time.

Table 2

MET Survey Questions on Curriculum, PD, Collaboration, and Instructional Autonomy

\begin{tabular}{|c|c|c|c|}
\hline 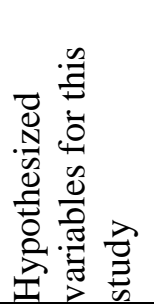 & 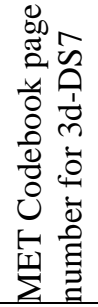 & $\begin{array}{l}\text { MET Survey } \\
\text { Variable Name }\end{array}$ & $\begin{array}{l}\text { Please rate how strongly you agree or disagree with the } \\
\text { following statements using the scale: strongly disagree to } \\
\text { strongly agree. } \\
\text { Survey Question }\end{array}$ \\
\hline \multirow{4}{*}{$\stackrel{\Xi}{\Xi}$} & 12 & FRL21APPMATERIAL & $\begin{array}{l}\text { Teachers have sufficient access to appropriate instructional } \\
\text { materials. }\end{array}$ \\
\hline & 86 & MET21MTLCONTENT & $\begin{array}{l}\text { They contain useful information for me about the content I am } \\
\text { teaching. }\end{array}$ \\
\hline & 86 & MET21MTLTEACH & $\begin{array}{l}\text { They provide me with useful information about how to teach } \\
\text { particular skills, strategies, texts, or other topics. }\end{array}$ \\
\hline & 87 & MET21MTLKNOW & $\begin{array}{l}\text { They provide me with useful information about what students } \\
\text { typically know and can do and about typical difficulties they } \\
\text { have. }\end{array}$ \\
\hline \multirow{4}{*}{$\stackrel{2}{2}$} & 39 & PDL21SUFFRES & $\begin{array}{l}\text { Sufficient resources are available for professional development } \\
\text { in my school. }\end{array}$ \\
\hline & 39 & PDL21TIME & $\begin{array}{l}\text { An appropriate amount of time is provided for professional } \\
\text { development. }\end{array}$ \\
\hline & 41 & PDL21DEEPEFFECT & $\begin{array}{l}\text { Professional development deepens teachers' content } \\
\text { knowledge. }\end{array}$ \\
\hline & 43 & PDL21ENHANCE & $\begin{array}{l}\text { Professional development enhances teachers' abilities to } \\
\text { improve student learning. }\end{array}$ \\
\hline \multirow{3}{*}{ 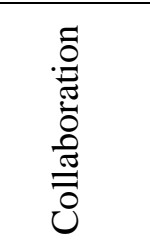 } & 42 & PDL21COLLEAGUE & $\begin{array}{l}\text { Professional development provides ongoing opportunities for } \\
\text { teacher to work with colleagues to refine teaching practices. }\end{array}$ \\
\hline & 52 & IPL21PLCINSTR & $\begin{array}{l}\text { Teachers work in professional learning communities to develop } \\
\text { and align instructional practices. }\end{array}$ \\
\hline & 4 & TML21COLLAB & Teachers have time available to collaborate with colleagues. \\
\hline \multirow{3}{*}{ 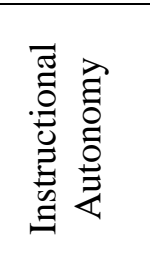 } & 53 & IPL21TRYNEW & $\begin{array}{l}\text { Teachers are encouraged to try new things to improve } \\
\text { instruction. }\end{array}$ \\
\hline & 54 & IPL21MAXSUCCESS & $\begin{array}{l}\text { Teachers are assigned classes that maximize their likelihood of } \\
\text { success with students. }\end{array}$ \\
\hline & 54 & IPL21AUTONOMY & $\begin{array}{l}\text { Teachers have the autonomy to make decisions about } \\
\text { instructional delivery (i.e., pacing, materials and pedagogy). }\end{array}$ \\
\hline
\end{tabular}


Table 3

MET Survey Questions on Planning Time

\begin{tabular}{lll} 
& $\begin{array}{l}\text { Please answer the survey questions using the following } \\
\text { categories: none, } \leq 1 \text { hour, 1-3 hours, 3-5 hours, 5-10 } \\
\text { hours, or > 10 hours }\end{array}$ \\
& $\begin{array}{lll}\text { TMT46COLLABPLN } \\
\text { TMT46INDPLN }\end{array}$ & $\begin{array}{l}\text { In an average week, how much time do you devote to } \\
\text { collaborative planning time during the school day (i.e., time for } \\
\text { which you are under contract to be at the school)? }\end{array}$ \\
& $\begin{array}{l}\text { In an average week, how much time do you devote to } \\
\text { individual planning time during the school day (i.e., time for } \\
\text { which you are under contract to be at the school)? }\end{array}$ \\
\hline
\end{tabular}

\section{Factor Analysis}

Factor analysis was used to examine how the survey questions functioned together to form factors, using the fewest interpretable factors needed to explain correlations within each construct (McCoach, Gable, \& Madura, 2013) and then to create factor scores. The sample was randomly separated in half in order to conduct first an exploratory factor analysis (EFA) followed by a confirmatory factor analysis (CFA). Assumptions of factor analysis include the presence of a large sample size, normality, linearity, absence of multicollinearity, and the absence of outliers in the data set (Stevens, 2009). Each assumption was checked for each of the randomly separated samples as well as the sample as a whole.

EFA is a technique outlined for large sample sizes; however, there are various suggestions regarding sample size. The most conservative suggestion is that 500 subjects is a very good sample size (Meyers, Gamst, \& Guarino, 2006) and allows for the weakest factor-loading relationship (McCoach et al., 2013). The data used in this project included 1,611 valid cases, an appropriate sample size using the aforementioned criterion.

Histograms for each question were evaluated. To further check the normality of each 
questions, skewness and kurtosis were analyzed. The Kolmogorov-Smirnov and ShapiroWilk statistics were also used to evaluate the normality assumption. Linearity for each question was evaluated from Q-Q scatterplots.

I conducted an EFA to determine how the survey items interrelated to form factors. I used principal axis factoring (PAF) to "explain the patterns of correlations among [the] measured variables" (McCoach et al., 2013, p. 119) and used direct oblimin rotation because factors likely were correlated (McCoach et al., 2013). The KaiserMeyer-Olkin (KMO) measure of sampling adequacy as well as the Bartlett's test of sphericity, measuring sufficient correlation between dependent variables, were used to determine whether the EFA was an appropriate analysis to conduct.

To determine the number of factors to extract, the following criteria were examined: Kaiser's criterion of eigenvalues greater than 1, scree plot analysis, and parallel analysis. Once I determined the number of factors to extract, I examined the pattern matrix for factor loadings higher than 0.4 and that were not double loading (McCoach et al., 2013). Based on the EFA, factors were named and defined (see Chapter $4)$.

These factors were used to conduct a CFA on the second half of the sample data. To conduct the CFA, the factors were represented as latent variables, with the items loading on their respective factors only and the factors being correlated. Model fit was estimated by three indices: RMSEA between 0.05 and 0.08 , SRMR between 0 and 0.08 , (Hooper, Coughlan, \& Mullen, 2008), and CFI greater than or equal to .90 (Lance, Butts, \& Michels, 2006). 
The reader will recall from Chapter 2 that several job resources may be related. In fact, physical resources (quality PD and curriculum) may theoretically be combined because materials and training work in tandem where PD could support adopted curriculum (McCrory et al., 2012; Polikoff \& Porter, 2014; Remillard, 2005). Therefore, two competing models (see Figure 9) were tested using CFA, (a) a model with individual factors identified from the EFA (see Table 4) representing the conceptual framework outlined in Chapter 2, and (b) a higher-order model to address the social and physical branches of job resources (see Table 5). A chi-square difference test was used to compare the higher-order model to the model with individual factors (McCoach et al., 2013).

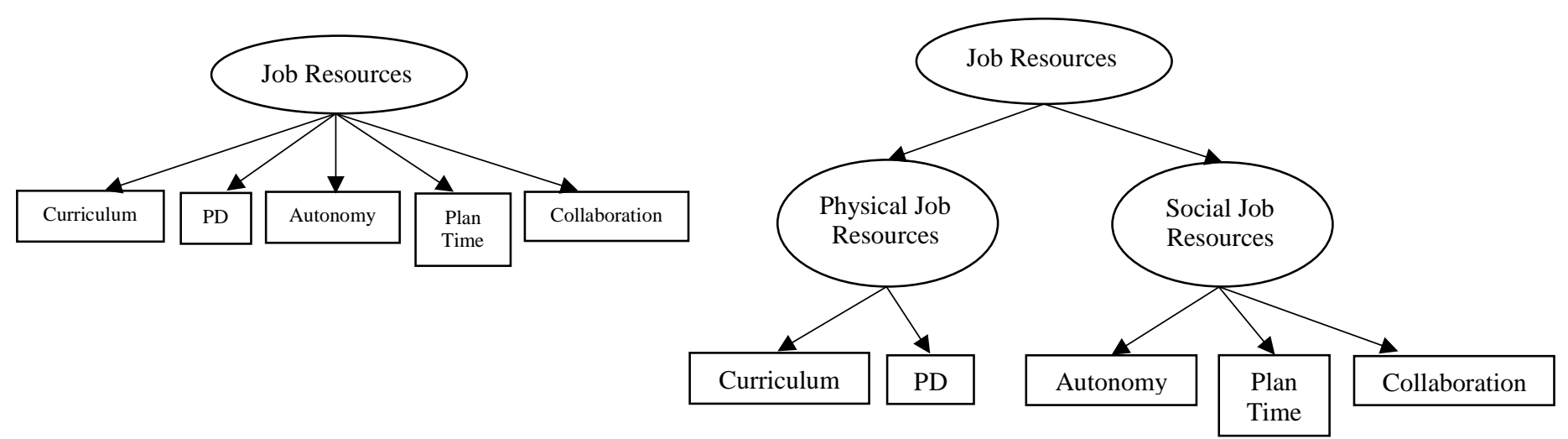

Figure 9. Five-factor model (left) and higher-order model (right) of the conjectured relationship of teacher job resources that may impact lesson planning and instruction and student achievement. 
Table 4

Hypothesized Five-Factor Model Independent Variables of Interest

\begin{tabular}{|c|c|c|c|c|}
\hline Level & $\begin{array}{l}\text { Variable } \\
\text { Name }\end{array}$ & Description & Coding & Centering \\
\hline \multirow[t]{5}{*}{$\mathrm{L} 2$} & COLLAB & Collaboration & $\begin{array}{l}\text { Factor scores } \\
\text { from CFA }\end{array}$ & $\begin{array}{l}\text { Grand-mean } \\
\text { centered }\end{array}$ \\
\hline & PLNTIME & Planning Time & $\begin{array}{l}\text { Factor scores } \\
\text { from CFA }\end{array}$ & $\begin{array}{l}\text { Grand-mean } \\
\text { centered }\end{array}$ \\
\hline & CURR & Curriculum & $\begin{array}{l}\text { Factor scores } \\
\text { from CFA }\end{array}$ & $\begin{array}{l}\text { Grand-mean } \\
\text { centered }\end{array}$ \\
\hline & PD & $\begin{array}{l}\text { Professional } \\
\text { Development }\end{array}$ & $\begin{array}{l}\text { Factor scores } \\
\text { from CFA }\end{array}$ & $\begin{array}{l}\text { Grand-mean } \\
\text { centered }\end{array}$ \\
\hline & AUTON & $\begin{array}{l}\text { Instructional } \\
\text { Autonomy }\end{array}$ & $\begin{array}{l}\text { Factor scores } \\
\text { from CFA }\end{array}$ & $\begin{array}{l}\text { Grand-mean } \\
\text { centered }\end{array}$ \\
\hline
\end{tabular}

Table 5

Hypothesized Higher-Order Model Independent Variables of Interest

\begin{tabular}{lllll}
\hline Level & $\begin{array}{l}\text { Variable } \\
\text { Name }\end{array}$ & Description & Coding & Centering \\
\hline L2 & PHY & $\begin{array}{l}\text { Physical Job Resources } \\
\text { (Curriculum \& Professional } \\
\text { Development) }\end{array}$ & $\begin{array}{l}\text { Factor scores } \\
\text { from CFA }\end{array}$ & Grand-mean centered \\
& & $\begin{array}{l}\text { Social Job Resources } \\
\text { (Collaboration, Time, \& } \\
\text { Autonomy) }\end{array}$ & $\begin{array}{l}\text { Factor scores } \\
\text { from CFA }\end{array}$ & Grand-mean centered \\
& SOC & & & \\
& &
\end{tabular}

\section{Relationship between Teacher Job Resources and Student Achievement}

To analyze the relationship of teacher job resources and student achievement, which involves students nested in classrooms that are nested in schools, a three-level hierarchical linear model was created using HLM7 software (Raudenbush et al., 2011). Accounting for the differences between classrooms and schools is important (McCoach \& Adelson, 2010) because teachers had different curriculum as well as other job resources that may have affected their students' achievement, thus violating the 
assumption of independence of observations. Models were estimated using Full Maximum Likelihood (FIML) because the sample consisted of more than 50 groups and models were examined with differing fixed effects (Raudenbush \& Bryk, 2002). Level-1 (student) and level-2 (classroom) predictor variables were analyzed with appropriately centered data so that all variables had a meaningful 0 . Cases with missing data were deleted at the time of analysis. In each case, model selection was based on methods outlined by Raudenbush and Bryk (2002) as well as McCoach and Black (2008) using AIC, BIC, and the chi-square difference test.

\section{HLM Model-Building Process}

The following model-building process was conducted separately for grades 4-8 and for grade 9. For each outcome, I followed the same process but only included data for students in the appropriate grade level(s).

The null model, which included only the outcome variable was built to determine the intraclass correlation coefficient (ICC). The ICC measured the proportion of variance that occurred between students within a classroom, $\frac{\sigma^{2}}{\sigma^{2}+\tau_{\pi}+\tau_{\beta}}$, between classrooms within a school, $\frac{\tau_{\pi}}{\sigma^{2}+\tau_{\pi}+\tau_{\beta}}$, and between schools, $\frac{\tau_{\beta}}{\sigma^{2}+\tau_{\pi}+\tau_{\beta}}$ (McCoach \& Adelson, 2010;

Raudenbush \& Bryk, 2002). Following the null model, the level-1 (student-level) model was built, which included student-level control variables, such as student gender, student free or reduced lunch status, and underrepresented minority status. Random effects for variables that did not vary across classes were fixed (Raudenbush \& Bryk, 2002) based on $p>.05$ and model fit comparisons. Next, random effects for variables that did not vary across schools were fixed (Raudenbush $\&$ Bryk, 2002) based on $p>.05$ and model fit comparisons. 
Following the level-1 model, the level-2 (teacher-level) control model was built by adding teacher-level control variables, such as teacher race, teacher gender, and years of experience as predictors of the intercept (Raudenbush \& Bryk, 2002). The proportion of variance explained by the level- 1 and level- 2 control variables was calculated by

comparing the variance in the level-2 model to the null model, $\frac{\tau_{\pi 00 \beta}-\tau_{\pi 00 F}}{\tau_{\pi 00 \beta}}$. Finally, the teacher variables of interest for the individual-factor model (i.e., COLLAB, TIME, CURR, PD, AUTON) were added to the level-2 model as predictors of the intercept. Thus, the relationship between the teacher job resource variables and student achievement could be examined while controlling for student and teacher characteristics. Additionally, I then could calculate the proportion of variance between classes and between schools in achievement that was explained by teacher job resources above and beyond the control variables.

This final process was repeated for the higher-order model factors. This allowed me to determine the relationship of physical and social job resources with student achievement while controlling for student and teacher contextual variables. Again, using the model-building process outlined by Raudenbush and Bryk (2002), I built models to examine the significance of the relationship between the teacher job resource variables of interest and student achievement while controlling for student and teacher background variables.

\section{Summary}

Using a large-scale secondary database, I was able to use multiple indicators to model five factors for teacher job resources: Curriculum, PD, Planning Time, Collaboration, and Autonomy. I expected to find that those factors could be grouped as 
follows: (a) physical job resources needed for planning effective instruction, which included curriculum materials and PD opportunities and (b) social job resources needed for planning effective instruction, which included teachers' planning time, collaboration, and their sense of autonomy. These factors were then used as variables of interest to examine the relationship between ITJR and student achievement using HLM. The model-building process of HLM allowed the statistical significance of these relationships to be analyzed while accounting for the clustering effect of students grouped into classes and controlling for student and teacher characteristics (McCoach \& Adelson, 2010; Raudenbush \& Bryk, 2002). By using this methodology, a more accurate analysis was possible than statistical techniques not accounting for the clustering effect (McCoach \& Adelson, 2010). 


\section{CHAPTER 4}

\section{RESULTS}

As stated in Chapter 1, this study examines the relationship between student achievement in mathematics and instructional teacher job resources (ITJR) such as curriculum materials, professional development (PD), time to collaborate with colleagues, and instructional autonomy. This chapter includes six parts: coding, normality and assumptions, exploratory factor analysis (EFA), confirmatory factor analysis (CFA), hierarchical linear modeling (HLM) for grades 4-8, and HLM for grade 9.

\section{Coding}

Each of the 14 survey questions for teacher working conditions from MET file 3d-DS7 ICPSR 34345 were recoded to have a meaningful zero, with a Likert scale ranging from 0 (strongly disagree) to 3 (strongly agree) and "don't know" coded as missing data. Coding for teacher working conditions relating to their time planning remained the same because it already had a meaningful zero. Control variables for both level-1 and level-2 variables were recoded as shown below in Table 6. 
Table 6

\begin{tabular}{|c|c|c|c|c|}
\hline \multirow{4}{*}{$\begin{array}{l}\text { Level } \\
1\end{array}$} & Variable Name & Description & Original Coding & Recoded \\
\hline & StGen & Student gender & $\begin{array}{l}1=\text { female } \\
2=\text { male }\end{array}$ & $\begin{array}{l}0=\text { female } \\
1=\text { male }\end{array}$ \\
\hline & FRL & $\begin{array}{l}\text { Free or reduced } \\
\text { lunch status }\end{array}$ & $\begin{array}{l}1=\text { full-price lunch } \\
2=\text { free/reduced } \\
\text { lunch }\end{array}$ & $\begin{array}{l}0=\text { full-price lunch } \\
1=\text { free/reduced } \\
\text { lunch }\end{array}$ \\
\hline & UndMin & $\begin{array}{l}\text { Underrepresented } \\
\text { minority status of } \\
\text { student }\end{array}$ & $\begin{array}{l}\text { White, Black, } \\
\text { Hispanic, Asian, } \\
\text { American Indian, or } \\
\text { other }\end{array}$ & $\begin{array}{l}0=\text { white or Asian } \\
1=\text { underrepresented } \\
\text { minority }\end{array}$ \\
\hline \multirow[t]{3}{*}{2} & T_MinSt & $\begin{array}{l}\text { Teacher minority } \\
\text { status }\end{array}$ & $\begin{array}{l}\text { White, Black, } \\
\text { Hispanic, or other }\end{array}$ & $\begin{array}{l}0=\text { white } \\
1=\text { underrepresented } \\
\text { minority }\end{array}$ \\
\hline & T_Gend & Teacher gender & $1=$ female, $2=$ male & $0=$ female, $1=$ male \\
\hline & T_Exper & Years of experience & Integers $[0,24]$ & No change \\
\hline
\end{tabular}

\section{Normality and Assumptions}

It was assumed that the survey questions were administered according to the MET guidelines such that teachers answered survey questions honestly and anonymously. Lastly, it was assumed that data for teacher surveys, student and teacher demographics, and student assessment scores were entered by MET without recording errors or data entry errors.

Data were not normally distributed, as expected due to the categorical and bimodal nature of the data. For instance, teacher survey items were comprised of four categorical choices of strongly disagree, disagree, agree, and strongly agree. Similarly, data on FRL, provided by MET, were dichotomous; students either were or were not identified as students on free and reduced lunch. Because of the categorical and dichotomous nature of the data and because it was assumed the data were entered correctly and without error, outliers were not removed (Stevens, 2009). 


\section{Exploratory Factor Analysis (EFA)}

The sample of questions from the teacher working conditions survey was randomly split and $49 \%$ or 1,024 of the 2,089 cases comprised the EFA sample. The Kaiser-Meyer-Olkin (KMO) measure of sampling adequacy (.874) as well as the Bartlett's test of sphericity (4955.625(120), $p<.001)$, which measures whether there is sufficient correlation between dependent variables, indicated that the EFA was an appropriate analysis to conduct. Kaiser's criterion of eigenvalues greater than 1 indicated four factors should remain, the parallel analysis indicated three factors should remain, and the scree plot analysis indicated one factor should remain. Without consistent criteria for determining the number of factors to retain, each of the models for a four-factor, three-factor, and one-factor EFA were examined, with all analyses using principle axis factoring and direct oblimin rotation.

Four-factor EFA. As shown in Table 7, most of the survey items had a factor loading of $|.400|$ or higher and were retained. These items each loaded clearly onto one of the four factors with no cross loadings and collectively explained $50.5 \%$ of the variance. The four factors operationally define Curriculum, Professional Development (PD), Autonomy, and Time to Collaborate. Time to Collaborate consisted of items that relate to two ideas discussed in Chapter 2, Time to Plan and Teacher Collaboration. Survey questions retained for Time to Collaborate contained only questions on time to plan collaboratively and not on individual planning time. Other than planning collaboratively, survey questions on planning time did not load on any factors with loadings greater than $|.400|$ and thus were not retained. 
Correlations across the subscales were also calculated. Autonomy and PD were

the highest correlated (.543) and Time to Collaborate and Curriculum were the lowest

correlated (.186).

Table 7

Pattern Matrix for the Four-Factor EFA

\begin{tabular}{|c|c|c|c|c|c|}
\hline \multirow{2}{*}{ Factor } & \multirow{2}{*}{ Survey Question } & \multicolumn{4}{|c|}{ Factor } \\
\hline & & 1 & 2 & 3 & 4 \\
\hline \multirow{5}{*}{$\begin{array}{l}\hat{2} \\
1 \\
-1\end{array}$} & $\begin{array}{l}\text { Sufficient resources are available for professional } \\
\text { development in my school. }\end{array}$ & .890 & & & -.103 \\
\hline & $\begin{array}{l}\text { An appropriate amount of time is provided for professional } \\
\text { development. }\end{array}$ & .807 & & & \\
\hline & $\begin{array}{l}\text { Professional development provides ongoing opportunities } \\
\text { for teachers to work with colleagues to refine teaching } \\
\text { practices. }\end{array}$ & .580 & & .101 & .232 \\
\hline & $\begin{array}{l}\text { Professional development enhances teachers' abilities to } \\
\text { improve student learning. }\end{array}$ & .562 & & & .289 \\
\hline & $\begin{array}{l}\text { Professional development deepens teachers' content } \\
\text { knowledge. }\end{array}$ & .524 & .126 & -.117 & .267 \\
\hline \multirow{3}{*}{ 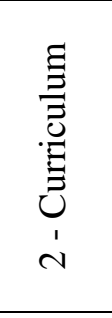 } & $\begin{array}{l}\text { They provide me with useful information about how to } \\
\text { teach particular skills, strategies, texts, or other topics. }\end{array}$ & & .984 & & \\
\hline & $\begin{array}{l}\text { They provide me with useful information about what } \\
\text { students typically know and can do and about typical } \\
\text { difficulties they have. }\end{array}$ & & .760 & & \\
\hline & $\begin{array}{l}\text { They contain useful information for me about the content I } \\
\text { am teaching. }\end{array}$ & & .687 & & \\
\hline \multirow{2}{*}{ 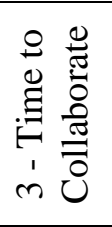 } & $\begin{array}{l}\text { In an average week, how much time do you devote to } \\
\text { collaborative planning time during the school day (i.e., time } \\
\text { for which you are under contract to be at the school)? }\end{array}$ & & & .784 & -.169 \\
\hline & $\begin{array}{l}\text { Teachers have time available to collaborate with } \\
\text { colleagues. }\end{array}$ & .185 & & .451 & .135 \\
\hline \multirow{3}{*}{ 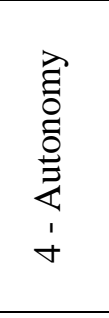 } & $\begin{array}{l}\text { Teachers have the autonomy to make decisions about } \\
\text { instructional delivery (i.e., pacing, materials and } \\
\text { pedagogy). }\end{array}$ & & & & .681 \\
\hline & $\begin{array}{l}\text { Teachers are assigned classes that maximize their } \\
\text { likelihood of success with students. }\end{array}$ & & & & .617 \\
\hline & $\begin{array}{l}\text { Teachers are encouraged to try new things to improve } \\
\text { instruction. }\end{array}$ & .204 & & & .546 \\
\hline \multirow{3}{*}{ 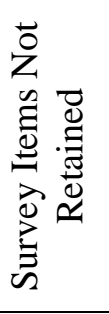 } & $\begin{array}{l}\text { Teachers have sufficient access to appropriate instructional } \\
\text { materials. }\end{array}$ & .298 & .123 & & .211 \\
\hline & $\begin{array}{l}\text { Teachers work in professional learning communities to } \\
\text { develop and align instructional practices. }\end{array}$ & .271 & & .261 & .202 \\
\hline & $\begin{array}{l}\text { In an average week, how much time do you devote to } \\
\text { individual planning time during the school day (i.e., time } \\
\text { for which you are under contract to be at the school)? }\end{array}$ & & & .245 & \\
\hline
\end{tabular}


Note. Factor loading values less than |.100| were suppressed from the table. Factor loadings greater than or equal to $|.400|$ were bolded as retained items.

Several survey questions loaded on variables not anticipated. For instance, MET survey question, "Professional development provides ongoing opportunities for teacher to work with colleagues to refine teaching practices," (item PDL21COLLEAGUE) loaded on PD instead of collaboration, as hypothesized. The formation of the new variable, Time to Collaborate, meant all of the items that loaded on Time to Collaborate were expected to load on other variables. As shown in Table 7, not all items loaded on one of the four factors, such as individual planning time.

Three-factor EFA. As shown in Table 8, all but one of the survey items had a factor loading of $|.400|$ or higher and were retained. These items each loaded clearly onto one of the three factors with no cross loadings and collectively explained $45.8 \%$ of the variance. In this solution, Curriculum and Time to Collaborate remained, but PD and Autonomy collapsed into one factor. Although this variable might be considered to operationalize a construct named "Professionalism," the term professionalism is a construct that is defined in education differently than professional development and autonomy (Hargreaves, 1999; Sykes, 1999). Therefore, the three factors for this model were Curriculum, Time to Collaborate, and PD + Instructional Autonomy. Again, items that were hypothesized to indicate individual planning time did not load on any factor. Correlations across the subscales were also calculated. PD + Instructional Autonomy and Curriculum were the highest correlated (.497) and, as before, Time to Collaborate and Curriculum were the lowest correlated (.166). 
Table 8

Pattern Matrix for the Three-Factor EFA

\begin{tabular}{|c|c|c|c|c|}
\hline \multirow{2}{*}{ Factor } & \multirow{2}{*}{ Survey Question } & \multicolumn{3}{|c|}{ Factor } \\
\hline & & 1 & 2 & 3 \\
\hline \multirow{10}{*}{ 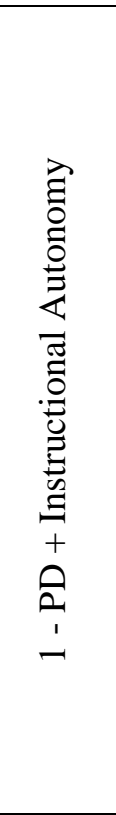 } & $\begin{array}{l}\text { Professional development enhances teachers' abilities to improve } \\
\text { student learning. }\end{array}$ & .819 & & -.111 \\
\hline & $\begin{array}{l}\text { Professional development provides ongoing opportunities for } \\
\text { teachers to work with colleagues to refine teaching practices. }\end{array}$ & .777 & & \\
\hline & Professional development deepens teachers' content knowledge. & .767 & & -.160 \\
\hline & $\begin{array}{l}\text { Sufficient resources are available for professional development in } \\
\text { my school. }\end{array}$ & .744 & & \\
\hline & $\begin{array}{l}\text { An appropriate amount of time is provided for professional } \\
\text { development. }\end{array}$ & 693 & & \\
\hline & Teachers are encouraged to try new things to improve instruction. & .639 & & \\
\hline & $\begin{array}{l}\text { Teachers are assigned classes that maximize their likelihood of } \\
\text { success with students. }\end{array}$ & .539 & & \\
\hline & $\begin{array}{l}\text { Teachers have the autonomy to make decisions about instructional } \\
\text { delivery (i.e., pacing, materials and pedagogy). }\end{array}$ & .473 & & \\
\hline & $\begin{array}{l}\text { Teachers have sufficient access to appropriate instructional } \\
\text { materials. }\end{array}$ & .472 & & \\
\hline & $\begin{array}{l}\text { Teachers work in professional learning communities to develop and } \\
\text { align instructional practices. }\end{array}$ & .436 & & .253 \\
\hline \multirow{3}{*}{ 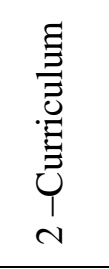 } & $\begin{array}{l}\text { They provide me with useful information about how to teach } \\
\text { particular skills, strategies, texts, or other topics. }\end{array}$ & \multicolumn{3}{|c|}{.966} \\
\hline & $\begin{array}{l}\text { They provide me with useful information about what students } \\
\text { typically know and can do and about typical difficulties they have. }\end{array}$ & \multicolumn{3}{|c|}{.737} \\
\hline & $\begin{array}{l}\text { They contain useful information for me about the content I am } \\
\text { teaching. }\end{array}$ & \multicolumn{3}{|c|}{.672} \\
\hline \multirow{2}{*}{ 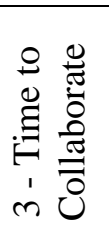 } & $\begin{array}{l}\text { In an average week, how much time do you devote to collaborative } \\
\text { planning time during the school day (i.e., time for which you are } \\
\text { under contract to be at the school)? }\end{array}$ & & & .739 \\
\hline & Teachers have time available to collaborate with colleagues. & .288 & & .459 \\
\hline 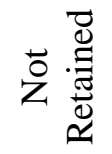 & $\begin{array}{l}\text { In an average week, how much time do you devote to individual } \\
\text { planning time during the school day (i.e., time for which you are } \\
\text { under contract to be at the school)? }\end{array}$ & & & .242 \\
\hline
\end{tabular}

Note. Factor loading values less than |.100| were suppressed from the table. Factor loadings greater than or equal to $|.400|$ were bolded as retained items.

One-factor EFA. As shown in Table 9, all but two of the survey items had a factor loading of $|.400|$ or higher and were retained, and the factors collectively explained $32.4 \%$ of the variance. All survey questions regarding Curriculum, PD, Instructional 
Autonomy, and Time to Collaborate were combined for the EFA with one factor retained.

Items that were hypothesized to indicate individual planning time did not load on the

factor.

Table 9

Pattern Matrix for a One-Factor EFA

\begin{tabular}{|c|c|c|}
\hline Factor & Survey Question & $\begin{array}{c}\text { Factor } \\
1\end{array}$ \\
\hline \multirow{14}{*}{ 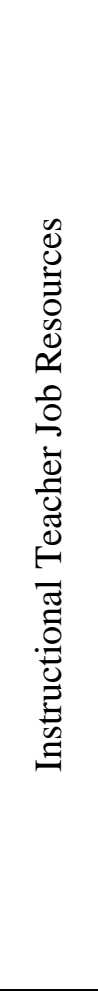 } & $\begin{array}{l}\text { Professional development provides ongoing opportunities for teachers to work } \\
\text { with colleagues to refine teaching practices. }\end{array}$ & .775 \\
\hline & $\begin{array}{l}\text { Professional development enhances teachers' abilities to improve student } \\
\text { learning. }\end{array}$ & .745 \\
\hline & Professional development deepens teachers' content knowledge. & .720 \\
\hline & Sufficient resources are available for professional development in my school. & .696 \\
\hline & An appropriate amount of time is provided for professional development. & .679 \\
\hline & Teachers are encouraged to try new things to improve instruction. & .638 \\
\hline & $\begin{array}{l}\text { Teachers are assigned classes that maximize their likelihood of success with } \\
\text { students. }\end{array}$ & .566 \\
\hline & $\begin{array}{l}\text { Teachers work in professional learning communities to develop and align } \\
\text { instructional practices. }\end{array}$ & .551 \\
\hline & $\begin{array}{l}\text { [Instructional materials] provide me with useful information about how to teach } \\
\text { particular skills, strategies, texts, or other topics. }\end{array}$ & .521 \\
\hline & Teachers have sufficient access to appropriate instructional materials. & .516 \\
\hline & $\begin{array}{l}\text { [Instructional materials] contain useful information for me about the content I } \\
\text { am teaching. }\end{array}$ & .498 \\
\hline & $\begin{array}{l}\text { Teachers have the autonomy to make decisions about instructional delivery (i.e., } \\
\text { pacing, materials and pedagogy). }\end{array}$ & .485 \\
\hline & $\begin{array}{l}\text { [Instructional materials] provide me with useful information about what students } \\
\text { typically know and can do and about typical difficulties they have. }\end{array}$ & .482 \\
\hline & Teachers have time available to collaborate with colleagues. & .469 \\
\hline \multirow{2}{*}{ 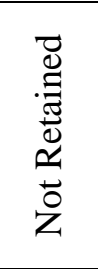 } & $\begin{array}{l}\text { In an average week, how much time do you devote to collaborative planning } \\
\text { time during the school day (i.e., time for which you are under contract to be at } \\
\text { the school)? }\end{array}$ & .228 \\
\hline & $\begin{array}{l}\text { In an average week, how much time do you devote to individual planning time } \\
\text { during the school day (i.e., time for which you are under contract to be at the } \\
\text { school)? }\end{array}$ & .103 \\
\hline
\end{tabular}

Note. Factor loadings greater than or equal to $|.400|$ were bolded as retained items.

EFA decision. Table 10 presents the MET survey questions, organized by their original hypothesized variables, and indicates factor loadings for each solution or whether they were eliminated. 
Table 10

MET Survey Items as Selected for each EFA Model

\begin{tabular}{|c|c|c|c|c|}
\hline Survey Question from the MET Project & $\begin{array}{l}\text { Hypothesized } \\
\text { Categories }\end{array}$ & $\begin{array}{l}\text { Four- } \\
\text { Factor } \\
\text { Model }\end{array}$ & $\begin{array}{l}\text { Three- } \\
\text { Factor } \\
\text { Model }\end{array}$ & $\begin{array}{l}\text { One- } \\
\text { Factor } \\
\text { Model }\end{array}$ \\
\hline $\begin{array}{l}\text { Teachers have sufficient access to appropriate } \\
\text { instructional materials. }\end{array}$ & CURR & - & $\mathrm{PD}+\mathrm{A}$ & ITJR \\
\hline $\begin{array}{l}\text { They contain useful information for me about the } \\
\text { content I am teaching. }\end{array}$ & CURR & CURR & CURR & ITJR \\
\hline $\begin{array}{l}\text { They provide me with useful information about how to } \\
\text { teach particular skills, strategies, texts, or other topics. }\end{array}$ & CURR & CURR & CURR & ITJR \\
\hline $\begin{array}{l}\text { They provide me with useful information about what } \\
\text { students typically know and can do and about typical } \\
\text { difficulties they have. }\end{array}$ & CURR & CURR & CURR & ITJR \\
\hline $\begin{array}{l}\text { Sufficient resources are available for professional } \\
\text { development in my school. }\end{array}$ & $\mathrm{PD}$ & PD & $\mathrm{PD}+\mathrm{A}$ & ITJR \\
\hline $\begin{array}{l}\text { An appropriate amount of time is provided for } \\
\text { professional development. }\end{array}$ & $\mathrm{PD}$ & PD & $\mathrm{PD}+\mathrm{A}$ & ITJR \\
\hline $\begin{array}{l}\text { Professional development deepens teachers' content } \\
\text { knowledge. }\end{array}$ & $\mathrm{PD}$ & PD & $\mathrm{PD}+\mathrm{A}$ & ITJR \\
\hline $\begin{array}{l}\text { Professional development enhances teachers' abilities to } \\
\text { improve student learning. }\end{array}$ & $\mathrm{PD}$ & PD & $\mathrm{PD}+\mathrm{A}$ & ITJR \\
\hline $\begin{array}{l}\text { Professional development provides ongoing } \\
\text { opportunities for teacher to work with colleagues to } \\
\text { refine teaching practices. }\end{array}$ & CLB & PD & $\mathrm{PD}+\mathrm{A}$ & ITJR \\
\hline $\begin{array}{l}\text { Teachers work in professional learning communities to } \\
\text { develop and align instructional practices. }\end{array}$ & CLB & - & $\mathrm{PD}+\mathrm{A}$ & ITJR \\
\hline $\begin{array}{l}\text { Teachers have time available to collaborate with } \\
\text { colleagues. }\end{array}$ & CLB & TIME & TIME & ITJR \\
\hline $\begin{array}{l}\text { Teachers are encouraged to try new things to improve } \\
\text { instruction. }\end{array}$ & AUTON & AUTON & $\mathrm{PD}+\mathrm{A}$ & ITJR \\
\hline $\begin{array}{l}\text { Teachers are assigned classes that maximize their } \\
\text { likelihood of success with students. }\end{array}$ & AUTON & AUTON & $\mathrm{PD}+\mathrm{A}$ & ITJR \\
\hline $\begin{array}{l}\text { Teachers have the autonomy to make decisions about } \\
\text { instructional delivery (i.e., pacing, materials and } \\
\text { pedagogy). }\end{array}$ & AUTON & AUTON & $\mathrm{PD}+\mathrm{A}$ & ITJR \\
\hline $\begin{array}{l}\text { In an average week, how much time do you devote to } \\
\text { collaborative planning time during the school day (i.e., } \\
\text { time for which you are under contract to be at the } \\
\text { school)? }\end{array}$ & $\begin{array}{l}\text { PLANNING } \\
\text { TIME }\end{array}$ & TIME & TIME & - \\
\hline $\begin{array}{l}\text { In an average week, how much time do you devote to } \\
\text { individual planning time during the school day (i.e., } \\
\text { time for which you are under contract to be at the } \\
\text { school)? }\end{array}$ & $\begin{array}{l}\text { PLANNING } \\
\text { TIME }\end{array}$ & - & - & - \\
\hline
\end{tabular}

Note. CURR refers to Curriculum, PD refers to Professional Development, CLB refers to Collaboration, AUTON refers to Autonomy, PLANNING TIME refers to Time to Plan during the work day, TIME refers to the merged variable of Time to Collaborate, PD+A refers to Professional Development plus Autonomy, and ITJR refers to Instructional Teacher Job Resources. A dash is used to indicate when survey items were not retained. 
The four-factor solution made the most theoretical sense of the three solutions that were tested and explained the most variance (50.5\%) among the three models. However, given that different criteria recommended different number of factors, I chose to test the model fit of all three solutions to further validate the decision to retain four factors.

\section{Confirmatory Factor Analysis (CFA)}

To test the fit of the three models from the EFA, I conducted a CFA on the second half of the sample data, $(n=1,065)$. Due to the discrepancy in criteria for EFA factor retention and to increase validity, each of the factor solutions (four, three, and one factors) were analyzed.

The four-factor model (see Figure 10, bottom) included factors for PD (five items), Curriculum (three items), Time to Collaborate (two items), and Autonomy (three items) and did not include the three items that did not have factor loadings of $|.400|$ or higher. The three-factor model (see Figure 10, top right) included factors for PD + Autonomy (10 items), Curriculum (three items), and Time to Collaborate (two items) and did not include the one item that did not have a factor loading of $|.400|$ or higher. Finally, the one-factor model (see Figure 10, top left) retained 14 of the 16 survey items that had factor loadings of |.400|, all as indicators of the latent factor Instructional Teacher Job Resources. Table 11 presents the model fit indices for each of these models. 

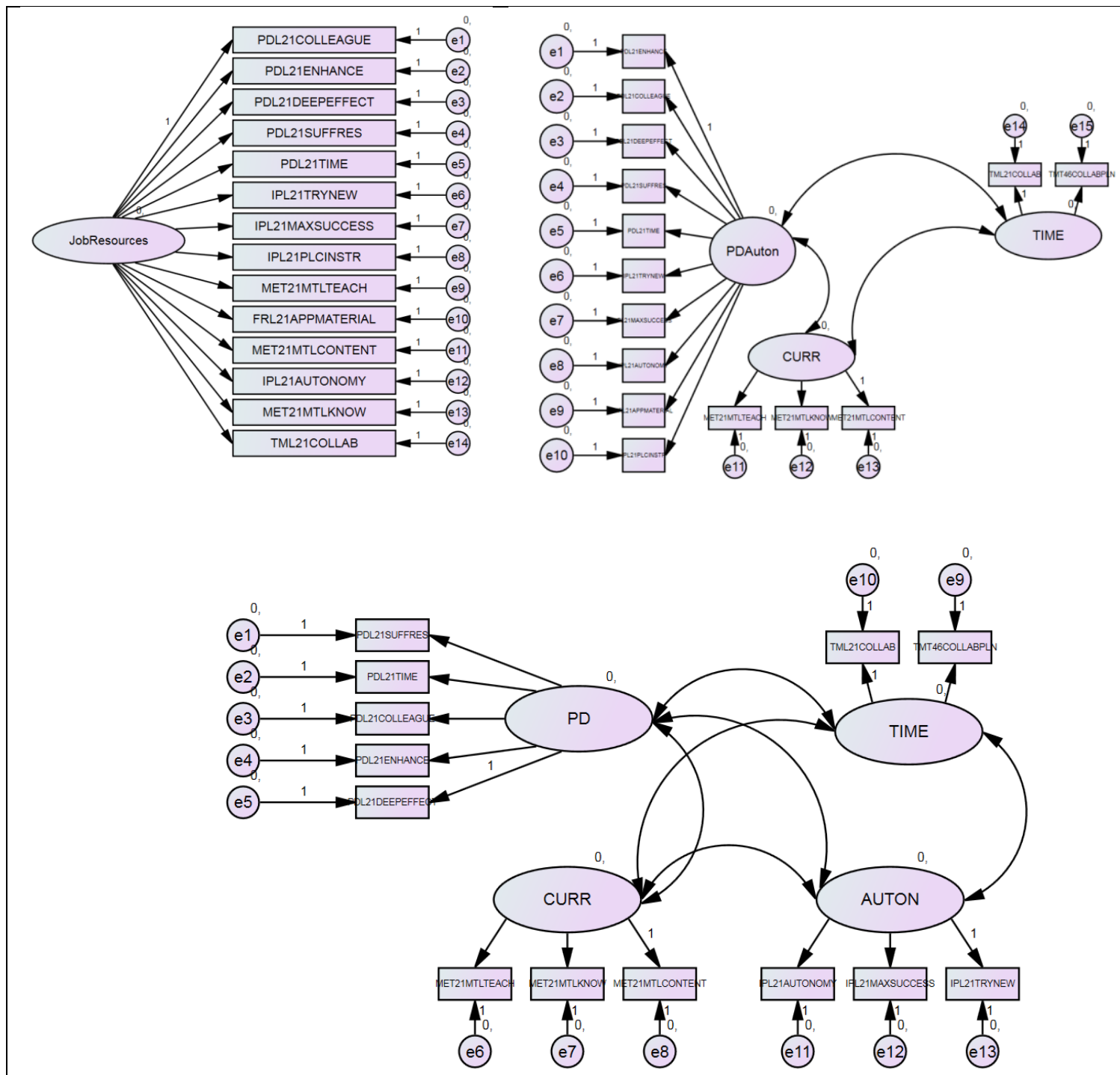

Figure 10. CFA diagrams for the One-Factor (top left), Three-Factor (top right), and Four-Factor Models (bottom).

Table 11

CFA Model Fit Indices

\begin{tabular}{llllll}
\hline $\begin{array}{l}\text { Factors } \\
\text { Retained }\end{array}$ & Description & RMSEA & AIC & CFI & $\chi^{2}$ \\
\hline 4 & Separate factors for & $.084(.077-.091)$ & 590.216 & .921 & $500.22(59) *$ \\
& CURR, PD, TIME, \& & & & & \\
& AUTON & & & &
\end{tabular}




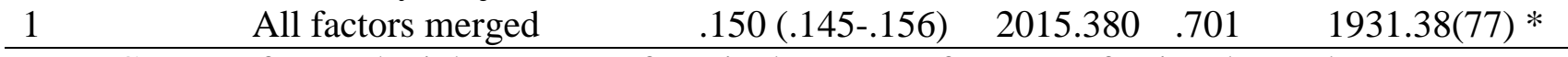

Note. CURR refers to the job resource of curriculum, PD refers to Professional Development, TIME refers to Time to Collaborate with colleagues, and AUTON refers to instructional autonomy. $* p<.001$

Between the fundamental models with either four, three, or one factors, the model with four factors was preferred with the lowest root mean square error of approximation (RMSEA) and Akaike information criterion (AIC) scores and highest comparative fit index (CFI) scores. Both the RMSEA and CFI indicate adequate model fit (Stevens, 2009). Standardized regression weights for the four-factor model are in Table 12. The final teacher-level variables for the individual-factor job resources model to be used in HLM were TIME for time to work collaboratively with colleagues (two items), CURR for curriculum job resources (three items), PD for professional development (five items), and AUTON for instructional autonomy (three items). Each of these variables were created from their CFA factor scores, which is explained in a following section.

Table 12

Four-Factor Model Standardized Regression Weights

\begin{tabular}{llll}
\hline MET Survey Items & & Factor & Estimate \\
\hline PDL21DEEPEFFECT & $<---$ & PD & .750 \\
PDL21ENHANCE & $<---$ & PD & .835 \\
PDL21COLLEAGUE & $<---$ & PD & .813 \\
PDL21TIME & $<---$ & PD & .682 \\
PDL21SUFFRES & $<---$ & PD & .728 \\
MET21MTLCONTENT & $<---$ & CURR & .764 \\
MET21MTLKNOW & $<---$ & CURR & .739 \\
MET21MTLTEACH & $<---$ & CURR & .917 \\
IPL21TRYNEW & $<---$ & AUTON & .749 \\
IPL21MAXSUCCESS & $<---$ & AUTON & .611 \\
IPL21AUTONOMY & $<---$ & AUTON & .604 \\
TML21COLLAB & $<---$ & TIME & .773 \\
TMT46COLLABPLN & $<---$ & TIME & .435 \\
\hline
\end{tabular}


Note. PD refers to Professional Development, CURR refers to Curriculum, AUTON refers to Instructional Autonomy, and TIME refers to Time to Collaborate.

\section{Higher-Order Models}

After determining that theoretically as well as statistically the four-factor model was the best model, I also tested two higher-order models. In one model, HO, there was one higher-order factor that explained all four of the job resource factors. In the other model, $\mathrm{HO} 2$, there were two higher-order factors: Autonomy and Time to Collaborate were indicators of Social ITJR and Curriculum and PD were indicators of Physical ITJR. Table 13 shows the model fit indices for these two models, which were used to make the final high-order model selection.

Table 13

Higher-Order CFA Model Fit indices

\begin{tabular}{llllll}
\hline Model & Description & RMSEA & AIC & CFI & $\chi^{2}$ \\
\hline HO & Job Resources (JRs) & $.083(.076-.090)$ & 593.72 & .920 & $507.72(61) *$ \\
HO2 & SOC \& PHY JRs & $.083(.077-.090)$ & 590.71 & .921 & $502.71(60) *$ \\
Note. SOC refers to the Social job resources comprised of Time to Collaborate and & \\
Instructional Autonomy. PHY refers to the Physical job resources comprised of Curriculum \\
and Professional Development.
\end{tabular}

Between the higher-order models, HO2 was slightly preferred with slightly lower AIC values. The final teacher-level variables for the higher-order ITJR model to be used in HLM were PHY for Physical ITJR (Curriculum and Professional Development) and SOC for Social ITJR (Time to Collaborate and Autonomy). Regression weights for this model are in Table 14. Both of the higher-order variables, PHY and SOC, were created from their CFA factor scores. 
Table 14

Higher-Order Model Standardized Regression Weights

\begin{tabular}{lllr} 
MET Survey Items & & Factor & Estimate \\
\hline PD & $<---$ & PHY & .790 \\
CURR & $<---$ & PHY & .545 \\
TIME & $<---$ & SOC & .573 \\
AUTON & $<--$ & SOC & .786 \\
PDL21DEEPEFFECT & $<---$ & PD & .751 \\
PDL21ENHANCE & $<---$ & PD & .835 \\
PDL21COLLEAGUE & $<---$ & PD & .813 \\
PDL21TIME & $<---$ & PD & .681 \\
PDL21SUFFRES & $<---$ & PD & .727 \\
MET21MTLCONTENT & $<---$ & CURR & .764 \\
MET21MTLKNOW & $<---$ & CURR & .739 \\
MET21MTLTEACH & $<---$ & CURR & .917 \\
IPL21TRYNEW & $<---$ & AUTON & .749 \\
IPL21MAXSUCCESS & $<---$ & AUTON & .612 \\
IPL21AUTONOMY & $<---$ & AUTON & .604 \\
TML21COLLAB & $<---$ & TIME & .769 \\
TMT46COLLABPLN & $<---$ & TIME & .438 \\
\hline
\end{tabular}

Note. Physical refers to Physical ITJRs comprised of

CURR and PD. Social refers to Social ITJRs

comprised of AUTON and TIME. PD refers to

Professional Development, CURR refers to

Curriculum, AUTON refers to Autonomy, and TIME

refers to Time to Collaborate.

\section{Factor Scores}

Factor scores were then created for the following variables: Curriculum, PD,

Time to Collaborate, Autonomy, Physical, and Social. Factor scores report each factor as a weighted sum of each survey item. Weighted output factors on each survey item from the CFA were applied to each teachers' responses, which created job resource scores that were specific for each teacher. These continuous factor scores were then used in HLM as the level-2 variables of interest.

Histograms and boxplots were analyzed for normality for the factor scores, as well as statistical normality tests. These indicated that each factor score, comprised of 
categorical and bimodal data, had issues with normality (see Table 15). Linearity for each question was evaluated from Q-Q scatterplots. Questions appeared to be relatively linear.

Table 15

Tests of Normality for ITJR Factor Scores

\begin{tabular}{|c|c|c|c|c|c|c|c|c|}
\hline \multirow[b]{2}{*}{ Variable } & \multicolumn{2}{|l|}{ Skewness } & \multicolumn{2}{|l|}{ Kurtosis } & \multicolumn{2}{|c|}{$\begin{array}{l}\text { Kolmogorov- } \\
\text { Smirnov }\end{array}$} & \multicolumn{2}{|c|}{ Shapiro-Wilk } \\
\hline & Statistic & $\begin{array}{l}\text { Std. } \\
\text { Error }\end{array}$ & Statistic & $\begin{array}{l}\text { Std. } \\
\text { Error }\end{array}$ & Statistic & $p$ & Statistic & $p$ \\
\hline PHY & -.255 & .061 & .607 & .122 & $.045(1611)$ & $<.001$ & $.045(1611)$ & $<.001$ \\
\hline $\mathrm{SOC}$ & -.282 & .061 & .684 & .122 & $.055(1611)$ & $<.001$ & $.055(1611)$ & $<.001$ \\
\hline CURR & -.459 & .061 & .819 & .122 & $.170(1611)$ & $<.001$ & $.170(1611)$ & $<.001$ \\
\hline PD & -.404 & .061 & .782 & .122 & $.106(1611)$ & $<.001$ & $.106(1611)$ & $<.001$ \\
\hline AUTON & -.311 & .061 & .563 & .122 & $.069(1611)$ & $<.001$ & $.069(1611)$ & $<.001$ \\
\hline TIME & -.306 & .061 & -.183 & .122 & $.080(1611)$ & $<.001$ & $.080(1611)$ & $<.001$ \\
\hline
\end{tabular}

\section{Hierarchical Linear Modeling}

I analyzed a three-level hierarchical linear model (HLM; Raudenbush \& Bryk, 2002) to examine whether students' achievement in mathematics was related to teacher work conditions, while controlling for student and teacher information. I used HLM version 7 statistical software. Data were at three levels. Level 1 included data pertaining to students, such as students' mathematical achievement and student control variables (i.e., gender, underrepresented minority status, and free or reduced lunch status). Level-2 data included teacher data addressing ITJR (i.e., Curriculum materials, PD, Time to Collaborate with colleagues, and Instructional Autonomy) as well as teacher control variables (i.e., gender, minority status, and years of experience). Although the analyses did not include any variables at level-3, the third level was needed in order to account for clustering at the school level, which violated the assumption of independence (McCoach 
\& Adelson, 2010). Students were linked to their teachers, and teachers were linked to their schools for the three-level HLM model. Separate analyses were run for the Balanced Assessment in Mathematics (BAM) z-scores for $4-8^{\text {th }}$ grade students and ACT QualityCore ${ }^{\circledR}$ z-scores for $9^{\text {th }}$ grade students. The HLM model results for ITJRs and student achievement in mathematics are reported according to the assessment, with BAM models and results reported first, followed ACT models and results. Models are presented in the following order: null, level-1 control, level-2 control, ITJR individualfactors, and ITJR higher-order factors.

\section{Results for student achievement on BAM, grades 4-8.}

Null Model. Achievement in mathematics on the BAM was the outcome variable. The null model included only the students' assessment score for achievement in mathematics, given by:

$$
B A M_{-} Z_{-} 4-8_{i j k}=\gamma_{000}+r_{0 j k}+u_{00 k}+e_{i j k}
$$

For this model, $B A M_{-} Z_{-} 4-8_{i j k}$ was the value of each student's mathematical achievement score, with student $i$ being in classroom $j$ and in school $k$. The parameter $\gamma_{000}$ represents the grand mean of students' mathematics achievement scores. The parameter $r_{o j k}$ represents the random classroom effect, or the deviation of classroom $j k^{6} \mathrm{~s}$ mean from the school mean. The parameter $u_{00 k}$ represents the random school effect, or the deviation of school $k^{c}$ s mean from the grand mean. The parameter $e_{i j k}$ indicated the random student effect, or the deviation of each student's assessment score from the classroom mean, which was assumed to be normally distributed with a mean of zero and variance of $\sigma^{2}$. 
The variance in achievement scores between students within classes for $4^{\text {th }}-8^{\text {th }}$ grade students was $\sigma^{2}=0.596$. The variance in achievement scores between classes within schools was $\tau_{\pi 00}=0.118$. The variance in achievement scores between schools was $\tau_{\beta 00}=0.166$ for $4^{\text {th }}-8^{\text {th }}$ grade.

The ratio of variance among students within classes to the total variance, or the intra-class correlation (ICC), was $I C C_{B A m}=\frac{\sigma^{2}}{\sigma^{2}+\tau_{\pi}+\tau_{\beta}}=.678$. The ICC for the ratio of between-group variance among classes within schools to the total variance was as follows: $I C C_{B A m}=\frac{\tau_{\pi}}{\sigma^{2}+\tau_{\pi}+\tau_{\beta}}=.134$. The ICC for the ratio of between-group variance among schools to the total variance was as follows: $I C C_{B A m}=\frac{\tau_{\pi}}{\sigma^{2}+\tau_{\pi}+\tau_{\beta}}=.189$.

According to the ICC calculations, approximately $67.8 \%$ of the variance in student achievement scores on the BAM test was attributable to students within classes. Approximately $13.4 \%$ of the variability in BAM assessment scores was between classes within schools. Variance in assessment scores between schools was found to be approximately $18.9 \%$ for $4^{\text {th }}-8^{\text {th }}$ graders who took the BAM test. Furthermore, BAM assessment scores statistically significantly varied between schools $\left(\tau_{\beta 00}=0.167, p<\right.$ .001). Sufficient variation in student scores between schools existed for the BAM test scores to merit a three-level HLM model.

Level-1 Control Model. All student (level-1) control variables were added to the model. The reader will recall the student control variables were student gender (STGEN), whether a student receives free or reduced lunch (FRL), and student minority status (UNDMIN). In the initial model, the slopes for these variables were allowed to 
vary randomly at both the class and school levels, and any slopes that did not statistically significantly vary were fixed one at a time. Multiple iterations of models were generated for the purpose of fixing slopes one at a time, whenever significance is noted, the $p$ values are from the most current model iteration. Relationships between student achievement and student free or reduced lunch status $\left(r_{2}=0.028, p=.002\right)$ as well as student underrepresented minority status $\left(r_{3}=0.031, p<.001\right)$ statistically varied across classes. The relationship between student gender and student achievement did not vary across classes $\left(r_{1}=0.004, p>.500\right)$ and was fixed. The relationship between underrepresented minority status and student achievement statistically varied across schools $\left(u_{30}=0.015, p=.009\right)$. Relationships between student achievement and free or reduced lunch status $\left(u_{20}=0.007, p=.399\right)$ as well as student gender $\left(u_{10}=0.005, p=\right.$ .153) did not vary across schools and were fixed, respectively, one at a time. The final level-1 control model for the BAM assessment, where BAM_Z_4 $-8_{i j k}$ the BAM assessment z-score for student $i$ in classroom $j$ in school $k$, was as follows:

Level-1 Model

$$
\begin{aligned}
& B A M \_Z \_4-8_{i j k}=\pi_{0 j k}+\pi_{1 j k} *\left(S T G E N_{i j k}\right)+\pi_{2 j k} *\left(F R L_{i j k}\right)+\pi_{3 j k} * \\
& \left(U N D M I N_{i j k}\right)+e_{i j k}
\end{aligned}
$$

Level-2 Model

$$
\begin{aligned}
& \pi_{0 j k}=\beta_{00 k}+r_{0 j k} \\
& \pi_{1 j k}=\beta_{10 k} \\
& \pi_{2 j k}=\beta_{20 k}+r_{2 j k} \\
& \pi_{3 j k}=\beta_{30 k}+r_{3 j k}
\end{aligned}
$$

Level-3 Model 


$$
\begin{aligned}
& \beta_{00 k}=\gamma_{000}+u_{00 k} \\
& \beta_{10 k}=\gamma_{100} \\
& \beta_{20 k}=\gamma_{200} \\
& \beta_{30 k}=\gamma_{300}+u_{30 k}
\end{aligned}
$$

Table 16 shows the final estimation of the fixed effects as well as the final estimation of level-1, level-2, and level-3 variance components. The proportion of variance explained by the level-1 control variables within classes, between classes $\left(\frac{\tau_{\pi 00 B}-\tau_{\pi 00 F}}{\tau_{\pi 00 B}}\right)$ and between schools $\left(\frac{\tau_{\beta 00 B}-\tau_{\beta 00 F}}{\tau_{\beta 00 B}}\right)$ were calculated by comparing the variance in the level-1 model to the null model. Student control variables accounted for about $4 \%$ of the variance between students within classes, $40 \%$ of the variance between classes, and about $32 \%$ of the variance between schools in $4^{\text {th }}-8^{\text {th }}$ grade student

\begin{tabular}{|c|c|c|c|c|c|}
\hline \multirow{2}{*}{ Fixed Effect } & \multirow{2}{*}{ Coefficient } & \multirow{2}{*}{$\begin{array}{l}\text { Standard } \\
\text { error }\end{array}$} & \multirow{2}{*}{$p$-value } & \multicolumn{2}{|c|}{ Reliability } \\
\hline & & & & Level-1 & Level-2 \\
\hline For INTRCPT $1, \pi_{0}$ & & & & .554 & \\
\hline For INTRCPT $2, \beta_{00}$ & & & & & .648 \\
\hline INTRCPT3, $\gamma_{000}$ & 0.360 & 0.050 & $<.001$ & & \\
\hline \multicolumn{6}{|l|}{ For STGEN slope, $\pi_{1}$} \\
\hline \multicolumn{6}{|l|}{ For INTRCPT $2, \beta_{10}$} \\
\hline INTRCPT3, $\gamma_{100}$ & -0.061 & 0.015 & $<.001$ & & \\
\hline For FRL slope, $\pi_{2}$ & & & & .232 & \\
\hline For INTRCPT2, $\beta_{20}$ & -0.239 & 0.023 & $<.001$ & & \\
\hline
\end{tabular}
achievement scores for the BAM assessment.

Table 16

Final Estimation of the Fixed and Random Effects for the Final Level-1 Control Model for BAM 
INTRCPT3, $\gamma_{200}$

For UNDMIN slope, $\pi_{3}$

For INTRCPT2, $\beta_{30}$

INTRCPT3, $\gamma_{300}$

$-0.199 \quad 0.028<.001$

\begin{tabular}{lcccc}
\hline \multicolumn{1}{c}{ Random Effect } & $\begin{array}{c}\text { Variance } \\
\text { Component }\end{array}$ & d.f. & $\chi^{2}$ & $p$-value \\
\hline INTRCPT1, $r_{0}$ & 0.071 & 137 & 380.220 & $<.001$ \\
FRL slope, $r_{2}$ & 0.028 & 200 & 264.244 & .002 \\
UNDMIN slope, $r_{3}$ & 0.016 & 137 & 182.922 & .006 \\
$\quad$ level-1, $e$ & 0.570 & & & \\
INTRCPT1/INTRCPT2, $u_{00}$ & 0.114 & 63 & 220.866 & $<.001$ \\
UNDMIN/INTRCPT2, $u_{30}$ & 0.015 & 63 & 92.575 & .009 \\
\hline
\end{tabular}

Note. STGEN refers to student gender, FRL refers to the socioeconomic status of students noting whether students received a free or reduced lunch, and UNDMIN refers to the underrepresented minority status of the student.

This model shows that the expected z-score for a white or Asian, female student who is not on free or reduced lunch is $\gamma_{000}=0.360$. Each student control characteristic negatively relates to student achievement, controlling for the other variables in the model. That is, male students are expected to earn a z-score of 0.061 less than their female peers, $p<.001\left(\gamma_{100}\right)$. Students who receive free or reduced lunch are expected to earn a $\mathrm{z}$ score 0.239 less than their peers who do not receive free or reduced lunch, $p<.001$ $\left(\gamma_{200}\right)$. Students who identify as an underrepresented racial group are expected to earn a Z-score of 0.199 points less than their peers who identify as white or Asian, $p<.001$ $\left(\gamma_{300}\right)$. 
Level-2 Control Model. Following the final level-1 control model, the level-2 (teacher-level) control model was built by adding teacher-level control variables as predictors of the intercept. The reader will recall the teacher control variables were: teacher gender (T_GEND), teacher minority status (T_MINST), and years of experience (T_EXPER). First, the slopes for these variables were allowed to vary across schools. Relationships between student achievement and teacher minority status $\left(u_{02}=0.029, p=\right.$ $.237)$, teacher gender $\left(u_{01}=0.014, p>.500\right)$, and years of experience $\left(u_{03}=0.00004, p=\right.$ .096) did not vary across schools and were fixed, respectively, one by one. Because multiple iterations of models were generated when fixing slopes one at a time, the $p$ values noted are from the most current model iteration. Next, the estimation of fixed effects were analyzed for teacher gender, minority status, and experience. As shown in Table 17, Teacher minority status was the only teacher control variable that was statistically significantly related to student achievement on the BAM assessment $\left(\beta_{01}=-\right.$ $0.199, p<.001)$. Teacher gender and years of experience were not related to student achievement, controlling for other variables in the model $\left(\beta_{01}=-0.022, p=.679\right.$; and $\beta_{03}$ $=0.005, p=.125$, respectively). Therefore, I removed those control variables from the model for a more parsimonious control model. The final level-2 control model for the BAM assessment, where $B A M \_Z \_4-8_{i j k}$ was the BAM assessment $\mathrm{z}$-score for student $i$ in classroom $j$ in school $k$, was as follows:

Level-1 Model

$B A M_{\_} Z_{-} 4-8_{i j k}=\pi_{0 j k}+\pi_{1 j k} *\left(S T G E N_{i j k}\right)+\pi_{2 j k} *\left(F R L_{i j k}\right)+\pi_{3 j k} *$ $\left(U N D M I N_{i j k}\right)+e_{i j k}$

Level-2 Model 


$$
\begin{aligned}
& \pi_{0 j k}=\beta_{00 k}+\beta_{01 k} *\left(T_{-} M_{I N S T} T_{j k}\right)+r_{0 j k} \\
& \pi_{1 j k}=\beta_{10 k} \\
& \pi_{2 j k}=\beta_{20 k}+r_{2 j k} \\
& \pi_{3 j k}=\beta_{30 k}+r_{3 j k}
\end{aligned}
$$

Level-3 Model

$$
\beta_{00 k}=\gamma_{000}+u_{00 k}
$$$$
\beta_{01 k}=\gamma_{010}
$$$$
\beta_{10 k}=\gamma_{100}
$$$$
\beta_{20 k}=\gamma_{200}
$$$$
\beta_{30 k}=\gamma_{300}+u_{30 k}
$$

Table 17 shows the final estimation of the fixed effects as well as the final estimation of level-1, level-2, and level-3 variance components. The proportion of variance between classes $\left(\frac{\tau_{\pi 00 B}-\tau_{\pi 00 F}}{\tau_{\pi 00 B}}\right)$ and between schools $\left(\frac{\tau_{\beta 00 B}-\tau_{\beta 00 F}}{\tau_{\beta 00 B}}\right)$ explained by the teacher control variables, above and beyond the student control variables, were calculated by comparing the variance in the level- 2 control model to the level- 1 control model. Teacher control variables accounted for essentially $0 \%$ of the variance between classes and about $19 \%$ of the variance between schools in student achievement scores for the BAM assessment. 
Table 17

Final Estimation of the Fixed and Random Effects for the Final Level-2 Control Model for BAM

\begin{tabular}{|c|c|c|}
\hline Fixed Effect & Coefficient & $\begin{array}{l}\text { Standard } \\
\text { error }\end{array}$ \\
\hline
\end{tabular}

Reliability

Level-1 Level-2

For INTRCPT1, $\pi_{0}$ .554

For INTRCPT2, $\beta_{00}$ .610

INTRCPT3, $\gamma_{000}$

$0.421 \quad 0.050<.001$

For T_MINST, $\beta_{01}$
INTRCPT3, $\gamma_{010}$
$-0.199$
$0.055<.001$

For STGEN slope, $\pi_{1}$

For INTRCPT2, $\beta_{10}$

INTRCPT3, $\gamma_{100} \quad-0.061 \quad 0.015<.001$

For FRL slope, $\pi_{2}$

For INTRCPT2, $\beta_{20}$

INTRCPT3, $\gamma_{200} \quad-0.240 \quad 0.023<.001$

For UNDMIN slope, $\pi_{3}$

.161

For INTRCPT2, $\beta_{30}$

.295

INTRCPT3, $\gamma_{300}$

$-0.200 \quad 0.028 \quad<.001$

\begin{tabular}{lcccc}
\hline \multicolumn{1}{c}{ Random Effect } & $\begin{array}{c}\text { Variance } \\
\text { Component }\end{array}$ & d.f. & $\chi^{2}$ & $p$-value \\
\hline INTRCPT1, $r_{0}$ & 0.070 & 136 & 382.524 & $<.001$ \\
FRL slope, $r_{2}$ & 0.027 & 200 & 264.281 & .002 \\
UNDMIN slope, $r_{3}$ & 0.016 & 137 & 182.996 & .005 \\
$\quad$ level-1, $e$ & 0.570 & & & \\
INTRCPT1/INTRCPT2, $u_{00}$ & 0.093 & 63 & 193.791 & $<.001$ \\
UNDMIN/INTRCPT2, $u_{30}$ & 0.014 & 63 & 91.459 & .011 \\
\hline
\end{tabular}

Note. STGEN refers to student gender, FRL refers to the socioeconomic status of students noting whether students received a free or reduced lunch, and UNDMIN refers to the underrepresented minority status of the student. 
This model shows the relationship between teacher minority status and student achievement on the BAM test after controlling for student minority status, gender, and free/reduced lunch status. Controlling for student variables, the expected z-score for students who had white teachers is $\gamma_{000}=0.421$. Holding student characteristics constant, students in classes where the teacher identifies as an underrepresented minority, are expected to earn a z-score of 0.199 points lower than their peers with white teachers, $p<.001\left(\gamma_{010}\right)$

ITJR (Individual-Factor) Final Model. Finally, the relationship between the ITJR variables and student achievement could be examined while controlling for student and teacher characteristics by adding the teacher variables of interest for the individualfactor ITJR model (TIME, CURR, PD, AUTON) to the level-2 model as predictors of the intercept.

The slope of PD was the only ITJR slope that varied across schools. The relationships between student achievement and instructional autonomy $\left(u_{04}=0.024, p=\right.$ $.124)$, curriculum $\left(u_{02}=0.011, p>.500\right)$, and time to collaborate $\left(u_{05}=0.005, p=.314\right)$ did not vary across classes and were fixed, one by one, in the model. Because multiple iterations of models were generated when fixing slopes one at a time, the $p$-values noted are from the most current model iteration. The final individual-factor model, where $B A M$ $Z_{Z} 4-8_{i j k}$ was the BAM assessment $\mathrm{z}$-score for student $i$ in classroom $j$ in school $k$, was as follows :

Level-1 Model

$B A M \_Z \_4-8_{i j k}=\pi_{0 j k}+\pi_{1 j k} *\left(S T G E N_{i j k}\right)+\pi_{2 j k} *\left(F R L_{i j k}\right)+\pi_{3 j k} *$ $\left(U N D M I N_{i j k}\right)+e_{i j k}$ 
Level-2 Model

$$
\begin{aligned}
& \pi_{0 j k}=\beta_{00 k}+\beta_{01 k} *\left(T_{-} M I N S T_{j k}\right)+\beta_{02 k} *\left(C U R R_{j k}\right)+\beta_{03 k} *\left(P D_{j k}\right)+\beta_{04 k} \\
& *\left(\text { AUTON }_{j k}\right)+\beta_{05 k} *\left(T I M E_{j k}\right)+r_{0 j k} \\
& \pi_{1 j k}=\beta_{10 k} \\
& \pi_{2 j k}=\beta_{20 k}+r_{2 j k} \\
& \pi_{3 j k}=\beta_{30 k}+r_{3 j k}
\end{aligned}
$$

Level-3 Model

$\beta_{00 k}=\gamma_{000}+u_{00 k}$

$\beta_{01 k}=\gamma_{010}$

$\beta_{02 k}=\gamma_{020}$

$\beta_{03 k}=\gamma_{030}+u_{03 k}$

$\beta_{04 k}=\gamma_{040}$

$\beta_{05 k}=\gamma_{050}$

$\beta_{10 k}=\gamma_{100}$

$\beta_{20 k}=\gamma_{200}$

$\beta_{30 k}=\gamma_{300}+u_{30 k}$

Table 18 shows the final estimation of the fixed effects as well as the final estimation of level-1, level-2, and level-3 variance components. After controlling for student and teacher characteristics, teacher instructional Autonomy was the only ITJR that was statistically significantly related to student achievement, $p .024\left(\gamma_{040}=\right.$ $0.225, p=.024)$. For each unit increase in teacher autonomy, there was an expected increase in student achievement on the BAM assessment z-score by 0.225 points, $p<.05$ $\left(\gamma_{040}\right)$. The remaining ITJR variables were not statistically related to student 
achievement for grades 4-8: Curriculum $\left(\gamma_{020}=-0.102, p=.122\right), \operatorname{PD}\left(\gamma_{030}=\right.$ $-0.022, p=.806)$, and Time to Collaborate $\left(\gamma_{050}=-0.082, p=.217\right)$.

The proportion of variance between classes $\left(\frac{\tau_{\pi 00 B}-\tau_{\pi 00 F}}{\tau_{\pi 00 B}}\right)$ and between schools $\left(\frac{\tau_{\beta 00 B}-\tau_{\beta 00 F}}{\tau_{\beta 00 B}}\right)$ explained by the individual ITJR factors, above and beyond the student and control variables, was calculated by comparing the variances in this model to the level-2 control model. The ITJR factors (CURR, PD, TIME, and AUTON) accounted for about $20 \%$ of the variance between classes and almost $11 \%$ of the variance between schools in student achievement scores for the BAM assessment, above and beyond the control variables.

Table 18

Final Estimation of the Fixed Effects for the Final Individual-Factor, Level-2 Model for BAM

Fixed Effect Coefficient $\begin{gathered}\text { Standard } \\ \text { error }\end{gathered} p$-value Reliability Level-1 Level-2

For INTRCPT $1, \pi_{0}$ .510

For INTRCPT2, $\beta_{00}$

INTRCPT3, $\gamma_{000}$

$0.431 \quad 0.048<.001$

For T_MINST, $\beta_{01}$

INTRCPT3, $\gamma_{010}$

$\begin{array}{lll}-0.228 & 0.054<.001\end{array}$

For CURR, $\beta_{02}$

INTRCPT3, $\gamma_{020}$

$\begin{array}{lll}-0.102 & 0.064 & .122\end{array}$

For PD, $\beta_{03}$

INTRCPT3, $\gamma_{030}$

$\begin{array}{lll}-0.022 & 0.090 & .806\end{array}$

For AUTON, $\beta_{04}$ INTRCPT3, $\gamma_{040}$

$\begin{array}{lll}0.225 & 0.095 & .024\end{array}$

For TIME, $\beta_{05}$

$\begin{array}{lll}-0.082 & 0.065 & .217\end{array}$




\section{INTRCPT3, $\gamma_{050}$}

For STGEN slope, $\pi_{1}$

For INTRCPT2, $\beta_{10}$

$\begin{array}{llll}\text { INTRCPT3, } \gamma_{100} & -0.061 & 0.015<.001\end{array}$

For FRL slope, $\pi_{2}$

For INTRCPT2, $\beta_{20}$

INTRCPT3, $\gamma_{200}$

$-0.241 \quad 0.023<.001$

For UNDMIN slope, $\pi_{3}$

For INTRCPT2, $\beta_{30}$

INTRCPT3, $\gamma_{300}$

$-0.196$

$0.027<.001$

\begin{tabular}{lcccc}
\hline \multicolumn{1}{c}{ Random Effect } & $\begin{array}{c}\text { Variance } \\
\text { Component }\end{array}$ & $d_{\text {.f. }}$ & $\chi^{2}$ & $p$-value \\
\hline INTRCPT1, $r_{0}$ & 0.056 & 75 & 256.417 & $<.001$ \\
FRL slope, $r_{2}$ & 0.027 & 194 & 255.859 & .002 \\
UNDMIN slope, $r_{3}$ & 0.018 & 137 & 183.137 & .005 \\
$\quad$ level-1, $e$ & 0.570 & & & \\
INTRCPT1/INTRCPT2, $u_{00}$ & 0.082 & 57 & 145.054 & $<.001$ \\
INTRCPT1/PD, $u_{03}$ & 0.057 & 57 & 85.411 & .009 \\
UNDMIN/INTRCPT2, $u_{30}$ & 0.012 & 57 & 84.317 & .011 \\
\hline
\end{tabular}

Note. STGEN refers to student gender, FRL refers to the socioeconomic status of students noting whether students received a free or reduced lunch, and UNDMIN refers to the underrepresented minority status of the student.

To determine how much of the variance was explained by autonomy because it was the only statistically significant predictor of achievement, AUTON was removed from the full level-2 ITJR model, and variability between classes $\left(\frac{\tau_{\pi 00 B}-\tau_{\pi 00 F}}{\tau_{\pi 00 B}}\right)$ and between schools $\left(\frac{\tau_{\beta 00 B}-\tau_{\beta 00 F}}{\tau_{\beta 00 B}}\right)$ was compared in the models with and without AUTON. In 
these formulas, the full model refers to the level-2 model with all four ITJR variables and the baseline model refers to the level-2 model without instructional autonomy.. The proportion of variance between classes that teacher autonomy explains, above and beyond student and teacher control variables and other job resources is $0 \%$. The proportion of variance between schools that teacher autonomy explains for student achievement, above and beyond student and teacher control variables and other job resources, is $5 \%$.

ITJR (Higher Order) Final Model. To analyze the higher-order relationship of ITJR (Physical and Social) with student achievement while controlling for student and teacher contextual variables, the higher-order ITJR variables (PHY and SOC) were added to the model as predictors of the intercept in place of the individual-factor ITJR factors.

The relationship between student achievement and physical ITJR $\left(u_{02}=0.123, p\right.$ $>$.500) did not vary across classes and was fixed in the model. The relationship between student achievement and social ITJR $\left(u_{03}=0.147, p=.005\right)$ statistically varied across classes. Because multiple iterations of models were generated when fixing slopes one at a time, the $p$-values noted are from the most current model iteration. The final higherorder, level-2 model for the BAM assessment was as follows:

Level-1 Model

$B A M_{-} Z_{-} 4-8_{i j k}=\pi_{0 j k}+\pi_{1 j k} *\left(S T G E N_{i j k}\right)+\pi_{2 j k} *\left(S E S_{i j k}\right)+\pi_{3 j k} *$ $\left(U N D M I N_{i j k}\right)+e_{i j k}$

Level-2 Model

$$
\begin{aligned}
& \pi_{0 j k}=\beta_{00 k}+\beta_{01 k} *\left(T_{-} R A C E_{j k}\right)+\beta_{02 k} *\left(P H Y_{j k}\right)+\beta_{03 k} *\left(S O C_{j k}\right)+r_{0 j k} \\
& \pi_{1 j k}=\beta_{10 k} \\
& \pi_{2 j k}=\beta_{20 k}+r_{2 j k}
\end{aligned}
$$




$$
\begin{aligned}
& \pi_{3 j k}=\beta_{30 k}+r_{3 j k} \\
& \quad \text { Level-3 Model } \\
& \beta_{00 k}=\gamma_{000}+u_{00 k} \\
& \beta_{01 k}=\gamma_{010} \\
& \beta_{02 k}=\gamma_{020} \\
& \beta_{03 k}=\gamma_{030}+u_{03 k} \\
& \beta_{10 k}=\gamma_{100} \\
& \beta_{20 k}=\gamma_{200} \\
& \beta_{30 k}=\gamma_{300}+u_{30 k}
\end{aligned}
$$

Table 19 shows the final estimation of the fixed effects as well as the final estimation of level-1, level-2, and level-3 variance components.

The proportion of variance explained by the higher-order level-2 ITJR variables, above and beyond the student and teacher control variables, between classes and between schools were calculated by comparing the variance in the higher-order level-2

model to the level-2 control model respectively, $\frac{\tau_{\pi 00 B}-\tau_{\pi 00 F}}{\tau_{\pi 00 B}}=0.222$ and $\frac{\tau_{\beta 00 B}-\tau_{\beta 00 F}}{\tau_{\beta 00 B}}=$ -0.004. Teacher job resources (PHY and SOC) accounted for about $22 \%$ of the variance between classes and $0 \%$ of the variance between schools in student achievement scores for grades 4-8, above and beyond the control variables. 
Table 19

Final Estimation of the Fixed Effects for the Final Higher-Order Level-2 Model for BAM

\begin{tabular}{|c|c|c|c|c|c|}
\hline \multirow{2}{*}{ Fixed Effect } & \multirow{2}{*}{ Coefficient } & \multirow{2}{*}{$\begin{array}{l}\text { Standard } \\
\text { error }\end{array}$} & \multirow{2}{*}{$p$-value } & \multicolumn{2}{|c|}{ Reliability } \\
\hline & & & & Level-1 & Level-2 \\
\hline For INTRCPT $1, \pi_{0}$ & & & & .505 & \\
\hline For INTRCPT $2, \beta_{00}$ & & & & & .583 \\
\hline INTRCPT3, $\gamma_{000}$ & 0.432 & 0.049 & $<.001$ & & \\
\hline \multicolumn{6}{|l|}{ For T_MINST, $\beta_{01}$} \\
\hline INTRCPT3, $\gamma_{010}$ & -0.220 & 0.054 & $<.001$ & & \\
\hline \multicolumn{6}{|l|}{ For PHY, $\beta_{02}$} \\
\hline INTRCPT3, $\gamma_{020}$ & 0.386 & 0.266 & .156 & & \\
\hline For SOC, $\beta_{03}$ & & & & & .250 \\
\hline INTRCPT3, $\gamma_{030}$ & -0.375 & 0.324 & .251 & & \\
\hline \multicolumn{6}{|l|}{ For STGEN slope, $\pi_{1}$} \\
\hline \multicolumn{6}{|l|}{ For INTRCPT2, $\beta_{10}$} \\
\hline INTRCPT3, $\gamma_{100}$ & -0.061 & 0.015 & $<.001$ & & \\
\hline For FRL slope, $\pi_{2}$ & & & & .230 & \\
\hline \multicolumn{6}{|l|}{ For INTRCPT2, $\beta_{20}$} \\
\hline INTRCPT3, $\gamma_{200}$ & -0.240 & 0.023 & $<.001$ & & \\
\hline For UNDMIN slope, $\pi_{3}$ & & & & .167 & \\
\hline For INTRCPT2, $\beta_{30}$ & & & & & .296 \\
\hline INTRCPT3, $\gamma_{300}$ & -0.200 & 0.027 & $<.001$ & & \\
\hline Random Effect & $\begin{array}{c}\text { Variance } \\
\text { Component }\end{array}$ & d.f. & $\chi^{2}$ & \multicolumn{2}{|c|}{$p$-value } \\
\hline INTRCPT1, $r_{0}$ & 0.055 & 77 & 242.789 & \multicolumn{2}{|c|}{$<.001$} \\
\hline FRL slope, $r_{2}$ & 0.027 & 194 & 255.784 & \multicolumn{2}{|c|}{.002} \\
\hline UNDMIN slope, $r_{3}$ & 0.017 & 137 & 183.017 & \multicolumn{2}{|c|}{.005} \\
\hline level-1, $e$ & 0.570 & & & & \\
\hline
\end{tabular}




$\begin{array}{lcccc}\text { INTRCPT1/INTRCPT2, } u_{00} & 0.093 & 57 & 165.945 & <.001 \\ \text { INTRCPT1/SOC, } u_{03} & 0.147 & 57 & 88.174 & .005 \\ \text { UNDMIN/INTRCPT2, } u_{30} & 0.013 & 57 & 86.846 & .007\end{array}$

Note. STGEN refers to student gender, FRL refers to the socioeconomic status of students noting whether students received a free or reduced lunch, and UNDMIN refers to the underrepresented minority status of the student. SOC refers to the Social job resources comprised of Time to Collaborate and Instructional Autonomy. PHY refers to the Physical job resources comprised of Curriculum and Professional Development.

Neither physical $\left(\gamma_{020}=0.386, p=.156\right)$ or social $\left(\gamma_{030}=-0.375, p=.251\right)$ ITJR were found to have a statistically significant relationship with student achievement for grades $4-8$.

\section{Results for student achievement on ACT, grade 9.}

Null Model. Achievement in mathematics on the ACT QualityCore ${ }^{\circledR}$ was the outcome variable. The null model included only the students' assessment score for achievement in mathematics, given by:

$$
A C T_{-} Z_{-} 9_{i j k}=\gamma_{000}+r_{0 j k}+u_{00 k}+e_{i j k}
$$

For this model, $A C T \_Z_{-} 9_{i j k}$ was the value of each student's mathematical achievement score, with student $i$ being in classroom $j$ and in school $k$. The parameter $\gamma_{000}$ represents the grand mean of students' mathematics achievement scores. The parameter $r_{o j k}$ represents the random classroom effect, or the deviation of classroom $j k^{6} \mathrm{~s}$ mean from the school mean. The parameter $u_{00 k}$ represents the random school effect, or the deviation of school $k^{6}$ s mean from the grand mean. The parameter $e_{i j k}$ indicated the random student effect, or the deviation of each student's assessment score from the classroom 
mean, which was assumed to be normally distributed with a mean of zero and variance of $\sigma^{2}$

The variance in achievement scores between students within teachers and schools for $9^{\text {th }}$ grade students was $\sigma^{2}=0.665$. The variance in achievement scores between classes within schools was $\tau_{\pi 00}=0.076$ for $9^{\text {th }}$ grade. The variance in achievement scores between schools was $\tau_{\beta 00}=0.019$ for $9^{\text {th }}$ grade.

The ratio of between group variance among students within classes to the total variance, or the intra-class correlation (ICC), was $I C C_{A C T}=\frac{\sigma^{2}}{\sigma^{2}+\tau_{\pi}+\tau_{\beta}}=.875$. The ICC for the ratio of between group variance among classes within schools to the total variance was $I C C_{A C T}=\frac{\tau_{\pi}}{\sigma^{2}+\tau_{\pi}+\tau_{\beta}}=.100$. The ICC for the ratio of between group variance among schools to the total variance was $I C C_{A C T}=\frac{\tau_{\pi}}{\sigma^{2}+\tau_{\pi}+\tau_{\beta}}=.025$.

According to the ICC calculations, approximately $87.5 \%$ of the variance in student achievement scores on the ACT QualityCore test was attributable to students within classes. Approximately $10 \%$ of the variability in ACT QualityCore assessment scores was between classes within schools. Variance in assessment scores between schools was found to be approximately $2.5 \%$ for $9^{\text {th }}$ graders who took the ACT QualityCore test. The small variation between schools for ACT test scores $\left(\tau_{\beta}=\right.$ $0.019, p=.077$ ) indicated a two-level model may be justified for the $9^{\text {th }}$ grade model. For uniformity and because of the $2.5 \%$ of variability at the school level (Roberts, 2007), the analysis proceeded using a three-level model for $9^{\text {th }}$ grade ACT QualityCore ${ }^{\circledR}$ scores, consistent with the models for the $4^{\text {th }}-8^{\text {th }}$ grade BAM scores. 
Level-1 Control Model. All student (level-1) control variables were added to the model. The reader will recall the student control variables were student gender (STGEN), whether a student receives free or reduced lunch (FRL), and student minority status (UNDMIN). The slopes for these variables were allowed to vary randomly at both the class and school levels. Multiple iterations of models were generated for the purpose of fixing slopes one at a time, whenever significance is noted, the $p$-values are from the most current model iteration. First, I examined the random effects across classes. The relationship between student underrepresented minority status and student achievement statistically varied across classes $\left(r_{3}=0.033, p=.025\right)$. The relationships between student achievement and student free or reduced lunch status $\left(r_{2}=0.011, p>.500\right)$ and student gender $\left(r_{1}=0.002, p>.500\right)$ did not vary across classes and were fixed one at a time. Next, random effects for the slopes of student control variables were analyzed across schools. The relationships between student achievement and student free or reduced lunch status $\left(u_{20}=0.001, p>.500\right)$, student gender $\left(u_{10}=0.003, p>.500\right)$, and student underrepresented minority status $\left(u_{30}=0.015, p=.349\right)$ did not vary across schools and were fixed, respectively, one at a time. The final level-1 control model for the ACT assessment, where $A C T \_Z_{-} 9_{i j k}$ the ACT assessment $\mathrm{z}$-score for student $i$ in classroom $j$ in school $k$, was as follows:

Level-1 Model

$A C T_{-} Z_{-} 9_{i j k}=\pi_{0 j k}+\pi_{1 j k} *\left(S T G E N_{i j k}\right)+\pi_{2 j k} *\left(F R L_{i j k}\right)+\pi_{3 j k} *\left(U N D M I N_{i j k}\right)+$ $e_{i j k}$

Level-2 Model

$\pi_{0 j k}=\beta_{00 k}+r_{0 j k}$ 


$$
\begin{aligned}
& \pi_{1 j k}=\beta_{10 k} \\
& \pi_{2 j k}=\beta_{20 k} \\
& \pi_{3 j k}=\beta_{30 k}+r_{3 j k}
\end{aligned}
$$

Level-3 Model

$\beta_{00 k}=\gamma_{000}+u_{00 k}$

$\beta_{10 k}=\gamma_{100}$

$\beta_{20 k}=\gamma_{200}$

$\beta_{30 k}=\gamma_{300}$

Table 20 shows the final estimation of the fixed effects and the level-1, level-2, and level-3 variance components. The proportion of variance explained by the level-1 control variables within classes, between classes $\left(\frac{\tau_{\pi 00 B}-\tau_{\pi 00 F}}{\tau_{\pi 00 B}}\right)$ and between schools $\left(\frac{\tau_{\beta 00 B}-\tau_{\beta 00 F}}{\tau_{\beta 00 B}}\right)$ was calculated by comparing the variance in the level-1 model to the null model. Student control variables accounted for about $2 \%$ of the variance between students within classes, $0 \%$ of the variance between classes, and about $16 \%$ of the variance between schools in $9^{\text {th }}$ grade student achievement scores.

Table 20

Final Estimation of the Fixed and Random Effects for the Final Level-1 Control Model for ACT

Fixed Effect Coefficient Standard Reliability Level-1 Level-2

For INTRCPT1, $\pi_{0}$ .583

For INTRCPT2, $\beta_{00}$ INTRCPT3, $\gamma_{000}$

0.142

0.071 .058

For STGEN slope, $\pi_{1}$ $-.114$ 0.035 .001 
For INTRCPT2, $\beta_{10}$

INTRCPT3, $\gamma_{100}$

For FRL slope, $\pi_{2}$

For INTRCPT2, $\beta_{20}$

$\begin{array}{llll}\text { INTRCPT3, } \gamma_{200} & -.101 & 0.043 & .020\end{array}$

For UNDMIN slope, $\pi_{3}$

.282

For INTRCPT2, $\beta_{30}$

INTRCPT3, $\gamma_{300}$

$\begin{array}{lll}-0.076 & 0.054 \quad .173\end{array}$

\begin{tabular}{lcccc}
\hline \multicolumn{1}{c}{ Random Effect } & $\begin{array}{c}\text { Variance } \\
\text { Component }\end{array}$ & d.f. & $\chi^{2}$ & $p$-value \\
\hline INTRCPT1, $r_{0}$ & 0.089 & 20 & 122.545 & $<.001$ \\
UNDMIN slope, $r_{3}$ & 0.033 & 41 & 60.455 & .025 \\
level-1, $e$ & 0.653 & & & .090 \\
INTRCPT1/INTRCPT2, $u_{00}$ & 0.016 & 21 & 30.073 & .090 \\
\hline
\end{tabular}

Note. STGEN refers to student gender, FRL refers to the socioeconomic status of students noting whether students received a free or reduced lunch, and UNDMIN refers to the underrepresented minority status of the student.

Although not significant, this model shows that the expected z-score for a white or Asian female student who is not on free or reduced lunch is $\gamma_{000}=0.142, p=.058$. Each student control characteristic negatively relates to student achievement, controlling for the other variables in the model. That is, male students are expected to earn a z-score of 0.114 less than their female peers, $p=.001\left(\gamma_{100}\right)$. Students who receive free or reduced lunch are expected to earn a z-score 0.101 less than their peers who are not receiving free or reduced lunch, $p=.020\left(\gamma_{200}\right)$. Students who identify as an underrepresented racial group are expected to earn a z-score of 0.076 points less than their peers who identify as white or Asian, $p<.173\left(\gamma_{300}\right)$. 
Level-2 Control Model. Following the final level-1 control model, the level-2 (teacher-level) control model was built by adding teacher-level control variables as predictors of the intercept. The reader will recall the teacher control variables were: teacher gender (T_GEND), teacher minority status (T_MINST), and years of experience (T_EXPER). First, the slopes for these variables were allowed to vary across schools. Because multiple iterations of models were generated when fixing slopes one at a time, the $p$-values noted are from the most current model iteration. When all teacher control variables were allowed to vary, there were too few degrees of freedom to compute their significance. The relationship between the ITJR variable and student achievement with the largest $p$-value, teacher minority status $\left(\beta_{02}=0.060, p=.574\right)$ was fixed first, after which the other $p$-values could be calculated. After fixing the slope of teacher minority status, the relationships between student achievement and the slopes of gender $\left(u_{01}=\right.$ $0.052, p>.500)$ and years of experience $\left(u_{03}=0.0003, p=.051\right)$ did not vary across schools and were fixed, respectively, one by one. Next, the estimation of fixed effects were analyzed for teacher gender, minority status, and experience. Teacher gender, minority status, and years of experience were not related to student achievement, controlling for other variables in the model $\left(\beta_{01}=0.072, p=.461 ; \beta_{02}=0.027, p=.792\right.$; and $\beta_{03}=0.004, p=.642$, respectively). Therefore, I removed all teacher-level control variables from the model for a more parsimonious control model. Consequently, the final level-2 control model for the ACT assessment, where $A C T_{-} Z_{-} 9_{i j k}$ was the ACT assessment z-score for student $i$ in classroom $j$ in school $k$, was identical to the final level1 control model. 
ITJR (Individual-Factor) Final Model. Finally, the relationship between the ITJR variables and student achievement could be examined while controlling for student (and teacher) characteristics by adding the teacher variables of interest for the individualfactor ITJR model (TIME, CURR, PD, AUTON) to the level-2 model as predictors of the intercept.

When all of the individual-factor ITJR variables were allowed to vary, there were too few degrees of freedom to compute their significance. Because multiple iterations of models were generated when fixing slopes one at a time, the $p$-values noted are from the most current model iteration. The relationship between the ITJR variable and student achievement with the largest $p$-value, $\mathrm{PD}\left(\beta_{02}=0.005, p=.971\right)$ was fixed first, after which the other $p$-values could be calculated. After fixing the slope of professional development, the relationships between student achievement and the slopes of instructional autonomy $\left(u_{03}=0.093, p>.500\right)$, curriculum $\left(u_{01}=0.002, p>.500\right)$, and time to collaborate $\left(u_{04}=0.018, p=.076\right)$ did not vary across schools and were fixed respectively, one by one, in the model. The final individual-factor model, where ACT$Z_{-}{ }_{i j k}$ was the ACT assessment $z$-score for student $i$ in classroom $j$ in school $k$, was as follows :

Level-1 Model

$A C T_{-} Z_{-} 9_{i j k}=\pi_{0 j k}+\pi_{1 j k} *\left(S T G E N_{i j k}\right)+\pi_{2 j k} *\left(F R L_{i j k}\right)+\pi_{3 j k} *\left(U N D M I N_{i j k}\right)+$
$e_{i j k}$

Level-2 Model

$$
\begin{aligned}
& \begin{array}{l}
\pi_{0 j k}=\beta_{00 k}+ \\
\quad \beta_{01 k} *\left(C U R R_{j k}\right)+\beta_{02 k} *\left(P D_{j k}\right)+\beta_{03 k} *\left(A U T O N_{j k}\right)+\beta_{04 k} \\
\\
\quad *\left(T I M E_{j k}\right)+r_{0 j k}
\end{array} \\
& \pi_{1 j k}=\beta_{10 k}
\end{aligned}
$$




$$
\begin{aligned}
& \pi_{2 j k}=\beta_{20 k} \\
& \pi_{3 j k}=\beta_{30 k}+r_{3 j k} \\
& \quad \text { Level-3 Model } \\
& \beta_{00 k}=\gamma_{000}+u_{00 k} \\
& \beta_{01 k}=\gamma_{010} \\
& \beta_{02 k}=\gamma_{020} \\
& \beta_{03 k}=\gamma_{030} \\
& \beta_{04 k}=\gamma_{040} \\
& \beta_{10 k}=\gamma_{100} \\
& \beta_{20 k}=\gamma_{200} \\
& \beta_{30 k}=\gamma_{300}
\end{aligned}
$$

Table 21 shows the final estimation of the fixed effects as well as the final estimation of level-1, level-2, and level-3 variance components. None of the individualfactor ITJR were found to have a statistically significant relationship with student achievement: curriculum $\left(\gamma_{020}=0.225, p=.068\right)$, professional development $\left(\gamma_{030}=\right.$ 0.017, $p=.905)$, instructional autonomy $\left(\gamma_{040}=-0.079, p=.670\right)$, or time to collaborate $\left(\gamma_{050}=-0.039, p=.747\right)$.

The proportion of variance between classes $\left(\frac{\tau_{\pi 00 B}-\tau_{\pi 00 F}}{\tau_{\pi 00 B}}\right)$ and between schools $\left(\frac{\tau_{\beta 00 B}-\tau_{\beta 00 F}}{\tau_{\beta 00 B}}\right)$ explained by the individual-factor ITJR variables, above and beyond the control variables, was calculated by comparing the variances in this model to the level-2 control model. The ITJR (CURR, PD, TIME, and AUTON) accounted for about $11 \%$ of 
the variance between classes and about $24 \%$ of the variance between schools in student achievement scores for the ACT assessment, above and beyond the control variables.

Table 21

Final Estimation of the Fixed Effects for the Final Individual-Factor, Level-2 Model for ACT

Fixed Effect Coefficient $\begin{gathered}\text { Standard } \\ \text { error }\end{gathered} p$-value

Reliability Level-1 Level-2

For INTRCPT1, $\pi_{0}$ .561

For INTRCPT2, $\beta_{00}$

INTRCPT3, $\gamma_{000}$

$0.139 \quad 0.069 \quad .054$

For CURR, $\beta_{02}$

INTRCPT3, $\gamma_{020}$

0.225

$0.117 \quad .068$

For PD, $\beta_{03}$

INTRCPT3, $\gamma_{030}$

$\begin{array}{lll}0.017 & 0.139 & .905\end{array}$

For AUTON, $\beta_{04}$

INTRCPT3, $\gamma_{040}$

$\begin{array}{lll}-0.079 & 0.181 \quad .670\end{array}$

For TIME, $\beta_{05}$
INTRCPT3, $\gamma_{050}$
$-0.039$
0.119
.747

For STGEN slope, $\pi_{1}$

For INTRCPT2, $\beta_{10}$

INTRCPT3, $\gamma_{100}$

$\begin{array}{lll}-0.115 & 0.035 & .001\end{array}$

For FRL slope, $\pi_{2}$

For INTRCPT2, $\beta_{20}$

$\begin{array}{llll}\text { INTRCPT3, } \gamma_{200} & -0.100 & 0.043 & .020\end{array}$

For UNDMIN slope, $\pi_{3}$

For INTRCPT2, $\beta_{30}$

INTRCPT3, $\gamma_{300}$

$\begin{array}{lll}-0.072 & 0.054 \quad .198\end{array}$

Random Effect

Variance
Component

d.f.

$\chi^{2}$

$p$-value 


\begin{tabular}{|c|c|c|c|c|}
\hline INTRCPT1, $r_{0}$ & 0.079 & 16 & 109.740 & $<.001$ \\
\hline UNDMIN slope, $r_{3}$ & 0.033 & 41 & 60.370 & .026 \\
\hline level-1, $e$ & 0.653 & & & \\
\hline INTRCPT1/INTRCPT2, $u_{00}$ & 0.012 & 21 & 28.598 & .124 \\
\hline
\end{tabular}

ITJR (Higher Order) Final Model. To analyze the higher-order relationship of ITJR (Physical and Social) with student achievement while controlling for student and teacher contextual variables, the higher-order ITJR variables (PHY and SOC) were added to the model, as predictors of the intercept, in place of the individual-factor ITJR variables.

The relationships between student achievement and both physical ITJR $\left(\mathrm{u}_{02}=\right.$ $0.147, p>.500)$ and social ITJR $\left(\mathrm{u}_{01}=0.007, p=.149\right)$ did not vary across schools and were fixed, one by one, in the model. Because multiple iterations of models were generated when fixing slopes one at a time, the $p$-values noted are from the most current model iteration. The final higher-order, level-2 model for the ACT assessment was as follows:

Level-1 Model $A C T_{-} Z_{-} 9_{i j k}=\pi_{0 j k}+\pi_{1 j k} *\left(S T G E N_{i j k}\right)+\pi_{2 j k} *\left(S E S_{i j k}\right)+\pi_{3 j k} *\left(U N D M I N_{i j k}\right)+$ $e_{i j k}$

Level-2 Model

$$
\begin{aligned}
& \pi_{0 j k}=\beta_{00 k}+\beta_{01 k} *\left(P H Y_{j k}\right)+\beta_{02 k} *\left(S O C_{j k}\right)+r_{0 j k} \\
& \pi_{1 j k}=\beta_{10 k}
\end{aligned}
$$




$$
\begin{aligned}
& \pi_{2 j k}=\beta_{20 k} \\
& \pi_{3 j k}=\beta_{30 k}+r_{3 j k} \\
& \quad \text { Level-3 Model } \\
& \beta_{00 k}=\gamma_{000}+u_{00 k} \\
& \beta_{01 k}=\gamma_{010} \\
& \beta_{02 k}=\gamma_{020} \\
& \beta_{10 k}=\gamma_{100} \\
& \beta_{20 k}=\gamma_{200} \\
& \beta_{30 k}=\gamma_{300}
\end{aligned}
$$

Table 22 shows the final estimation of the fixed effects and the level-1, level-2, and level-3 variance components. Neither physical $\left(\gamma_{020}=-0.479, p=.336\right)$ nor social $\left(\gamma_{030}=0.665, p=.252\right)$ ITJR were found to have a statistically significant relationship with student achievement for grade 9.

The proportion of variance between classes $\left(\frac{\tau_{\pi 00 B}-\tau_{\pi 00 F}}{\tau_{\pi 00 B}}\right)$ and between schools $\left(\frac{\tau_{\beta 00 B}-\tau_{\beta 00 F}}{\tau_{\beta 00 B}}\right)$ explained by the higher-factor ITJR variables was calculated by comparing the variances in this model to the level-2 control model. The higher-order ITJR (PHY and SOC) accounted for about $2 \%$ of the variance between classes and $0 \%$ of the variance between schools in student achievement scores for the ACT assessment.

Table 22

Final Estimation of the Fixed Effects for the Final Higher-Order Level-2 Model for ACT

\begin{tabular}{lccccc} 
Fixed Effect & Coefficient & $\begin{array}{c}\text { Standard } \\
\text { error }\end{array}$ & $p$-value & \multicolumn{2}{c}{ Reliability } \\
Level-1 & Level-2 \\
\hline For INTRCPT1, $\pi_{0}$ & 0.134 & 0.074 & .083 & .580
\end{tabular}


For INTRCPT $2, \beta_{00}$

INTRCPT3, $\gamma_{000}$

For PHY, $\beta_{02}$

INTRCPT3, $\gamma_{020}$

$-0.479$

0.487

.336

For SOC, $\beta_{03}$

INTRCPT3, $\gamma_{030}$

0.665

0.565

.252

For STGEN slope, $\pi_{1}$

For INTRCPT2, $\beta_{10}$

INTRCPT3, $\gamma_{100}$

$\begin{array}{lll}-0.113 & 0.035 & .001\end{array}$

For FRL slope, $\pi_{2}$

For INTRCPT2, $\beta_{20}$

INTRCPT3, $\gamma_{200}$

$-0.101$

0.043

.020

For UNDMIN slope, $\pi_{3}$

For INTRCPT $2, \beta_{30}$

INTRCPT3, $\gamma_{300}$

$-0.071$

0.054

.199

\begin{tabular}{lcccc}
\hline \multicolumn{1}{r}{ Random Effect } & $\begin{array}{c}\text { Variance } \\
\text { Component }\end{array}$ & $d . f$. & $\chi^{2}$ & $p$-value \\
\hline INTRCPT1, $r_{0}$ & 0.087 & 18 & 122.793 & $<.001$ \\
UNDMIN slope, $r_{3}$ & 0.032 & 41 & 60.342 & .026 \\
$\quad 0.653$ & & & \\
$\quad$ level-1, $e$ & 0.024 & 21 & 35.864 & .022 \\
INTRCPT1/INTRCPT2, $u_{00}$ & &
\end{tabular}

Note. STGEN refers to student gender, FRL refers to the socioeconomic status of students noting whether students received a free or reduced lunch, and UNDMIN refers to the underrepresented minority status of the student. SOC refers to the Social job resources comprised of Time to Collaborate and Instructional Autonomy. PHY refers to the Physical job resources comprised of Curriculum and Professional Development.

\section{Summary}

With the survey questions that were available in the dataset, the factors for mathematics Instructional Teacher Job Resources (ITJR) that were identified were (a) 
quality curriculum, (b) quality professional development, (c) instructional autonomy, and (d) time to collaborate with colleagues. The EFA and CFA provided validity evidence for a four-factor model that fit the data well (RMSEA (.084), AIC (590.216), CFI (.921), and $\left.\chi^{2} 500.22(59), p<.001\right)$. The main difference between the hypothesized five-factor model that included (a) quality curriculum, (b) quality professional development, (c) instructional autonomy, (d) collaborating with colleagues, and (e) planning time and the confirmed four-factor model was that variables for Time to Plan and Collaborating with Colleagues were merged to become Time to Collaborate.

Accounting for the cluster effect of students nested in classrooms nested in schools using an HLM model, I found a statistically significant positive relationship between teacher instructional autonomy and student achievement for grades 4-8 after controlling for student and teacher characteristics, $\gamma_{040}=0.225, p=.024$. For each unit increase in teacher autonomy, there was an expected increase in student achievement on the BAM assessment $\mathrm{z}$-score by 0.22 points for grades $4-8, p<.05$. The relationship between teacher instructional autonomy and student achievement in mathematics for grades 4-8 was statistically significant, but not for grade 9. Relationships between student achievement and the other ITJR for all grades were not statistically significant. The proportion of variance that teacher instructional autonomy explains, above and beyond student and teacher control variables and other job resources is $0 \%$ between classes and 5\% between schools. Significance was not found for any other relationships between student achievement and the other ITJR for all other grades using this data set. Aside from Instructional Autonomy, a fair amount of variance was collectively explained even though the relationships between student achievement and each of the ITJR were 
not significant. Table 23 summarized the variance in student achievement, explained by the IJTR.

Table 23

Summary of Explained Variance from the Final Individual-Factor, Level-2 Models for BAM and ACT

Grades 4-8 Grade 9

\begin{tabular}{lcccc} 
ITJR (Individual-Factor) Model & $\begin{array}{c}\text { between } \\
\text { classes }\end{array}$ & $\begin{array}{c}\text { between } \\
\text { schools }\end{array}$ & $\begin{array}{c}\text { between } \\
\text { classes }\end{array}$ & $\begin{array}{c}\text { between } \\
\text { schools }\end{array}$ \\
\hline CURR, PD, TIME, \& AUTON & $20 \%$ & $11 \%$ & $11 \%$ & $24 \%$ \\
AUTON alone & $0 \%$ & $5 \%$ & - & -
\end{tabular}

Note. ITJR refers to Instructional Teacher Job Resources. CURR refers to Curriculum, PD refers to Professional Development, TIME refers to Time to Collaborate, and AUTON refers to Instructional Autonomy. 


\section{CHAPTER 5 \\ DISCUSSION}

\section{Introduction}

This chapter contains five sections. The first contains a summary of the study including an overview of the problem, purpose statement and research question, review of methodology, and major findings. The second addresses how the major findings relate to the literature presented in Chapter 2. The third section discusses surprising or unexpected findings from the study. The fourth section discloses limitations of the study. Finally, the fifth section summarizes the findings, noting implications for action and finishing with concluding remarks.

\section{Summary of the Study}

Overview of the problem. Job demands for teachers are high (Hakanen et al., 2006) and yet teachers, especially teachers of mathematics (Gewertz, 2014), do not have the job resources needed to meet their students' needs (e.g., Bidwell, 2013; Layton, 2015; Rentner \& Kober, 2014a). Without this needed job support, teachers may become less engaged with their work (Klusmann et al., 2008), which may reduce their effectiveness as educators (Bakker \& Bal, 2010; Kahn, 1990). Research on teacher job resources is especially important for mathematics teachers who are burnt-out and leaving the field of education (Sutcher, Darling-Hammond, \& Carver-Thomas, 2016).

Purpose statement and research question. Teachers know these job resources matter and want support for instructional demands of the job (MET, 2010). For example, 
on the Measures of Effective Teaching (MET) survey, teachers were asked what was most important to their students' learning, and their most frequent reply (32\% of teachers) was Instructional Practice and Support. MET (2010) outlined the following as examples of Instructional Practice and Support: providing instructional coaching, working in professional learning communities to develop and align instructional practices, feeling encouraged to try new things to improve instruction, and having autonomy to make decisions about instructional delivery (e.g. pacing, materials and pedagogy). Job resources for teachers have been identified as five broad categories: job control, supervisory support, access to information, social climate, and innovativeness (Hakanen et al., 2006). However, specifics as to how these job resources relate to teachers' daily needs were not explicit. The goal of this research was not only to examine how job resources for teachers' day-to-day instructional needs measure individual factors that create a model of ITJR but also to examine how these resources may relate to student achievement.

Although teachers self-report on the MET Study that job support and resources are the most important to student learning, thus far research has not explored nor defined specific job resources for instruction that might be related to student learning. In this study, my specific research question was "What is the relationship between instructional teacher job resources (ITJR) and student achievement in mathematics?” I specifically focused on job resources for mathematics teachers, as mathematics is an area with high attrition rates due to poor working conditions (Sutcher, Darling-Hammond, \& CarverThomas, 2016). 
After reviewing the MET survey questions and the research of Hakanen and colleagues (2006), the following five job resources for mathematics teachers' instruction were theorized: curriculum materials of high quality being that they provided useful information regarding the mathematics content standards as well as information on pedagogy strategies and anticipated student misunderstandings, professional development (PD) intended to meet mathematics teachers' needs, the ability to collaborate with their colleagues regarding their teaching practices, time during the work day for planning, and a sense of autonomy to make decisions regarding instruction for their students. As explained in Chapter 2, these ITJR were hypothetically split into Social and Physical job resources. I identified 16 survey questions from the MET study as potential indicators of these ITJR and examined their relationships in an Exploratory Factor Analysis (EFA) and a Confirmatory Factor Analysis (CFA) to develop and validate a model of job resources as factors.

Review of methodology. Data purchased from the MET Project were used to explore the research question posed. Both the EFA and CFA supported four factors: Curriculum, PD, Instructional Autonomy, and Time to Collaborate. Survey questions for both time to plan during the work day and for ability to collaborate with colleagues were indicators of Time to Collaborate. Factor scores, which report each factor as a weighted sum of each survey item, were created for the four job resource factors: CURR (Curriculum), PD, TIME (Time to Collaborate), and AUTON (Instructional Autonomy). Factor scores were also created for the higher-order factors: PHY for Physical ITJR (CURR and PD) and SOC for Social ITJR (TIME and AUTON). These ITJR variables were then used in Hierarchical Linear Modeling (HLM) to assess whether significant 
relationships exist between mathematics teachers' job resources for instruction and their students' achievement.

HLM accounted for the clustering effect that occurs when students are nested in classrooms (Raudenbush \& Bryk, 2002) and was used to analyze a three-level model of students (level-1) who are nested in classrooms (level-2) that are nested in schools (level3). Level-1 control variables consisted of student gender, student minority status, and student free or reduced lunch status. Level-2 control variables consisted of teacher gender, teacher minority status, and years of experience. Student achievement was the outcome variable and two models were created, one for grades 4-8 using the Balanced Assessment in Mathematics (BAM) test as the outcome and one for grade 9 using the ACT QualityCore ${ }^{\circledR}$ test as the outcome. Variables of interest were all level-2 variables for ITJR: CURR, PD, TIME, and AUTON for the individual-factor models and PHY and SOC for the higher-order models.

Major Findings. As previously stated, prior to this model, research for bigpicture job resources occurred but research for specific job resources for teachers' instruction had not yet been identified (Bakker, Demerouti, \& Verbeke, 2004; Hakanen, Bakker, \& Schaufeli, 2006). The EFA and CFA provided validity evidence for a fourfactor model that fit the data well. The main difference between the hypothesized fivefactor model (i.e., the model including Curriculum, PD, Instructional Autonomy, Collaborating with Colleagues, and Planning Time) and the confirmed four-factor model was that variables for Time to Plan and Collaborating with Colleagues were merged to become Time to Collaborate. The hypothesized higher-order ITJR Model where Physical ITJR, comprised of Curriculum and PD, and Social ITJR, comprised of Time to 
Collaborate and Instructional Autonomy was additionally supported using CFA. This is the first study to examine empirically how job resources that specifically support teachers' instruction are measured.

Accounting for the cluster effect of students nested in classrooms nested in schools using an HLM model, I found a statistically significant positive relationship between teacher instructional autonomy and student achievement for grades 4-8 after controlling for student and teacher characteristics, $\gamma_{040}=0.225, p=.024$. For each unit increase in teacher instructional autonomy, there was an expected increase in student achievement on the BAM assessment z-score by 0.22 points for grades $4-8, p<.05$. However, the other ITJR were not statistically significantly related to achievement in grades 4-8. Above and beyond the student and teacher characteristics, the four ITJR of CURR, PD, TIME, and AUTON collectively accounted for $20 \%$ of the variance explained in student achievement between classrooms and almost $11 \%$ of the variance explained between schools for grades 4-8. Autonomy alone accounted for about $0 \%$ of the variance explained in student achievement between classrooms but about 5\% of the variance explained between schools for grades $4-8$, above and beyond the other ITJR and student and teacher characteristics.

Again, accounting for the cluster effect of students nested in classrooms nested in schools using an HLM model, I found that none of the ITJR were statistically significantly related to achievement in grade 9 . Furthermore, for both grades 4-8 and grade 9, including the higher-order ITJR Model factors of Physical and Social teacher job resources did not yield statistically significant relationships with student achievement. 


\section{Findings Related to the Literature}

Using the ITJR model supported by the CFA in this study to build on the Job Demands-Resources Model (JD-R; Fig. 1, Chapter 2; Bakker, Demerouti, \& Verbeke, 2004) as well as the Job Demands-Resources (JD-R) Model for Education (Fig. 2, Chapter 2; Hakanen, Bakker, \& Schaufeli, 2006), I propose a new JD-R Model for education with day-to-day resources for instructional support. The CFA provided validity evidence that the four resources of Instructional Autonomy, quality PD, quality Curriculum, and Time to Collaborate fit the data well for the ITJR hypothesized in this study. Figure 11 illustrates how these four ITJR may fit within the existing JD-R Model. The reader will recall from Figure 1 in Chapter 2 that the Job Resources listed were not specific for day-to-day support and included Autonomy, Possibilities Development, and Social Support. The reader also will recall from Figure 2 in Chapter 2 that the JD-R Model for Education did not list any specifics for Job Resources. The model presented here in Figure 11 provides administrators with specific ways they can support teachers, thereby equipping administrators to understand better how to reduce the risk of teacher burnout and increasing the potential for teachers to be engaged with their work of teaching students.

The reader will recall from Chapter 2 that teaching has various job demands. Chapter 2 also addresses that professionals who are supported with job resources will remain in their profession and remain engaged with their work, even when job demands are high; stress falls out of the model when employees are supported. Therefore, additional job resources were included, such as support for student counseling and student conduct, to emphasize the point that there may be many job resources for 
supporting teachers. Future research is needed to examine if those job resources would also fit into the measurement of ITJR. Support for instructional job resources, as examined in this study, is just one area in which teachers need support.

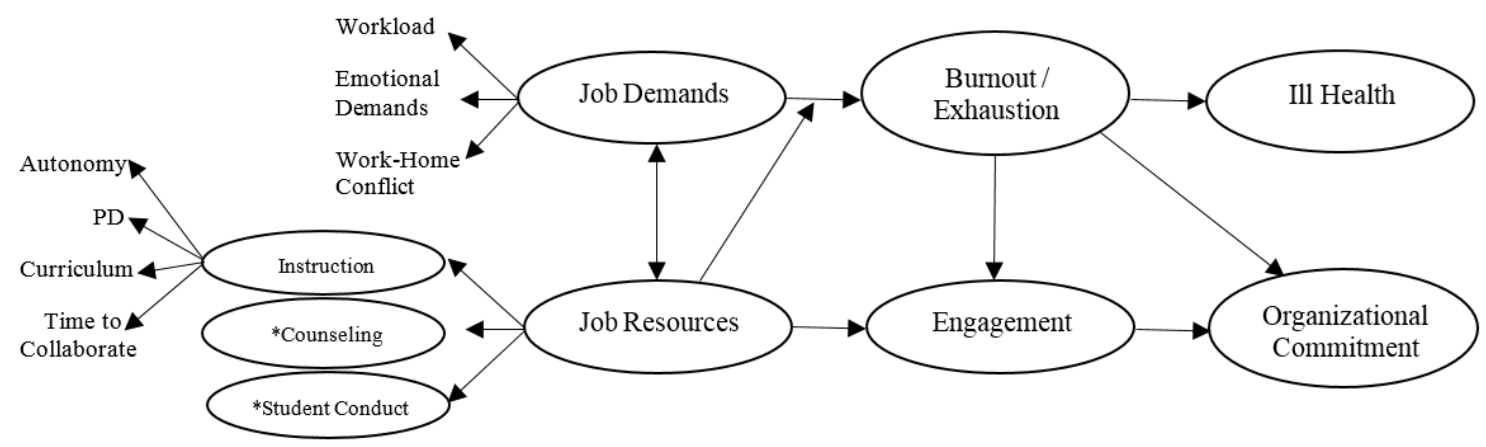

Figure 11. Job Demands-Resources Model for Education with resources for dayto-day Instructional Support. Job Resources with an * have not been explored or examined in this study.

Results from this study show that teachers who reported receiving higher levels of instructional autonomy from their administrators tended to have students with higher achievement. Supporting teachers with instructional autonomy also may decrease on-thejob stress and increase empowerment and professionalism (Pearson \& Moomaw, 2005). Based on the theory proposed in the JD-R model (Bakker, Demerouti, \& Verbeke, 2004; Hakanen, Bakker, and Schaufeli, 2006), mathematics teachers supported with instructional autonomy may be more likely to be engaged with their work (Klusmann et al., 2008) and may be less likely to leave the teaching profession (Klassen et al., 2012) than teachers who do not feel supported with instructional autonomy.

The finding from this study, that instructional autonomy is positively related to student achievement, is most similar to Pearson and Moomaw's (2005) study, using a multivariate analysis of variance, where autonomy was statistically related to on-the-job 
stress, empowerment, and professionalism. Pearson and Moomaw (2005) defined two types of autonomy that span this study's definition of instructional autonomy: (a) curriculum autonomy in which teachers had control over instructional sequencing, materials, activities, and planning, and (b) general teaching autonomy which allowed onthe-job decision making. In that study, an increase in curriculum autonomy was found to be statistically significantly related to a decrease in on-the-job stress and an increase in general teaching autonomy was found to be statistically significantly related to increases in empowerment and professionalism (Pearson \& Moomaw, 2005). In this current study, teacher autonomy for instructional planning was significantly and positively related to student achievement in mathematics for grades 4-8 after controlling for student and teacher characteristics. Instructional Autonomy was not a significant predictor for grade 9 achievement in this study. It is important to point out that, in some instances, the idea of working autonomously has been synonymous with working alone (Kelchtermans, 2006); however, this is not what is intended as an ITJR. As defined in Chapter 1, autonomy as an ITJR allows teachers to work alone or collaboratively to make instructional decisions to meet their students' needs.

\section{Unexpected Findings}

Only one of the four factors had a statistically significant relationship with student achievement, Instructional Autonomy, and only for grades 4-8. This was unexpected due to previous findings from literature. However, considering the survey questions I used were not intended for this study, as addressed in the next section, the findings here are reasonable. Another unexpected finding was that the two variables Collaborating with Colleagues and Planning Time merged into one variable, Time to Collaborate. A 
possible reason for this, as stated in Chapter 2, is that the complex tasks for teaching cannot be completed during planning time and as such, the survey questions may not be direct enough to represent Planning Time well. The need for survey questions to be more direct is addressed in the following section.

\section{Limitations}

A major limitation for this study was that the data used were not designed for ITJR as defined in Chapter 2. These data, purchased from the MET Project, included survey questions that were designed for the purpose of measuring effective teaching (MET, 2010). Although the survey questions used in this study were still relevant to concepts delineated in Chapter 2 for ITJR, the final variables may have benefited from (a) expanded questions (Stevens, 2009) and (b) more direct questions.

For instance, expanding the number of questions may have resulted in more survey items for each variable, which may have increased their reliability and validity. Five survey questions loaded onto the variable for PD where only three loaded on to AUTON and CURR each, and TIME only had two questions. With only two survey questions loading significantly, TIME needed more questions to increase its reliability (Stevens, 2009).

Questions could have been more direct as well by addressing issues of alignment. For instance, for CURR, survey questions addressed whether the materials provided "useful information about how to teach particular skills, strategies, texts, or other topics" or whether they "contain[ed] useful information for me about the content I am teaching," but the questions could have gone farther. If the curriculum materials were helpful, a teacher may agree or strongly agree to both of those questions, saying that they contain 
useful information about the content they are teaching. Yet that would not necessarily indicate whether the curriculum materials were aligned to the teacher's content standards or if the materials were aligned to their students' assessments. It may be possible that the curriculum materials used by teachers in the MET Project study were not aligned to either the instructional content standards or the assessments given; however, those specific questions were not asked of teachers on the surveys. If the alignment was weak between the measure of student achievement and teachers' content standards, results should be interpreted with caution.

Aside from the intention of the survey questions, another limitation was issues with normality for both the survey questions and the factor scores for the ITRJ variables. Data from the survey questions were categorical and even bimodal in some instances, which resulted in issues with normality. Reviewing the Q-Q Plots, however, revealed generally linear behavior of the ITJR variables.

To include as many students as possible in each model, I chose to listwise delete cases with missing data separately for each HLM model. Therefore, calculations of each proportion of variance explained may be biased as the models did not necessarily include all the same participants, depending on missing data for the variables in the models.

An additional limitation includes a procedural error during the EFA. The survey item for Individual Planning Time had a low communality score from the EFA and should have been removed. Because the item did not load on to any factors it most likely did not change the outcome of the EFA but removing it may have resulted in a more succinct path to the four-factor model. After realizing the error, I reran the EFA without 
the survey question on Individual Planning Time and got the same results, suggesting three different models, a four-factor, a three-factor, and a one-factor model for the CFA.

\section{Conclusions}

Implications for action. In this first study on instructional job resources and student achievement, validity support for a four-factor model for day-to-day teacher support based on variables available in a large-scale teacher effectiveness dataset was provided. The validated four-factor model for ITJR may help administrators be more knowledgeable about how to support their teachers. With this operationalized understanding, administrators may be more likely to offer support to teachers so that they may receive job resources such as: (a) availability to quality curriculum, (b) PD sessions that develop teacher knowledge, (c) appropriate time provided to collaborate with other math teachers, and (d) autonomy from their administrators to create or modify their instructional plans to meet their students' needs.

In particular, administrators should look for ways to offer, communicate, and encourage instructional autonomy for their teachers. Again, in this study, instructional autonomy included the following three survey questions: (a) Teachers have the autonomy to make decisions about instructional delivery (i.e., pacing, materials and pedagogy), (b) Teachers are assigned classes that maximize their likelihood of success with students, and (c) Teachers are encouraged to try new things to improve instruction. Results from this study show that teachers who reported receiving higher levels of those three items from their administrators, also had students with higher achievement. Supporting teachers with instructional autonomy also may decrease on-the-job stress and increase empowerment, professionalism (Pearson \& Moomaw, 2005). Based on the theory 
proposed in the JD-R model, mathematics teachers supported with instructional autonomy may make them more likely to be engaged with their work (Klusmann et al., 2008) and may make them less likely to leave the teaching profession (Klassen et al., 2012) than teachers who do not feel supported with instructional autonomy.

Although not widely accepted at this point, linking teacher pay to student achievement has been debated (Goldhaber, 2015). Merit pay attempts to quantify teachers' efforts and effectiveness through their students' end-of-course achievements. I would argue, based on the four-factor ITJR model validated in this study and the statistically significant relationship between one of the four factors and student achievement, that if a model for teacher merit pay is being considered, teacher job resources such as ITJR, or at least instructional autonomy, need to be included in the model. For instance, consider that two teachers are judged on their students' achievement and they receive students of similar background, race, gender, ability, and so on, yet the teachers have vastly different ITJRs with which to work. According to the results of this study, teachers with higher levels of support, in particular instructional autonomy, will have higher results, yet these resources are often beyond their control.

Recommendations for further research. Continuing to examine the relationship between ITJRs and student achievement may offer additional or refined understandings of ways in which teachers may be supported with job resources. As only one of the four factors in the validated model was statistically related to student achievement, the findings in this study indicate that specific resources that support teachers' instruction is an area for further research. 
Additionally, finding a relationship between ITJR and teacher work engagement may further highlight the relationship as a potential mediator for reducing teacher burnout and attrition (Klusmann et al., 2008). By identifying, acknowledging, and addressing teachers' professional needs, teachers may be more inclined to remain in their profession (Klassen et al., 2012). Moreover, doing so may allow teachers to feel as though they are treated as professionals (Pearson \& Moomaw, 2005). As stated in Chapter 2, other professional fields have benefited from the Job Demands-Job Resources Model (e.g., Harter et al. 2002; Kahn, 1992; Leiter \& Maslach, 2004; Schaufeli, Salanova, GonzálezRomá, \& Bakker, 2002); teachers may as well.

A next step for continuing to understand Instructional Teacher Job Resources would be to develop an ITJR Survey. As previously discussed, the ITJR Survey should include specific questions regarding alignment of content teaching standards, curriculum, and student assessment. A future study could replicate the statistical methods used in this study using the new ITJR Survey and student assessments that are aligned to instructional content standards. Although this study focused on mathematics teachers because of issues with attrition, future studies could include teachers of other content areas. Additionally, future studies could investigate whether there is a contextual difference for which ITJR are needed based on the grade level they teach.

As previously stated, analyzing possible interaction effects between each of the job resources such as Autonomy and PD would be helpful in future studies. For instance, does an increase in PD have a negative effect on teachers' autonomy? By better understanding the relationships between ITJRs, administrators and district policy makers may be better equipped to support their teachers with a balanced set of resources. 
Another step for continuing to understand how to support teachers is to investigate whether there is a statistical relationship between ITJR and Teacher Work Engagement. Previous studies have offered survey design suggestions for Work Engagement as may be considered in future research (Dalal, Baysinger, Brummel, \& LeBreton, 2012; Klassen et al., 2012). If a link between these two constructs can be found, teachers should receive ITJR support regardless of the relationship between ITJR and student achievement. If ITJRs moderate Teacher Work Engagement and teachers are then provided ITJRs, teachers may feel supported as professionals (Pearson \& Moomaw, 2005), and attrition may be reduced (Klassen et al., 2012).

To better understand how to support teachers' complex job demands, future studies could extend the instructional category of teacher job resources to other areas. Disruptive pupil behavior, for example, is a job demand factor for teachers (Hakanen et al., 2006). What specific job resources for disruptive pupil behavior might help teachers feel supported to be engaged with their work? Likewise, might teachers be more engaged with their work if school counseling services were offered for their students who may benefit from mental health services? Pupil behavior and Counseling for Students are only two additional job resources that may help teachers feel supported as professionals so that they may be engaged with their work.

Concluding remarks. Dissatisfied with administrative support and working conditions, mathematics teacher attrition has reached alarming rates due, in large part, to lack of support (Sutcher, Darling-Hammond, \& Carver-Thomas, 2016). To help administrators and researchers understand how to better support mathematics teachers, a specific set of day-to-day ITJR were researched, hypothesized, analyzed, and presented in 
this study. A model was presented, illustrating how the following ITJR fit with existing research: Instructional Autonomy, Professional Development, Curriculum, and Time to Collaborate.

Instructional job resources are just one set of job resources with which teachers may be supported to meet the demands of their job. Benefits of supporting teachers with job resources may include a decrease in attrition rates, an increase in teacher work engagement, and an increase in student achievement. Only one of the ITJR, Instructional Autonomy, was found to have a statistically significant relationship with student achievement for grades 4-8. For each unit increase in teacher autonomy, there was an expected increase in student achievement on the BAM assessment z-score by 0.22 points for grades $4-8, p<.05$. The four ITJR collectively accounted for $20 \%$ of the variance in student achievement between classrooms and almost $11 \%$ of the variance between schools for grades 4-8. Instructional Autonomy alone accounted for about $5 \%$ of the variance explained in student achievement between schools for grades 4-8, above and beyond the other ITJR and student and teacher characteristics. 


\section{CHAPTER 6}

\section{INSTRUCTIONAL TEACHER JOB RESOURCES: A CURRENT EXAMPLE}

This study focused on the relationship between teacher job resources that support mathematics teachers' instruction and student achievement. This chapter provides a current example of the importance of ITJR in the context of implementing new content standards; specifically, the Common Core State Standard for Mathematics (CCSS-M), which were released in 2010 .

Teams of education specialists and mathematicians researched commonalities of the standards used in the most successful countries as a basis for CCSS-M. As of July 2013, the CCSS-M were voluntarily adopted by 45 states and the District of Columbia; however, curriculum resources that may have eased the transition to adopt the CCSS were not ready (Bidwell, 2013; Rentner \& Kober, 2014a).

In the sections that follow, possible complications from the implementation of CCSS-M without appropriate ITJR are presented such as (a) resources for CCSS-M implementation, (b) student assessments aligned to the CCSS-M, and (c) mathematics teacher recruitment and retention.

\section{Resources for CCSS-M Implementation}

CCSS-M resources supporting teacher implementation, such as professional development (PD) and aligned curriculum materials, are still being refined (Layton, 2015; Rentner, 2013). The Center on Education Policy (CEP) reported that in 2014 only 
one-third of teachers were prepared to teach the CCSS (Rentner \& Kober, 2014a). The CEP surveyed nine of the 45 states that adopted CCSS and found that at least six of the nine states reported CCSS-related PD for English or Mathematics had been provided to less than half of their teachers (Bidwell, 2013). In addition, three other states had reduced or ceased PD altogether due to funding (Bidwell, 2013). A survey administered by the Education Week Research Center found that of the CCSS PD available, teachers rated the sessions as low quality with more PD sessions offered for English teachers than mathematics teachers (Gewertz, 2014). Although achievement scores for mathematics merit more focused PD, mathematics teachers may have gone without this support (Gewertz, 2014).

Curriculum support for mathematics teachers may be even worse. In addition to less opportunities for PD support, current curriculum resources for the CCSS-M are characterized as misaligned (Layton, 2015; Rentner \& Kober, 2014a). The CEP reports approximately $90 \%$ of districts struggled to identify or develop CCSS-M aligned curriculum materials. This is due in part to publishing companies that presented existing materials to districts claiming alignment with CCSS-M when they were not (Layton, 2015; Rentner \& Kober, 2014a). Groups such as the CCSS Mathematics Curriculum Materials Analysis Project are working to sort out the issue to determine which materials are actually aligned but in the meantime, teachers may be left without accurate guiding resources (McShane, 2013). Inadequate ITJR such as PD and curriculum materials, coupled with pressure to provide effective instruction, may heighten teachers' job demands such as requiring them to develop their own materials for new content standards which they may not fully understand as discussed in Chapter 2. 


\section{Student assessments aligned to the CCSS-M}

Each state using CCSS-M is not required to use an end-of-course (EOC) exam for mathematics that is aligned to the CCSS-M (Gewertz, 2015; Rentner \& Kober, 2014b). Two federally-funded test consortia exist, PARCC (Partnership for Assessment of Readiness for College and Careers) and SBAC (Smarter Balanced Assessment Consortium), but not all states who have adopted CCSS have purchased them (Rentner \& Kober, 2014b). Out of the 45 states, currently nine states have adopted PARRC (www.parcconline.org/about/states), and 15 states have adopted SBAC (www.smarterbalanced.org/about/members). The remaining 21 states are left to design or purchase their own test.

One of the first states to begin testing for CCSS-M, Kentucky, used their own exam (Rentner \& Kober, 2014b). For instance, Kentucky uses an exam for its Algebra 2 EOC that was created by ACT, Incorporated's "QualityCore" ${ }^{\circledR}$ prior to the creation of CCSS-M (education.ky.gov/AA/Assessments/Pages/EOC.aspx). On the QualityCore EOC exam for Algebra 2, matrix algebra was assessed even though it was not listed in the CCSS-M for teachers to cover in regular Algebra 2 classes (R. Davis, personal communication, April 23, 2016). Soon after CCSS-M was adopted, teachers in Kentucky had been told matrix test items would not be on the EOC and yet they were (R. Davis, personal communication, April 23, 2016). Teachers may then choose to cover matrix algebra for two reasons: in case it is actually counted in the assessment score or to support student moral while taking the EOC exam as seeing unfamiliar content may startle students. Doing so however, erodes instructional time for other content that needs to be taught for future course advancement. Schools in the 21 states like Kentucky that do not purchase CCSS-M-endorsed exam packages may be using misaligned exams, scoring students on old content material that teachers are not supposed to 
cover according to CCSS-M. Inadequate job resources such as misaligned assessments, coupled with pressure to increase student achievement, may heighten teachers' job demands.

\section{Mathematics teacher recruitment and retention}

Mathematics teacher recruitment and retention has been an issue for middle and secondary schools for some time in the U. S. (Sutcher, Darling-Hammond, \& Carver-Thomas, 2016). The recent implementation of CCSS-M has the potential to increase stressful working conditions for mathematics teachers in the U.S. who may experience burnout or disengagement, which may lead to teachers leaving the field of education. Teachers certified in secondary mathematics are among the most difficult positions to fill (Ronfeldt, Loeb, \& Wyckoff, 2013; Shaul \& Ganson, 2005); yet, these teachers are critical because they are responsible for student performance in a high-stakes content area (Walker, 2014). In fact, the

U.S. Government Accountability Office acknowledges problematic issues around the recruiting and retaining of mathematics teachers (Shaul \& Ganson, 2005). Furthermore, researchers assert that the mathematics teacher shortage is not due to issues with recruitment but to issues with retention (Ingersoll, 2001; Schaffhauser, 2014).

This chapter provided a brief example of the importance of ITJR in the context of implementing the CCSS-M. Mathematics teachers do not have the ITJR needed to successfully implement the CCSS-M (Rentner \& Kober, 2014a). In light of the current conditions described above it is likely that job demands may be high and job resources may be low for many mathematics educators in the U.S. The combination of the pressure on mathematics teachers to increase student achievement on high-stakes testing (job demands), the lack of resources needed to implement the CCSS-M (job resources), and the need to retain effective mathematics teachers, make factors of work engagement and 
ITJR a needed area of research. Increasing student achievement in mathematics requires retaining quality teachers who are engaged in their work and are supported with instructional job resources. 


\section{REFERENCES}

ASCD. (2012). Fulfilling the promise of the common core standards. Moving from adoption to implementation to sustainability. www.ascd.org/commoncore. 1-48.

$\mathrm{Au}, \mathrm{W}$. (2007). High-stakes testing and curricular control: A qualitative metasynthesis. Educational Researcher, 36(5), 258-267.

Bakker, A. B., Demerouti, E., \& Verbeke, W. (2004). Using the job demands-resources model to predict burnout and performance. Human resource management, 43(1), 83-104.

Bakker, A. B., Emmerik, H. \& Euwema, M. C., (2006). Crossover of burnout and engagement in work teams. Work and Occupations, 33(4), 464-489. doi: $10.1177 / 0730888406291310$

Barnes, G., Crowe, E., \& Schaefer, B. (2007). The Cost of Teacher Turnover in Five School Districts: A Pilot Study. National Commission on Teaching and America's Future.

Bidwell, A. (2013, August 7). States lack resources, funds to implement common core: A lack of funding and resources may hinder states' abilities to implement the standards and assessments - Many states are struggling to train teacher for common core standards [Web news article]. Retrieved from http://www.usnews.com/news/articles/2013/08/07/states-lack-resources-funds-toimplement-common-core

Bolam, R., McMahon, A., Stoll, L., Thomas, S., \& Wallace, M. (2005). Creating and sustaining effective professional learning communities. London: Department for Education and Skills.

Boxall, P., Purcell, J., \& Wright, P. M. (2008). Human Resource Management. http://www.oxfordhandbooks.com/view/10.1093/oxfordhb/9780199547029.001.0 001/oxfordhb-9780199547029-e-1. doi:

10.1093/oxfordhb/9780199547029.003.0001

Brodie, K., \& Shalem, Y. (2011). Accountability conversations: mathematics teachers' learning through challenge and solidarity. Journal of mathematics teacher education. 14 (6) 419-439. 
Broussard, M. (2014, July 15). Why poor schools can't win at standardized testing: The companies that create the most important state and national exams also publish textbooks that contain many of the answers. Unfortunately, low-income school districts can't afford to buy them [Web news article]. Retrieved from https://www.theatlantic.com/education/archive/2014/07/why-poor-schools-cantwin-at-standardized-testing/374287/

Certo, J. L, \& Fox, J. E. (2002). Retaining quality teachers. The High School Journal, $86(1), 57-75$.

CCSSO. National Governors Association Center for Best Practices, Council of Chief State School Officers. Common Core State Standards for Mathematics. National Governors Association Center for Best Practices, Council of Chief State School Officers, Washington D.C. 2010.

Chetty, R., Friedman, J. N., \& Rockoff, J. E. (2014). Measuring the impacts of teachers I: Evaluating bias in teacher value-added estimates. The American Economic Review, 104(9), 2593-2632.

Christian, M. S., Garza, A. S., \& Slaughter, J. E. (2011). Work engagement: A quantitative review and test of its relations with task and contextual performance. Personnel Psychology, 64, 89-136. doi:10.1111/j.1744-6570.2010.01203.

Coburn, C. E., \& Turner, E. O. (2011). Research on data use: A framework and analysis. Measurement: Interdisciplinary Research \& Perspective. 9(4), 173-206.

Cole, M. S., Walter, F., Bedeian, A. G., \& O'Boyle, E. H. (2012). Job burnout and employee engagement: A meta-analytic examination of construct proliferation. Journal of Management, 38, 1550-1581. doi:10.1177/0149206311415252.

Confrey, J. \& Krupa, E. (2010, August). Curriculum design, development, and implementation in an era of common core state standards: Summary report of a conference. Center for the Study of Mathematics Curriculum National Science Foundation. Arlington, VA.

Common core state standards (CCSS). Mathematics curriculum materials analysis project. (2011) Bush W. S. et al. [Pdf file]. Council of chief state school officers, Brookhill foundation, and Texas instruments.

Dalal, R. S., Baysinger, M., Brummel, B. J., \& LeBreton, J. M. (2012). The relative importance of employee engagement, other job attitudes, and trait affect as predictors of job performance. Journal of Applied Social Psychology, 42, E295E325.

Darling-Hammond, L. (2015). Can value added add value to teacher evaluation?. Educational Researcher, 44(2), 132-137. 
Darling-Hammond, L., Wei, R. C., \& Andree, A. (2010). How high-achieving countries develop great teachers. Stanford Center for Opportunity Policy in Education Research Brief, 1-8.

DeBray-Pelot, E., \& McGuinn, P. (2009). The New Politics of Education Analyzing the Federal Education Policy Landscape in the Post-NCLB Era. Educational Policy, 23(1), 15-42.

Demerouti, E., Bakker, A. B., Nachreiner, F., \& Schaufeli, W. B. (2001). The job demands-resources model of burnout. Journal of Applied psychology, 86(3), 499.

Dillon, S. (2006, March 26). Schools Cut Back Subjects to Push Reading and Math. http://www.nytimes.com/2006/03/26/education/26child.html?hp\&_r=0.

Dinham, S., \& Scott, C. (1996). Teacher Satisfaction, Motivation and Health: Phase One of the Teacher 2000 Project.

Doerr, Goldsmith, \& Lewis (2010). Mathematics professional development. National Council of Teachers of Mathematics Research Briefs. Retrieved from http://www.nctm.org/Research-and-Advocacy/Research-Brief-and-Clips/Goalsof-Professional-Development

Endres, G. M., \& Mancheno-Smoak, L. (2008). The human resource craze: Human performance improvement and employee engagement. Organization Development Journal, 26(1), 69-78.

Flinders, D. J., Thornton, S. J. (2013). The curriculum studies reader. New York: Rutledge.

Friedman, I. A. (1999). Teacher-perceived work autonomy: The concept and its measurement. Educational and psychological Measurement, 59(1), 58-76.

Froiland, J. J., Davison, M., \& Worrell, F. (2016). Aloha teachers: teacher autonomy support promotes Native Hawaiian and Pacific Islander students' motivation, school belonging, course-taking and math achievement. Social Psychology of Education, 19(4), 879-894.

Garet, M. S., Porter, A. C., Desimone, L., Birman, B. F., \& Yoon, K. S. (2001). What makes professional development effective? Results from a national sample of teachers. American educational research journal, 38(4), 915-945.

Garland, S. (2014). Who was behind the common core math standards, and will they survive? [Web news article]. Retrieved from: www.hechingerreport.org/behindcommon-core-math-standards-will-survive 
Gewertz, C. (2014, August 14). Despite training, half of teachers feel inadequately prepared for common core [Web news article]. Retrieved from http://blogs.edweek.org/edweek/curriculum/2014/08/study_despite_more_pd_teac hers.html

Gewertz, Catherine (2015, Feb 4). A Map of States' 2015 Testing Plans: The Dust Has Finally Settled [Web news article]. Retrieved from http://blogs.edweek.org/edweek/curriculum/2015/02/a_map_of_states_2015_testi ng_p.html. Retrieved on Aug 11, 2015.

Goddard, Y. L., Goddard, R. D., \& Tschannen-Moran, M. (2007). A theoretical and empirical investigation of teacher collaboration for school improvement and student achievement in public elementary schools. Teacher College Record. 109(4), 877-896.

Goldhaber, D. (2015). Teacher Effectiveness Research and the Evolution of US Teacher Policy. The Productivity for Results Series No. 5. George W. Bush Institute, Education Reform Initiative.

Hakanen, J. J., Bakker, A. B., \& Schaufeli, W. B. (2006). Burnout and work engagement among teachers. Journal of School Psychology, 43(6), 495-513.

Hakanen, J. J., Perhoniemi, R., \& Toppinen-Tanner, S. (2008). Positive gain spirals at work: From job resources to work engagement, personal initiative and work-unit innovativeness. Journal of Vocational Behavior, 73(1), 78-91.

Hanushek, E. A., Rivkin, S. G., Rothstein, R., \& Podgursky, M. (2004). How to improve the supply of high-quality teachers. Brookings papers on education policy, (7), 744.

Harter, J. K., \& Schmidt, F. L. (2000). Validation of a performance-related and actionable management tool: A meta-analysis and utility analysis. Technical paper, The Gallup Organization, Lincoln, NE.

Harter, J. K., Schmidt, F. L., \& Hayes, T. L. (2002). Business-unit-level relationship between employee satisfaction, employee engagement, and business outcomes: a meta-analysis. Journal of applied psychology, 87(2), 268.

Harter, J. K., \& Schmidt, F. L. (2002). Employee engagement, satisfaction, and businessunit-level outcomes: A meta-analysis. Technical paper, The Gallup Organization, Lincoln, NE. Copyright (C 2003 The Gallup Organization, Princeton, NJ. All rights reserved.

Harter, J. K., Schmidt, F. L., \& Keyes, C. L. (2003). Well-being in the workplace and its relationship to business outcomes: A review of the Gallup studies. Flourishing: Positive psychology and the life well-lived, 2, 205-224. 
Herbel-Eisenmann, B. A. (2007). From intended curriculum to written curriculum: Examining the "voice" of a mathematics textbook. Journal for Research in Mathematics Education. 38(4), 344-369.

Hooper, D., Coughlan, J., \& Mullen, M. (2008). Structural equation modelling: Guidelines for determining model fit. Articles, 2.

Johnson, S. M., \& Birkeland, S. E. (2003). Pursuing a "sense of success": New teachers explain their career decisions. American Educational Research Journal, 40(3), 581-617.

Kagan, D. M. (1992). Implications of research on teacher belief. Educational Psychologist, 27(1), 65-90.

Kahn, W. A. (1990). Psychological conditions of personal engagement and disengagement at work. Academy of Management Journal, 33(4), 692-724.

Kahn, W. A. (1992). To be fully there: Psychological presence at work. Human Relations, 45(4), 321-349. doi: 10.1177/001872679204500402

Kahn, J. H., Schneider, K. T., Jenkins-Henkelman, T. M., Moyle, L. L. (2006). Emotional social support and job burnout among high-school teachers: Is it all due to dispositional affectivity? Journal of Organizational Behavior, 27(6), 793-807.

Kelchtermans, G. (2006). Teacher collaboration and collegiality as workplace conditionsA review. Zeitschrift für Pädagogik, 52(2), 220-237.

Kim, I., \& Loadman, W. E. (1994). Predicting Teacher Job Satisfaction. [Report]. 1-19.

Klassen, R. M., Aldhafri, S., Mansfield, C. F., Purwanto, E., Siu, A. F., Wong, M. W., \& Woods-McConney, A. (2012). Teachers' engagement at work: An international validation study. The Journal of Experimental Education, 80(4), 317-337.

Klusmann, U., Kunter, M., Trautwein, U., Lüdtke, O., \& Baumert, J. (2008). Engagement and emotional exhaustion in teachers: Does the school context make a difference? Applied Psychology, 57(s1), 127-151.

Koyama, J. P. (2012). Making Failure Matter Enacting No Child Left Behind's standards, accountabilities, and classifications. Educational Policy, 26(6), 870-891. DOI: $10.1177 / 0895904811417592$

Kraft, M. A., \& Papay, J. P. (2014). Can professional environments in schools promote teacher development? Explaining heterogeneity in returns to teaching experience. Educational Evaluation and Policy Analysis. 36(4), 476-500. 
Ingersoll, R. M. (2001). Teacher turnover and teacher shortages: An organizational analysis. American Educational Research Journal, 38(3), 499-534.

Lance, C. E., Butts, M. M., \& Michels, L. C. (2006). The sources of four commonly reported cutoff criteria what did they really say? Organizational Research Methods, 9(2), 202-220.

Layton, Lyndsey (2015, March 4). New 'consumer reports' for common core finds learning materials lacking. https://www.washingtonpost.com/local/education/newconsumer-reports-for-common-core-finds-learning-materialslacking/2015/03/04/3153d264-c1f6-11e4-9ec2-b418f57a4a99_story.html

Leiter, J. (1981). Perceived Teacher Autonomy and the Meaning of Organizational Control. The Sociological Quarterly, 22(2), 225-239.

Leiter, M. P., \& Maslach, C. (2004). Areas of worklife: A structured approach to organizational predictors of job burnout. Research in Occupational Stress and Well-being, 3, 91-134.

Levine, T. H., \& Marcus, A. S. (2010). How the structure and focus of teachers' collaborative activities facilitate and constrain teacher learning. Teaching and Teacher Education, 26(3), 389-398.

Lockwood, N. R. (2007). Leveraging employee engagement for competitive advantage. Society for Human Resource Management Research Quarterly, 1, 1-12.

Louis, K. S., \& Marks, H. M. (1998). Does professional community affect the classroom? Teachers' work and student experiences in restructuring schools. American Journal of Education, 106(4), 532-575.

Lüdemann, E., Schütz, G., West, M. R., \& Woessmann, L. (2007). School Accountability, Autonomy, Choice and the Level of Student Achievement: International Evidence from PISA 2003. Books.

Macpherson, I., Brooker, R., Aspland, T., \& Elliott, B. (1999, April). Enhancing the profile of teachers as curriculum decision-makers: Some international perspectives. Paper presented at the Annual Meeting of the American Educational Research Association, Montreal: Quebec.

Mäkinen, M. (2013). Becoming engaged in inclusive practices: Narrative reflections on teaching as descriptors of teachers' work engagement. Teaching and Teacher Education, 35, 51-61.

Markos, S., \& Sridevi, M. S. (2010). Employee engagement: The key to improving performance. International Journal of Business and Management, 5(12), 89. 
Maslach, C., Leiter, M., 1997. The Truth about burnout. San Francisco, CA: Jossey-Bass.

Mauno, S., Kinnunen, U., \& Ruokolainen, M. (2007). Job demands and resources as antecedents of work engagement: A longitudinal study. Journal of Vocational Behavior, 70(1), 149-171.

McCoach, D. B., \& Adelson, J. L. (2010). Dealing with dependence (Part I): Understanding the effects of clustered data. Gifted Child Quarterly, 54, 152-155.

McCoach, D. B., \& Black, A. C. (2008). Evaluation of model fit and adequacy. In D. B. McCoach \& A. A. O'Connell, Multilevel modeling of educational data (245-272). Charlotte, NC.

McCoach, D. B., Gable, R. K., \& Madura, J. P. (2013). Instrument development in the affective domain. New York: Springer.

McCrory, R., Floden, R., Ferrini-Mundy, J., Reckase, M. D., \& Senk, S. L. (2012). Knowledge of algebra for teaching: A framework of knowledge and practices. Journal for Research in Mathematics Education, 43(5), 584-615.

McLaughlin, M. W., \& Talbert, J. E. (1993). Contexts that matter for teaching and learning: Strategic opportunities for meeting the nation's educational goals. Center for Research on the Context of Secondary School Teaching, 143.

McShane, M. (2013, July 3). Common Core Complications: There are several speed bumps in the way of national education standards [Web news article]. Retrieved from http://www.usnews.com/opinion/blogs/economicintelligence/2013/07/03/five-complications-of-common-core-education-standards

Measures of effective teaching (MET) project. (2013, September 23). Bill and Melinda Gates Foundation. ICPSR34771-v2. Ann Arbor, MI: Inter-university Consortium for Political and Social Research [distributor]. http://doi.org/10.3886/ICPSR34771.v2

Measures of effective teaching (MET). (2010). Teacher Work Conditions Survey. http://www.icpsr.umich.edu/icpsrweb/METLDB/holdings/documentation

Meyers, L. S., Gamst, G., \& Guarino, A. J. (2006). Applied multivariate research: Design and interpretation. Thousand Oaks, CA: Sage.

National center for education statistics, (2013). [NCES]. National center for education statistics [Official website]. Retrieved from: http://nces.ed.gov/whatsnew/commissioner/remarks2013/10_24_2013.asp

National Research Council. (2001). Adding it up: Helping children learn mathematics. Kilpatrick, J., Swafford, J., \& Findell, B. (Eds.). Mathematics Learning Study 
Committee, Center for Education, Division of Behavioral and Social Sciences and Education. Washington, DC: National Academy Press.

NCTM (2013). National council of teachers of mathematics [Official website]. Retrieved from:

http://www.nctm.org/resources/content.aspx?id=12630\#sthash.KwdiD6Z7.dpuf

Nicol, C. C., \& Crespo, S. M. (2006). Learning to teach with mathematics textbooks: How preservice teachers interpret and use curriculum materials. Educational Studies in Mathematics, 62(3), 331-355.

Nye, B., Konstantopoulos, S., \& Hedges, L. V. (2004). How large are teacher effects?. Educational Evaluation and Policy Analysis, 26(3), 237-257.

Öztürk, I. H. (2012). Teacher's Role and Autonomy in Instructional Planning: The Case of Secondary School History Teachers with regard to the Preparation and Implementation of Annual Instructional Plans. Educational Sciences: Theory and Practice, 12(1), 295-299.

Parker, S. K., \& Griffin, M. A. (2011). Understanding active psychological states: Embedding engagement in a wider nomological net and closer attention to performance. European Journal of Work and Organizational Psychology, 20(1), 60-67.

Parker, F., \& Novak J. (2012, December 6). Common core: Now what? Implementing the common core mathematical practices. $8(5)$. Retrieved from http://www.ascd.org/ascd-express/vol8/805-parker.aspx

Pearson, L. C., \& Hall, B. W. (1993). Initial Construct Validation of the Teaching Autonomy Scale. The Journal of Educational Research, 172-178.

Pearson, L. C., \& Moomaw, W. (2006). Continuing validation of the teaching autonomy scale. The Journal of Educational Research, 100(1), 44-51.

Polikoff, M. S., \& Porter, A. C. (2014). Instructional alignment as a measure of teaching quality. Educational Evaluation and Policy Analysis, 0162373714531851.

Porter, A. C. (1989). External standards and good teaching: The pros and cons of telling teachers what to do. Educational Evaluation and Policy Analysis, 11(4), 343-356.

Porter, C. (2015, April 29). U.S. Students Stagnate in Social Studies. http://www.wsj.com/articles/u-s-students-stagnate-in-social-studies-1430280062.

Raudenbush, S. W. \& Bryk, A. S. (2002) Hierarchical linear models: Applications and data analysis methods. Thousand Oaks, CA: Sage Publications. 
Raudenbush, S. W., Bryk, A. S., Cheong, Y. F., Congdon, R. T., \& Du Toit, M. (2011). HLM 7. Lincolnwood, IL: Scientific Software International Inc.

Remillard, J. T. (2005). Examining Key Concepts in Research on Teachers' Use of Mathematics Curricula. Review of Educational Research. 75(2), 211-246.

Remillard, J. T., \& Heck, D. J. (2014). Conceptualizing the curriculum enactment process in mathematics education. ZDM, 46(5), 705-718.

Rentner, D. S. (2013, October 3). Ten big takeaways from CEP's research on state implementation of the common core [Web news article]. Retrieved from http://www.huntintersection.com/2013/10/03/ten-big-takeaways-from-cepsresearch-on-state-implementation-of-the-common-core/

Rentner, D. S. \& Kober, N. (2014a). Common core state standards in 2014: Curriculum and professional development at the district level. Center on Education Policy. 120. Retrieved from; http://www.cepdc.org/displayDocument.cfm?DocumentID=441

Rentner, D. S. \& Kober, N. (2014b). Common core state standards in 2014: District implementation of consortia-developed assessments. Center on Education Policy. 1-17. Retrieved from http://www.cepdc.org/displayDocument.cfm?DocumentID $=442$

Reeve, J., Jang, H., Carrell, D., Jeon, S., \& Barch, J. (2004). Enhancing students' engagement by increasing teachers' autonomy support. Motivation and emotion, 28(2), 147-169.

Reys, R., Reys, B., Lapan, R., Holliday, G., \& Wasman, D. (2003). Assessing the impact of standards-based middle grades mathematics curriculum materials on student achievement. Journal for Research in Mathematics Education, 74-95.

Reys, B., Reys, R., \& Rubenstein, R. (2010). Mathematics curriculum: Issues, trends, and future directions, 72nd yearbook. National Council of Teachers of Mathematics. 1906 Association Drive, Reston, VA 20191-1502.

Rich, B., LePine, J., \& Crawford, E. (2010). Job engagement: Antecedents and effects on job performance. The Academy of Management Journal, 53, 617-635. doi:10.5465/AMJ.2010.51468988

Roberts, J. K. (2007, April). Group dependency in the presence of small intraclass correlation coefficients: An argument in favor of not interpreting the ICC. Paper presented at the Annual Meeting of the American Educational Research Association. Chicago, IL. 
Rockoff, J. E. (2004). The impact of individual teachers on student achievement: Evidence from panel data. The American Economic Review, 94(2), 247-252.

Ronfeldt, M., Loeb, S., \& Wyckoff, J. (2013). How teacher turnover harms student achievement. American Educational Research Journal, 50(1), 4-36.

Ronfeldt, M., Farmer, S. O., McQueen, K., Grissom, J. A. (2015). Teacher Collaboration in Instructional Teams and Student Achievement. American Educational Research Journal. 52(3)3, 475-514. DOI: 10.3102/0002831215585562

Runhaar, P., Konermann, J., \& Sanders, K. (2013). Teachers' organizational citizenship behaviour: Considering the roles of their work engagement, autonomy and leader-member exchange. Teaching and Teacher Education, 30, 99-108.

Saderholm, J., Ronau, R., Brown, E. T., Collins, G. (2010) Validation of the diagnostic teacher assessment of mathematics and science instrument. School Science and Mathematics. 110(4), 180-192.

Sanders, W., \& Rivers, J. (1996). Cumulative and residual effects of teachers on future student academic achievement (Research progress report). Knoxville, TN: University of Tennessee Value-Added Assessment Center.

Schaffhauser, D. (2014, July 17). The Problem Isn't Teacher Recruiting; It's Retention. https://thejournal.com/articles/2014/07/17/the-problem-isnt-teacher-recruiting-itsretention.aspx

Schaufeli, W. B., Salanova, M., González-Romá, V., \& Bakker, A. B. (2002). The measurement of engagement and burnout: A two sample confirmatory factor analytic approach. Journal of Happiness Studies, 3(1), 71-92.

Schaufeli, W. B., \& Bakker, A. B. (2004). Job demands, job resources, and their relationship with burnout and engagement: A multi-sample study. Journal of Organizational Behavior, 25(3), 293-315.

Schaufeli, W. B., \& Bakker, A. B. (2010). Defining and measuring work engagement: Bringing clarity to the concept. Work engagement: A handbook of essential theory and research, 10-24.

Schaufeli, W. B., Bakker, A. B., \& Salanova, M. (2006). The measurement of work engagement with a short questionnaire a cross-national study. Educational and Psychological Measurement, 66(4), 701-716.

Schmidt, W., Houang, R., \& Cogan, L. (2002). A coherent curriculum: The case of mathematics. Journal of Direct Instruction, 4(1), 13-28. 
Shaul, M. S., Ganson, H. C. (2005). The no child left behind act of 2001: The federal government's role in strengthening accountability for student performance. Review of research in education, 29(1) 151-165.

Shuck, B., Nimon, K., \& Zigarmi, D. (2016). Untangling the predictive nomological validity of employee engagement: Decomposing variance in employee engagement using job attitude measures. Group and Organizational Management. doi: 10.1177/1059601116642364 [Advanced Online Publication]

Shuck, B., \& Wollard, K. (2010). Employee engagement and HRD: A seminal review of the foundations. Human Resource Development Review, 9(1), 89-110.

Simpson, M. R. (2009). Engagement at work: A review of the literature. International Journal of Nursing Studies, 46(7), 1012-1024.

Song, J. H., Bae, S. H., Park, S., \& Kim, H. K. (2013). Influential factors for knowledge creation practices of CTE teachers: mutual impact of perceived school support, transformational leadership, and work engagement. Asia Pacific Education Review, 14(4), 467-482.

Stecher, B. M., Garet, M. S., Hamilton, L. S., Steiner, E. D., Robyn, A., Poirier, J., Holtzman, D., Fulbeck, E.S., Chambers, J. \& de los Reyes, I. B. (2016). Improving Teaching Effectiveness: Implementation: The Intensive Partnerships for Effective Teaching Through 2013-2014. Rand Corporation.

Stein, M. K., \& Smith, M. S. (1998). Mathematical tasks as a framework for reflection: From research to practice. Mathematics Teaching in the Middle School, 3(4), 268275.

Stevens, J. P. (2009) Applied multivariate statistics for the social sciences ( $5^{\text {th }}$ ed.). New York, NY: Routledge.

Sutcher, L., Darling-Hammond, L., \& Carver-Thomas, D. (2016). A coming crisis in teaching? Teacher supply, demand, and shortages in the US. Palo Alto, CA: Learning Policy Institute. https://learningpolicyinstitute.org/product/comingcrisis-teaching.

U.S. Department of Education (2013). Elementary and secondary education act. Retrieved from: http://www.ed.gov/esea

U.S. Department of Education (2011). U.S. states in a global context - results from the 2011 NAEP-TIMSS linking study. Retrieved from: http://nces.ed.gov/nationsreportcard/subject/publications/studies/pdf/2013460.pdf 
Valli, L., Croninger, R. G., Walters, K. (2007). Who (Else) Is the Teacher? Cautionary Notes on Teacher Accountability Systems. American Journal of Education. 113(4) 635-662.

VanTassel-Baska, J., \& Stambaugh, T. (2005). Challenges and possibilities for serving gifted learners in the regular classroom. Theory Into Practice, 44(3), 211-217.

Vescio, V., Ross, D., \& Adams, A. (2008). A review of research on the impact of professional learning communities on teaching practice and student learning. Teaching and Teacher Education. 24(1), 80-91.

Vilson, Jose. (2013, January 16). Why the mathematical practices matter as much as the content. http://www.edutopia.org/blog/why-mathematical-practices-matter-josevilson

Walker, T. (2014, September 2). The testing obsession and the disappearing curriculum. http://neatoday.org/2014/09/02/the-testing-obsession-and-the-disappearingcurriculum-2/.

Waters, T., Marzano, R. J., \& McNulty, B. (2003). Balanced Leadership: What 30 Years of Research Tells Us about the Effect of Leadership on Student Achievement. A Working Paper.

Wiley, C. (2000). A Synthesis of Research on the Causes, Effects, and Reduction Strategies of Teacher Stress. Journal of Instructional Psychology, 27(2), 80-80.

Wong, E. H., Wiest, D. J., \& Cusick, L. B. (2002). Perceptions of autonomy support, parent attachment, competence and self-worth as predictors of motivational orientation and academic achievement: An examination of sixth-and ninth-grade regular education students. Adolescence, 37(146), 255.

Yoon, K. S., Duncan, T., Lee, S. W. Y., Scarloss, B., \& Shapley, K. L. (2007). Reviewing the Evidence on How Teacher Professional Development Affects Student Achievement. Issues \& Answers. REL 2007-No. 033. Regional Educational Laboratory Southwest (NJ1).

Yoong, W. K., \& Hoe, L. N. (2009). Singapore education and mathematics curriculum. In W. K. Yoong, L. P. Yee, B. Kaur, F. P. Yee, \& N. S. Fong (Eds). Mathematics Education: The Singapore Journey (pp. 14-47). Singapore: World Scientific. 


\section{APPENDIX A \\ COPYRIGHT PERMISSIONS}

JOHN WILEY AND SONS LICENSE TERMS AND CONDITIONS

Apr 28, 2017

This Agreement between Amy Stokes ("You") and John Wiley and Sons ("John Wiley and Sons") consists of your license details and the terms and conditions provided by John Wiley and Sons and Copyright Clearance Center.

License Number

4096251336336

License date

Licensed Content Publisher

John Wiley and Sons

Licensed Content Publication

Licensed Content Title

Human Resource Management

Using the job demands-resources model to predict burnout and performance

Licensed Content Author

Arnold B. Bakker,Evangelia Demerouti,Willem Verbeke

Licensed Content Date

Apr 19, 2004

Licensed Content Pages

22

Type of use

Dissertation/Thesis

Requestor type

University/Academic

Format

Print and electronic

Portion

Figure/table

Number of figures/tables

1

Original Wiley figure/table number(s)

Will you be translating?

Figure 1

Title of your thesis / dissertation

No

Expected completion date

Instructional Teacher Job Resources and Student Achievement in Mathematics

Expected size (number of pages)

May 2017

130 
Requestor Location

Publisher Tax ID

Billing Type

Billing Address

Total

Terms and Conditions
Amy Stokes-Levine

LOUIS VILLE, KY 40206

United States

Attn: Amy Stokes-Levine

EU826007151

Invoice

Amy Stokes-Levine

LOUIS VILLE, KY 40206

United States

Attn: Amy Stokes-Levine

0.00 USD

\section{TERMS AND CONDITIONS}

This copyrighted material is owned by or exclusively licensed to John Wiley \& Sons, Inc. or one of its group companies (each a"Wiley Company") or handled on behalf of a society with which a Wiley Company has exclusive publishing rights in relation to a particular work (collectively "WILEY"). By clicking "accept" in connection with completing this licensing transaction, you agree that the following terms and conditions apply to this transaction (along with the billing and payment terms and conditions established by the Copyright Clearance Center Inc., ("CCC's Billing and Payment terms and conditions"), at the time that you opened your RightsLink account (these are available at any time at http://myaccount.copyright.com).

\section{Terms and Conditions}

- The materials you have requested permission to reproduce or reuse (the "Wiley Materials") are protected by copyright.

- You are hereby granted a personal, non-exclusive, non-sub licensable (on a standalone basis), non-transferable, worldwide, limited license to reproduce the Wiley Materials for the purpose specified in the licensing process. This license, and any CONTENT (PDF or image file) purchased as part of your order, is for a onetime use only and limited to any maximum distribution number specified in the license. The first instance of republication or reuse granted by this license must be completed within two years of the date of the grant of this license (although copies prepared before the end date may be distributed thereafter). The Wiley Materials shall not be used in any other manner or for any other purpose, beyond what is granted in the license. Permission is granted subject to an appropriate acknowledgement given to the author, title of the material/book/journal and the publisher. You shall also duplicate the copyright notice that appears in the Wiley publication in your use of the Wiley Material. Permission is also granted on the understanding that nowhere in the text is a previously published source 
acknowledged for all or part of this Wiley Material. Any third party content is expressly excluded from this permission.

- With respect to the Wiley Materials, all rights are reserved. Except as expressly granted by the terms of the license, no part of the Wiley Materials may be copied, modified, adapted (except for minor reformatting required by the new Publication), translated, reproduced, transferred or distributed, in any form or by any means, and no derivative works may be made based on the Wiley Materials without the prior permission of the respective copyright owner.For STM Signatory Publishers clearing permission under the terms of the STM Permissions Guidelines only, the terms of the license are extended to include subsequent editions and for editions in other languages, provided such editions are for the work as a whole in situ and does not involve the separate exploitation of the permitted figures or extracts, You may not alter, remove or suppress in any manner any copyright, trademark or other notices displayed by the Wiley Materials. You may not license, rent, sell, loan, lease, pledge, offer as security, transfer or assign the Wiley Materials on a stand-alone basis, or any of the rights granted to you hereunder to any other person.

- The Wiley Materials and all of the intellectual property rights therein shall at all times remain the exclusive property of John Wiley \& Sons Inc, the Wiley Companies, or their respective licensors, and your interest therein is only that of having possession of and the right to reproduce the Wiley Materials pursuant to Section 2 herein during the continuance of this Agreement. You agree that you own no right, title or interest in or to the Wiley Materials or any of the intellectual property rights therein. You shall have no rights hereunder other than the license as provided for above in Section 2. No right, license or interest to any trademark, trade name, service mark or other branding ("Marks") of WILEY or its licensors is granted hereunder, and you agree that you shall not assert any such right, license or interest with respect thereto

- NEITHER WILEY NOR ITS LICENSORS MAKES ANY WARRANTY OR REPRESENTATION OF ANY KIND TO YOU OR ANY THIRD PARTY, EXPRESS, IMPLIED OR STATUTORY, WITH RESPECT TO THE MATERIALS OR THE ACCURACY OF ANY INFORMATION CONTAINED IN THE MATERIALS, INCLUDING, WITHOUT LIMITATION, ANY IMPLIED WARRANTY OF MERCHANTABILITY, ACCURACY, SATISFACTORY QUALITY, FITNESS FOR A PARTICULAR PURPOSE, USABILITY, INTEGRATION OR NON-INFRINGEMENT AND ALL SUCH WARRANTIES ARE HEREBY EXCLUDED BY WILEY AND ITS LICENSORS AND WAIVED BY YOU.

- WILEY shall have the right to terminate this Agreement immediately upon breach of this Agreement by you.

- You shall indemnify, defend and hold harmless WILEY, its Licensors and their respective directors, officers, agents and employees, from and against any actual or 
threatened claims, demands, causes of action or proceedings arising from any breach of this Agreement by you.

- IN NO EVENT SHALL WILEY OR ITS LICENSORS BE LIABLE TO YOU OR ANY OTHER PARTY OR ANY OTHER PERSON OR ENTITY FOR ANY SPECIAL, CONSEQUENTIAL, INCIDENTAL, INDIRECT, EXEMPLARY OR PUNITIVE DAMAGES, HOWEVER CAUSED, ARISING OUT OF OR IN CONNECTION WITH THE DOWNLOADING, PROVISIONING, VIEWING OR USE OF THE MATERIALS REGARDLESS OF THE FORM OF ACTION, WHETHER FOR BREACH OF CONTRACT, BREACH OF WARRANTY, TORT, NEGLIGENCE, INFRINGEMENT OR OTHERWISE (INCLUDING, WITHOUT LIMITATION, DAMAGES BASED ON LOSS OF PROFITS, DATA, FILES, USE, BUSINESS OPPORTUNITY OR CLAIMS OF THIRD PARTIES), AND WHETHER OR NOT THE PARTY HAS BEEN ADVISED OF THE POSSIBILITY OF SUCH DAMAGES. THIS LIMITATION SHALL APPLY NOTWITHSTANDING ANY FAILURE OF ESSENTIAL PURPOSE OF ANY LIMITED REMEDY PROVIDED HEREIN.

- Should any provision of this Agreement be held by a court of competent jurisdiction to be illegal, invalid, or unenforceable, that provision shall be deemed amended to achieve as nearly as possible the same economic effect as the original provision, and the legality, validity and enforceability of the remaining provisions of this Agreement shall not be affected or impaired thereby.

- The failure of either party to enforce any term or condition of this Agreement shall not constitute a waiver of either party's right to enforce each and every term and condition of this Agreement. No breach under this agreement shall be deemed waived or excused by either party unless such waiver or consent is in writing signed by the party granting such waiver or consent. The waiver by or consent of a party to a breach of any provision of this Agreement shall not operate or be construed as a waiver of or consent to any other or subsequent breach by such other party.

- This Agreement may not be assigned (including by operation of law or otherwise) by you without WILEY's prior written consent.

- Any fee required for this permission shall be non-refundable after thirty (30) days from receipt by the CCC.

- These terms and conditions together with CCC's Billing and Payment terms and conditions (which are incorporated herein) form the entire agreement between you and WILEY concerning this licensing transaction and (in the absence of fraud) supersedes all prior agreements and representations of the parties, oral or written. This Agreement may not be amended except in writing signed by both parties. This Agreement shall be binding upon and inure to the benefit of the parties' successors, legal representatives, and authorized assigns. 
- In the event of any conflict between your obligations established by these terms and conditions and those established by CCC's Billing and Payment terms and conditions, these terms and conditions shall prevail.

- WILEY expressly reserves all rights not specifically granted in the combination of (i) the license details provided by you and accepted in the course of this licensing transaction, (ii) these terms and conditions and (iii) CCC's Billing and Payment terms and conditions.

- This Agreement will be void if the Type of Use, Format, Circulation, or Requestor Type was misrepresented during the licensing process.

- This Agreement shall be governed by and construed in accordance with the laws of the State of New York, USA, without regards to such state's conflict of law rules. Any legal action, suit or proceeding arising out of or relating to these Terms and Conditions or the breach thereof shall be instituted in a court of competent jurisdiction in New York County in the State of New York in the United States of America and each party hereby consents and submits to the personal jurisdiction of such court, waives any objection to venue in such court and consents to service of process by registered or certified mail, return receipt requested, at the last known address of such party.

\section{WILEY OPEN ACCESS TERMS AND CONDITIONS}

Wiley Publishes Open Access Articles in fully Open Access Journals and in Subscription journals offering Online Open. Although most of the fully Open Access journals publish open access articles under the terms of the Creative Commons Attribution (CC BY) License only, the subscription journals and a few of the Open Access Journals offer a choice of Creative Commons Licenses. The license type is clearly identified on the article.

\section{The Creative Commons Attribution License}

The Creative Commons Attribution License (CC-BY) allows users to copy, distribute and transmit an article, adapt the article and make commercial use of the article. The CC-BY license permits commercial and non-

\section{Creative Commons Attribution Non-Commercial License}

The Creative Commons Attribution Non-Commercial (CC-BY-NC)License permits use, distribution and reproduction in any medium, provided the original work is properly cited and is not used for commercial purposes.(see below)

\section{Creative Commons Attribution-Non-Commercial-NoDerivs License} The Creative Commons Attribution Non-Commercial-NoDerivs License (CC-BY-NC-ND) permits use, distribution and reproduction in any medium, provided the original work is properly cited, is not used for commercial purposes and no modifications or adaptations are made. (see below)

\section{Use by commercial "for-profit" organizations}


Use of Wiley Open Access articles for commercial, promotional, or marketing purposes requires further explicit permission from Wiley and will be subject to a fee.

Further details can be found on Wiley Online Library

http://olabout.wiley.com/WileyCDA/Section/id-410895.html

Other Terms and Conditions: v1.10 Last updated September 2015

Questions? customercare@ copyright.com or +1-855-239-3415 (toll free in the US) or +1-978-646-2777. 


\section{ELSEVIER LICENSE TERMS AND CONDITIONS}

Apr 28, 2017

This Agreement between Amy Stokes ("You") and Elsevier ("Elsevier") consists of your license details and the terms and conditions provided by Elsevier and Copyright Clearance Center.

License Number

4097630997985

License date

Licensed Content Publisher

Elsevier

Licensed Content Publication

Journal of School Psychology

Licensed Content Title

Burnout and work engagement among teachers

Licensed Content Author

Licensed Content Date

Jari J. Hakanen,Arnold B. Bakker,Wilmar B. Schaufeli

Licensed Content Volume

January 2006

Licensed Content Issue

43

Licensed Content Pages

6

Start Page

19

End Page

495

Type of Use

513

Portion

Number of figures/tables/illustrations

reuse in a thesis/dissertation

figures/tables/illustrations

Format

1

both print and electronic

Are you the author of this Elsevier article? No

Will you be translating?

No

Order reference number

Original figure numbers

Figure 1

Title of your thesis/dissertation

Instructional Teacher Job Resources and Student Achievement in Mathematics

Expected completion date May 2017

Estimated size (number of pages)

130

Elsevier VAT number

GB 494627212

Amy Stokes-Levine

Requestor Location

LOUIS VILLE, KY 40206

United States

Attn: Amy Stokes-Levine

Publisher Tax ID

98-0397604

Total

$0.00 \mathrm{USD}$ 
Terms and Conditions

\section{INTRODUCTION}

1. The publisher for this copyrighted material is Elsevier. By clicking "accept" in connection with completing this licensing transaction, you agree that the following terms and conditions apply to this transaction (along with the Billing and Payment terms and conditions established by Copyright Clearance Center, Inc. ("CCC"), at the time that you opened your Rightslink account and that are available at any time at http://myaccount.copyright.com).

\section{GENERAL TERMS}

2. Elsevier hereby grants you permission to reproduce the aforementioned material subject to the terms and conditions indicated.

3. Acknowledgement: If any part of the material to be used (for example, figures) has appeared in our publication with credit or acknowledgement to another source, permission must also be sought from that source. If such permission is not obtained then that material may not be included in your publication/copies. Suitable acknowledgement to the source must be made, either as a footnote or in a reference list at the end of your publication, as follows:

"Reprinted from Publication title, Vol /edition number, Author(s), Title of article / title of chapter, Pages No., Copyright (Year), with permission from Elsevier [OR APPLICABLE SOCIETY COPYRIGHT OWNER]." Also Lancet special credit - "Reprinted from The Lancet, Vol. number, Author(s), Title of article, Pages No., Copyright (Year), with permission from Elsevier."

4. Reproduction of this material is confined to the purpose and/or media for which permission is hereby given.

5. Altering/Modifying Material: Not Permitted. However figures and illustrations may be altered/adapted minimally to serve your work. Any other abbreviations, additions, deletions and/or any other alterations shall be made only with prior written authorization of Elsevier Ltd. (Please contact Elsevier at permissions@elsevier.com). No modifications can be made to any Lancet figures/tables and they must be reproduced in full.

6. If the permission fee for the requested use of our material is waived in this instance, please be advised that your future requests for Elsevier materials may attract a fee.

7. Reservation of Rights: Publisher reserves all rights not specifically granted in the combination of (i) the license details provided by you and accepted in the course of this licensing transaction, (ii) these terms and conditions and (iii) CCC's Billing and Payment terms and conditions. 
8. License Contingent Upon Payment: While you may exercise the rights licensed immediately upon issuance of the license at the end of the licensing process for the transaction, provided that you have disclosed complete and accurate details of your proposed use, no license is finally effective unless and until full payment is received from you (either by publisher or by CCC) as provided in CCC's Billing and Payment terms and conditions. If full payment is not received on a timely basis, then any license preliminarily granted shall be deemed automatically revoked and shall be void as if never granted. Further, in the event that you breach any of these terms and conditions or any of CCC's Billing and Payment terms and conditions, the license is automatically revoked and shall be void as if never granted. Use of materials as described in a revoked license, as well as any use of the materials beyond the scope of an unrevoked license, may constitute copyright infringement and publisher reserves the right to take any and all action to protect its copyright in the materials.

9. Warranties: Publisher makes no representations or warranties with respect to the licensed material.

10. Indemnity: You hereby indemnify and agree to hold harmless publisher and CCC, and their respective officers, directors, employees and agents, from and against any and all claims arising out of your use of the licensed material other than as specifically authorized pursuant to this license.

11. No Transfer of License: This license is personal to you and may not be sublicensed, assigned, or transferred by you to any other person without publisher's written permission.

12. No Amendment Except in Writing: This license may not be amended except in a writing signed by both parties (or, in the case of publisher, by CCC on publisher's behalf).

13. Objection to Contrary Terms: Publisher hereby objects to any terms contained in any purchase order, acknowledgment, check endorsement or other writing prepared by you, which terms are inconsistent with these terms and conditions or CCC's Billing and Payment terms and conditions. These terms and conditions, together with CCC's Billing and Payment terms and conditions (which are incorporated herein), comprise the entire agreement between you and publisher (and CCC) concerning this licensing transaction. In the event of any conflict between your obligations established by these terms and conditions and those established by CCC's Billing and Payment terms and conditions, these terms and conditions shall control.

14. Revocation: Elsevier or Copyright Clearance Center may deny the permissions described in this License at their sole discretion, for any reason or no reason, with a full refund payable to you. Notice of such denial will be made using the contact information provided by you. Failure to receive such notice will not alter or invalidate the denial. In no event will Elsevier or Copyright Clearance Center be responsible or liable for any costs, expenses or damage incurred by you as a result of a denial of your permission request, 
other than a refund of the amount(s) paid by you to Elsevier and/or Copyright Clearance Center for denied permissions.

\section{LIMITED LICENSE}

The following terms and conditions apply only to specific license types:

15. Translation: This permission is granted for non-exclusive world English rights only unless your license was granted for translation rights. If you licensed translation rights you may only translate this content into the languages you requested. A professional translator must perform all translations and reproduce the content word for word preserving the integrity of the article.

16. Posting licensed content on any Website: The following terms and conditions apply as follows: Licensing material from an Elsevier journal: All content posted to the web site must maintain the copyright information line on the bottom of each image; A hyper-text must be included to the Homepage of the journal from which you are licensing at http://www.sciencedirect.com/science/journal/xxxxx or the Elsevier homepage for books at http://www.elsevier.com; Central Storage: This license does not include permission for a scanned version of the material to be stored in a central repository such as that provided by Heron/XanEdu.

Licensing material from an Elsevier book: A hyper-text link must be included to the Elsevier homepage at http://www.elsevier.com . All content posted to the web site must maintain the copyright information line on the bottom of each image.

Posting licensed content on Electronic reserve: In addition to the above the following clauses are applicable: The web site must be password-protected and made available only to bona fide students registered on a relevant course. This permission is granted for 1 year only. You may obtain a new license for future website posting.

17. For journal authors: the following clauses are applicable in addition to the above:

\section{Preprints:}

A preprint is an author's own write-up of research results and analysis, it has not been peerreviewed, nor has it had any other value added to it by a publisher (such as formatting, copyright, technical enhancement etc.).

Authors can share their preprints anywhere at any time. Preprints should not be added to or enhanced in any way in order to appear more like, or to substitute for, the final versions of articles however authors can update their preprints on arXiv or RePEc with their Accepted Author Manuscript (see below). 
If accepted for publication, we encourage authors to link from the preprint to their formal publication via its DOI. Millions of researchers have access to the formal publications on ScienceDirect, and so links will help users to find, access, cite and use the best available version. Please note that Cell Press, The Lancet and some society-owned have different preprint policies. Information on these policies is available on the journal homepage.

Accepted Author Manuscripts: An accepted author manuscript is the manuscript of an article that has been accepted for publication and which typically includes authorincorporated changes suggested during submission, peer review and editor-author communications.

Authors can share their accepted author manuscript:

- immediately

- via their non-commercial person homepage or blog

- by updating a preprint in arXiv or RePEc with the accepted manuscript

- via their research institute or institutional repository for internal institutional uses or as part of an invitation-only research collaboration work-group

- directly by providing copies to their students or to research collaborators for their personal use

- for private scholarly sharing as part of an invitation-only work group on commercial sites with which Elsevier has an agreement

- After the embargo period

- via non-commercial hosting platforms such as their institutional repository

- via commercial sites with which Elsevier has an agreement

In all cases accepted manuscripts should:

- $\quad$ link to the formal publication via its DOI

- bear a CC-BY-NC-ND license - this is easy to do

- if aggregated with other manuscripts, for example in a repository or other site, be shared in alignment with our hosting policy not be added to or enhanced in any way to appear more like, or to substitute for, the published journal article.

Published journal article (JPA): A published journal article (PJA) is the definitive final record of published research that appears or will appear in the journal and embodies all value-adding publishing activities including peer review co-ordination, copy-editing, formatting, (if relevant) pagination and online enrichment.

Policies for sharing publishing journal articles differ for subscription and gold open access articles:

Subscription Articles: If you are an author, please share a link to your article rather than the full-text. Millions of researchers have access to the formal publications on 
ScienceDirect, and so links will help your users to find, access, cite, and use the best available version.

Theses and dissertations which contain embedded PJAs as part of the formal submission can be posted publicly by the awarding institution with DOI links back to the formal publications on ScienceDirect.

If you are affiliated with a library that subscribes to ScienceDirect you have additional private sharing rights for others' research accessed under that agreement. This includes use for classroom teaching and internal training at the institution (including use in course packs and courseware programs), and inclusion of the article for grant funding purposes.

Gold Open Access Articles: May be shared according to the author-selected end-user license and should contain a CrossMark logo, the end user license, and a DOI link to the formal publication on ScienceDirect.

Please refer to Elsevier's posting policy for further information.

18. For book authors the following clauses are applicable in addition to the above: Authors are permitted to place a brief summary of their work online only. You are not allowed to download and post the published electronic version of your chapter, nor may you scan the printed edition to create an electronic version. Posting to a repository: Authors are permitted to post a summary of their chapter only in their institution's repository.

19. Thesis/Dissertation: If your license is for use in a thesis/dissertation your thesis may be submitted to your institution in either print or electronic form. Should your thesis be published commercially, please reapply for permission. These requirements include permission for the Library and Archives of Canada to supply single copies, on demand, of the complete thesis and include permission for Proquest/UMI to supply single copies, on demand, of the complete thesis. Should your thesis be published commercially, please reapply for permission. Theses and dissertations which contain embedded PJAs as part of the formal submission can be posted publicly by the awarding institution with DOI links back to the formal publications on ScienceDirect.

\section{$\underline{\text { Elsevier Open Access Terms and Conditions }}$}

You can publish open access with Elsevier in hundreds of open access journals or in nearly 2000 established subscription journals that support open access publishing. Permitted third party re-use of these open access articles is defined by the author's choice of Creative Commons user license. See our open access license policy for more information.

Terms \& Conditions applicable to all Open Access articles published with Elsevier: 
Any reuse of the article must not represent the author as endorsing the adaptation of the article nor should the article be modified in such a way as to damage the author's honour or reputation. If any changes have been made, such changes must be clearly indicated.

The author(s) must be appropriately credited and we ask that you include the end user license and a DOI link to the formal publication on ScienceDirect.

If any part of the material to be used (for example, figures) has appeared in our publication with credit or acknowledgement to another source it is the responsibility of the user to ensure their reuse complies with the terms and conditions determined by the rights holder.

\section{Additional Terms \& Conditions applicable to each Creative Commons user license:}

CC BY: The CC-BY license allows users to copy, to create extracts, abstracts and new works from the Article, to alter and revise the Article and to make commercial use of the Article (including reuse and/or resale of the Article by commercial entities), provided the user gives appropriate credit (with a link to the formal publication through the relevant DOI), provides a link to the license, indicates if changes were made and the licensor is not represented as endorsing the use made of the work. The full details of the license are available at http://creativecommons.org/licenses/by/4.0.

CC BY NC SA: The CC BY-NC-SA license allows users to copy, to create extracts, abstracts and new works from the Article, to alter and revise the Article, provided this is not done for commercial purposes, and that the user gives appropriate credit (with a link to the formal publication through the relevant DOI), provides a link to the license, indicates if changes were made and the licensor is not represented as endorsing the use made of the work. Further, any new works must be made available on the same conditions. The full details of the license are available at http://creativecommons.org/licenses/by-nc-sa/4.0.

CC BY NC ND: The CC BY-NC-ND license allows users to copy and distribute the Article, provided this is not done for commercial purposes and further does not permit distribution of the Article if it is changed or edited in any way, and provided the user gives appropriate credit (with a link to the formal publication through the relevant DOI), provides a link to the license, and that the licensor is not represented as endorsing the use made of the work. The full details of the license are available at http://creativecommons.org/licenses/by-nc-nd/4.0. Any commercial reuse of Open Access articles published with a CC BY NC SA or CC BY NC ND license requires permission from Elsevier and will be subject to a fee.

Commercial reuse includes:

- Associating advertising with the full text of the Article

- Charging fees for document delivery or access

- Article aggregation

- Systematic distribution via e-mail lists or share buttons 
Posting or linking by commercial companies for use by customers of those companies.

20. Other Conditions: v1.9

Questions? customercare@ copyright.com or +1-855-239-3415 (toll free in the US) or +1-978-646-2777. 


\section{CURRICULUM VITA}

\section{AMY STOKES-LEVINE}

403 Godfrey Avenue

astokes13@gmail.com

Louisville, KY 40206

(502) 599-7000

\section{EDUCATION}

University of Louisville, Louisville, KY

$2013-2017$

School of Education

Doctorate of Philosophy in Curriculum and Instruction

Dissertation: Instructional Teacher Job Resources and Student Achievement in Mathematics

Dean's Citation Award, top 10\% of degree program

Bellarmine University, Louisville, KY

$2004-2006$

School of Education

Master of Arts in Teaching, Secondary Mathematics

\section{Kappa Delta Pi}

Southern Methodist University, Dallas, TX

$1998-2002$

School of Engineering and Applied Sciences

Bachelor of Science in Engineering Management Information Systems

\section{CERTIFICATIONS}

Professional Certificate for Teaching Mathematics, Grades 8 Through 12

Expires 2018

Mathematics Program Consultant

Public Education \& Business Coalition: Planning for Thinking Institute

Cognitive Coaching Foundations Seminar

Grant Writing Academy

$2012-2018$

January 2009

April 2013

May 2017

\section{PROFESSIONAL EMPLOYMENT EXPERIENCE}

University of Louisville, Louisville, KY

August 2014 - May 2017

Graduate Teaching and Research Assistant.

Research Assistant

August 2014 - December 2016

Scored teacher participant entries for DTAMS research; assisted and facilitated summer professional development on statistics education for middle and secondary mathematics teachers with Dr. Susan Peters through the CAREER Grant; assisted and facilitated ongoing follow-up professional development sessions on statistics education for middle and secondary mathematics teachers through the CAREER Grant; transcribed video and audio files from the week-long summer professional development session as well as the ongoing follow-up sessions; coded and analyzed data from video, audio, and transcription files on teacher learning through Mezirow's Learning Theory.

Spring Research Conference Lead Organizer

August 2015 - March 2015

The Spring Research Conference unites three university institutions: University of Louisville, University of Kentucky, and the University of Cincinnati. Each year students conducting research at each of these institutions 
gain presentation experience and feedback and are exposed to emerging research in the fields of education, nursing, and sciences. As the lead conference organizer, I collaborated with all three institutions to plan conference logistics such as location, set-up, and food, as well as the online application process. Planning the presentation schedule included: fielding and categorizing online submissions, creating a time schedule, securing session facilitators, volunteers, and guest speakers for the lunch panel. Additionally, conference attendees received free gifts such as a bag, conference t-shirt, and a research book of their choosing.

Mathematics Methods Teacher, Middle/High.

August 2014 - May 2015

Taught middle- and high-school teacher candidates methods for teaching mathematics for grades 6-12. Some of the broad major topics included were algebra, geometry, statistics, technology, navigating content and process standards, and lesson planning. Students were also enrolled in a parallel course which gave the teacher candidates to field exposure for the first time. Lesson plans were submitted to me 48 hours prior to teaching in their field placement so that I could provide feedback before and after each session they taught.

Adolescent Literacy Project, Mathematics Specialist

June, 2014

Led mathematics break-out sessions for middle and high school mathematics teachers during an ALP summer institute. ALP provides high caliber, intensive, literacy professional development for middle and high school educators and administrators. Topics covered in June 2014 included: What can we learn from our students by incorporating appropriate reading and writing in the mathematics classroom?, Sources of appropriate reading materials for the mathematics classroom, Methods for appropriate writing in the mathematics classroom (Math Journals and Graphic Novels), and Interpreting mathematical understanding from student writing.

South Oldham High School, Crestwood, KY

August 2012 - May 2014

High School Math Teacher. Taught Advanced Pre-Calculus, AP Calculus, and Intro to College Algebra. Provided after-school tutoring for mathematics.

Academic Team Coach

$2012-2014$

Recruited for and organized team practices and study sessions for the Academic Team. Arranged travel to and from weekly quick recall meets across various counties. Secured volunteers such as question readers, timers, judges, and drivers, for each meet. Scored, cataloged, and communicated results to each team member arranging additional study materials when necessary.

Oldham County High School, Buckner, KY

August 2007 - May 2012

High School Math Teacher. Taught Algebra 1, Advanced Algebra 2, Advanced Pre-Calculus, and AP Calculus to high school students. Administered after-school tutoring for mathematics. Served on the Curriculum Committee and as sponsor to the senior class. Assisted in district mapping and task drafting for Mathematics Curriculum 9-12.

District Curriculum Team

$2011-2012$

Worked with Assistant Superintendent, Anita Davis, and five other high school teachers to draft unit guides for new mathematics curriculum as well as transfer tasks and grading rubrics during the Common Core for State Standards rollout which provided teachers across the district with high quality unit plans helps to ensure all students receive superior instruction.

Oldham County Learning Institute - Lab Host Teacher

$2010-2012$

Attended workshops at the Learning Institute in Denver, Colorado, Oldham County Board, and with the OCHS OCLI team to extend personal teaching practices and translate those practiced in the Public Education and Business Coalition to the high school math classroom. Offered classroom observations to, on average, thirteen colleagues at a time to demonstrate techniques of teaching through the use of Thinking Strategies, Building Community, and Guided Release.

Senior Class Sponsor

$2008-2012$

Planned prom, field trips, a privilege program, $\mathrm{t}$-shirt sales, and graduation for the senior class. The privilege program encourages seniors to have good grades and attendance in order to partake in the various incentives throughout the year.

Extended School Services Coordinator

$2009-2010$

Coordinated after school tutoring sessions for each subject and tracked student attendance. Communicated with high school teachers to maintain a smooth service for students in need of extra help. 
Eminence Independent School, Eminence, KY

August 2003 - July 2007

High School Math Teacher. Taught Algebra 1, Geometry, Algebra 2, and Advanced Algebra 2 to high school students. Led an independent Statistics course. Tutored college-bound Pre-Calculus students. Administered afterschool tutoring for all math subjects. Assisted in mapping and ensuring Vertical Alignment for Mathematics Curriculum K-12.

Extended School Services Coordinator

$2004-2007$

Coordinated after school tutoring sessions for each subject and tracked student attendance. Communicated with high school teachers to maintain a smooth service for students in need of extra help. ESS is aided by core subject teachers as well as ESS aids.

Master Schedule - Scheduling Coordinator

$2004-2007$

Aligned master schedule according to students' previous course enrollment with school expectations to create a balanced schedule for staff and students. Creating this new master schedule allowed teachers to create manageable caps for their classrooms to enhance the classroom experience for each student.

Testing Schedule - Scheduling Coordinator $2004-2007$

Scheduled each student and teacher during CATS testing to a specified room. Coordinated testing room set-ups, head counts, and test administrator needs. Provided schedules for students and staff during CATS testing and review week.

Freshmen Class Sponsor

$2003-2007$

Assisted first year high school students as an advisory. Administered locker distribution, student fee collection, and homecoming activities, as well as class fundraisers.

Beta Club Sponsor

$2004-2006$

Reinstated high standards such as GPA and service hours to Eminence's Sr. Beta Club. Members had to hold a 3.2 GPA and complete 30 hours of community service for the year. As a result, Beta Club Members raised over $\$ 3,000$ for Cystic Fibrosis Research through a student lead benefit concert and a 5K run/ walk. Other activities included directing a school play, after school tutoring, donating presents for Volunteers of America shelters, etc.

Women's Discussion Group Leader

$2004-2005$

Led a discussion group after school for high school girls interested in the effects of media and societal stereotypes.

Provided an outlet for girls to discuss personal experiences and sensitive issues.

Southern Methodist University, Dallas, TX

December 1999 - May 2002

Resident Assistant. Liaison between the residents and administration. Responsible for providing support, leadership, information, communication, mediation, and guidance while enforcing Residence Hall policies for residents. Accountable for residents' safety and contentment within reason. RAs stayed on call twenty-four hours a day, seven days a week.

General Electric, Louisville, KY

Summer 2001, Summer 2000

Engineering Intern. In 2001, I worked with a Korean-interfaced washer unit to design and implement test protocol to create innovative delicate cycles for home use. In 2000, I helped design consumer based dispenser control panel, and completed competitive benchmark testing for capacity, local temperature readings, and ice production rate.

AWARDS

Dean's Citation Award, top 10\% of Ph.D. program at the University of Louisville

May 2017

Doctoral Dissertation Completion Award

January 2017 - May 2017

Awarded to outstanding Ph.D. candidates in their final semester at the University of Louisville, this scholarship is granted to applicants who demonstrate strong evidence of scholarly ability and program progress. The award includes tuition, health care, and a stipend. Applicants must be nominated by their Department Chair.

Mathematics Teacher of the Year, Oldham County High School

$2009-2010$

Mathematics Teacher of the Year, Oldham County High School

$2007-2008$

Kappa Delta Pi, Bellarmine University 4.0 GPA

2007 
Teacher of the Year, Eminence Independent School

$2005-2006$

Teacher of the Year, Eminence Independent School

$2004-2005$

Who's Who Among America's Teachers, Nominated by students at Eminence Independent School

Who's Who Among America's Teachers, Nominated by students at Eminence Independent School

Rookie of the Year - SMU Residence Life and Student Housing

May 2000

Recognition Chair on Executive Council for SMU's Residence Life and Student Housing

Fall 2000

\section{PUBLICATIONS}

Peters, S. \& Stokes-Levine, A. (In Press). Secondary teachers' learning: Measures of variation. Teaching and Learning Statistics, Volume II.

McGatha, M. B., Davis, R., \& Stokes-Levine, A. (2017). Mathematics specialists: What does the research say? In M. B. McGatha \& N. R. Rigelman (Eds.), Elementary mathematics specialists: Developing, refining, and examining programs that support mathematics teaching and learning. Charlotte, NC: Information Age Publishing.

Bay-Williams, J. \& Stokes-Levine, A. (In Press). Teaching to Build Procedural Fluency. National Council of Teachers of Mathematics.

Peters, S. \& Stokes-Levine, A. (In Press). Teacher learning: Measures of variation. $13^{\text {th }}$ International Congress on Mathematical Education. Hamburg, Germany.

McGatha, M. B., Davis, R., \& Stokes, A. (2015). Impact of mathematics coaching on teachers and students. National Council of Teachers of Mathematics Research Briefs.

\section{PRESENTATIONS}

Bay-Williams, J. \& Stokes-Levine, A. Teaching and Assessing Addition Fact Fluency. National Council of Teachers of Mathematics (NCTM) Regional Meeting. Nashville, TN. November 20, 2015.

Peters, S. \& Stokes-Levine, A. Teacher learning: Measures of variation. International Congress on Mathematics Education (ICME). Hamburg, Germany. [Sue Peters presented alone as I could not travel due to pregnancy. July, 2016.]

Stokes-Levine, A. Adult Learning Theory: A Lens for Designing and Investigating Teacher Explorations With Statistical Variation. Association of Mathematics Teacher Educators (AMTE). Orlando, FL. February 10, 2017.

\section{PROFESSIONAL MEMBERSHIPS}

National Council Teachers of Mathematics

Association of Mathematics Teacher Educators

Kentucky Council Teachers of Mathematics

Kappa Delta Pi

\section{ACTIVITIES AND SERVICE}

Doctoral Induction Panel

Graduate Student Council Advocacy Group; Frankfort, KY

Met with state senators to report on and answer questions regarding the School to Prison Pipeline

Reviewer for Mathematics Teacher (NCTM)

University of Louisville Science Symposium, Judge

Habitat for Humanity

Society of Women Engineers; Women in Science Engineering
September 2015 \& August 2016

March 2016

2015 - Present Spring 2014

1998 - Present $1998-2001$ 